\title{
Resynthetisierter Raps als Modell zur Untersuchung der fixierten Heterosis bei allopolyploiden Pflanzen
}

\author{
Dissertation \\ zur Erlangung des Doktorgrades \\ der Fakultät für Agrarwissenschaften \\ der Georg-August-Universität Göttingen \\ vorgelegt von \\ Stefan Abel \\ geboren in Verden /Aller
}

Göttingen, im Februar 2006 
D7

1. Referent: Prof. Dr. Heiko C. Becker

2. Referent: Prof. Dr. Wolfgang Friedt

Tag der mündlichen Prüfung: 02.02.2006 
Das Ganze ist mehr als

die Summe seiner Teile

Aristoteles (384-322 v. Chr.)

für Iris 


\section{Inhaltsverzeichnis}

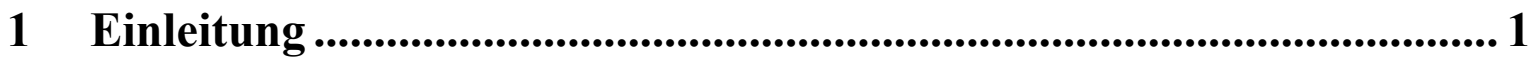

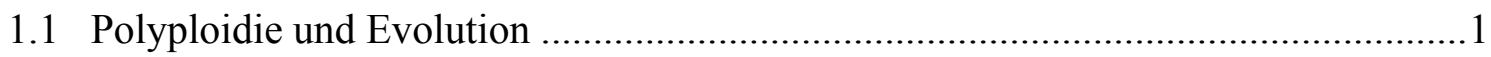

1.2 Raps (Brassica napus) als Modell für neu entstandene allopolyploide Arten ...........5

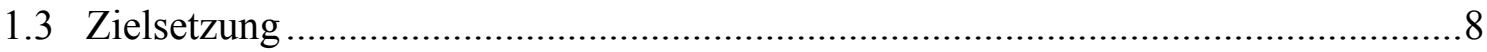

2 Material und Methoden ..................................................................... 10

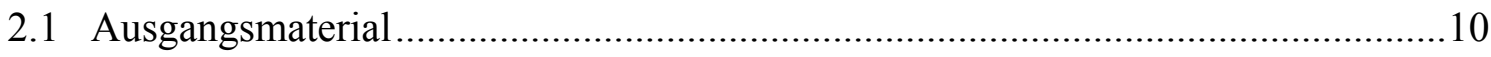

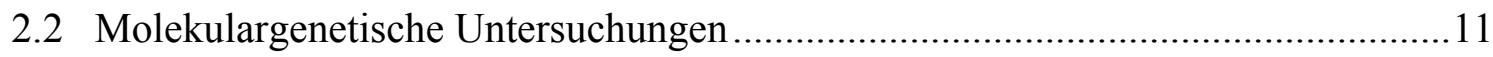

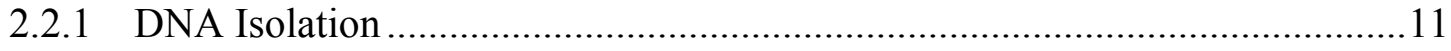

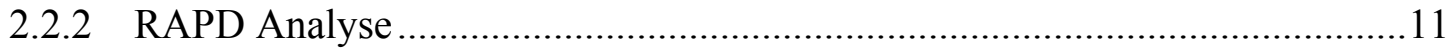

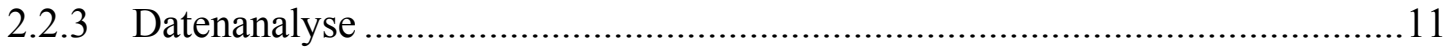

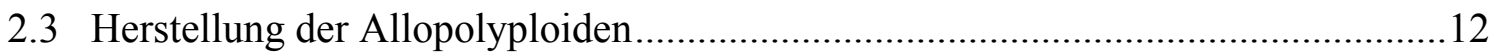

2.3.1 Anzucht der Elternpflanzen und interspezifische Kreuzungen ........................12

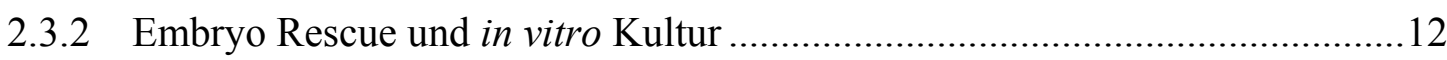

2.3.3 Colchizinierung und Anzucht der Allopolyploiden ......................................13

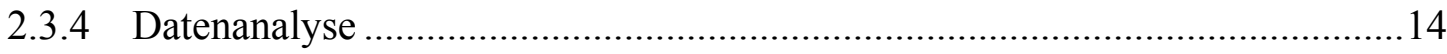

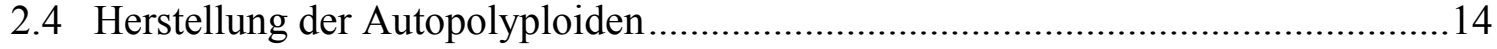

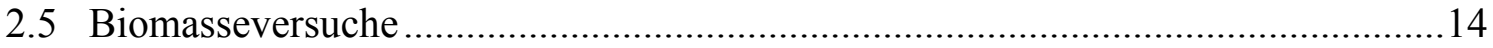

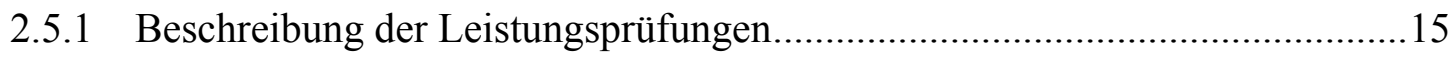

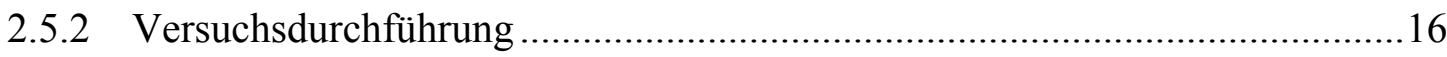

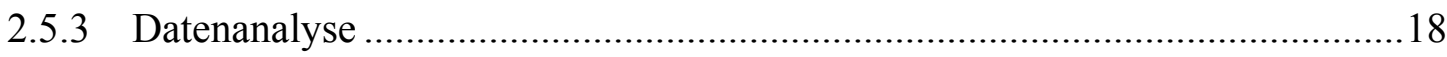

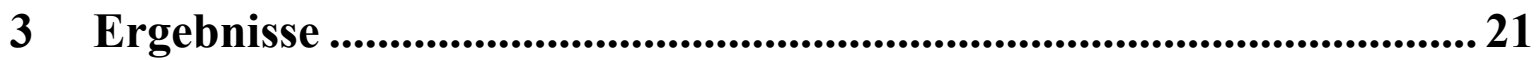

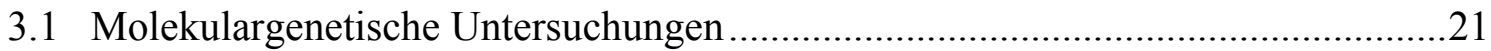

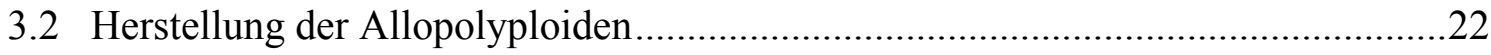

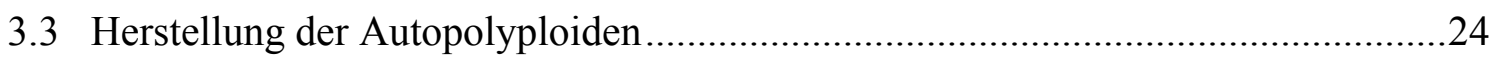

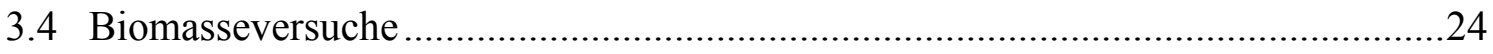

3.4.1 Korrelationen zwischen den erfassten Merkmalen ........................................24

3.4.2 Leistungsprüfung 1: Resynthesen und Eltern ..............................................26

3.4.3 Leistungsprüfung 2: Rübsen Diallel ............................................................29

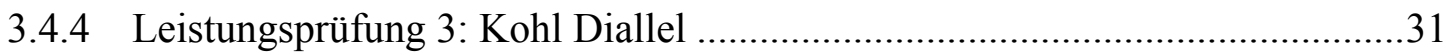




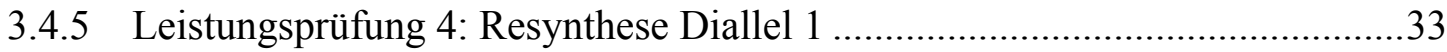

3.4.6 Leistungsprüfung 5: Resynthese Diallel 2 ...................................................36

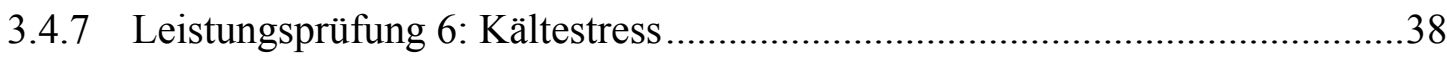

3.4.8 Beziehung zwischen klassischer und fixierter Heterosis ...............................39

4 Diskussion ................................................................................................... 43

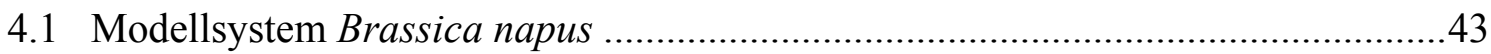



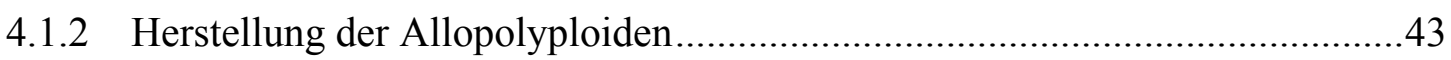

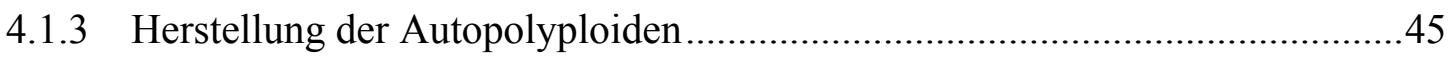

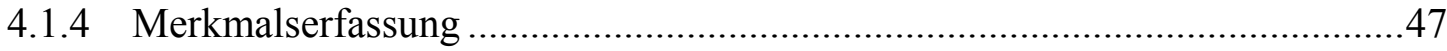

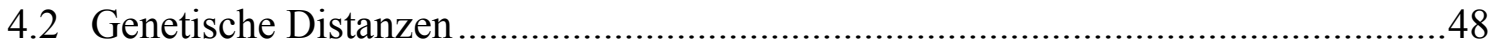

4.2.1 Bestimmung genetischer Distanzen mit RAPD Markern ...............................48

4.2.2 Beziehung zwischen genetischen Distanzen und klassischer Heterosis ..........49

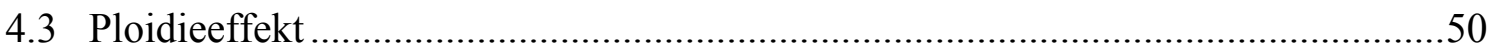

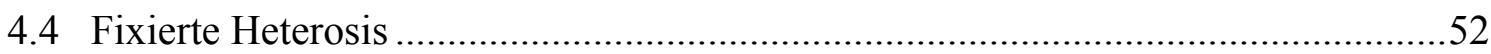

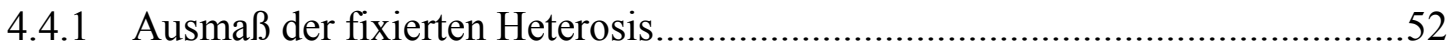

4.4.2 Fixierte Heterosis bei Kältestress .............................................................53

4.4.3 Beziehung zwischen fixierter und klassischer Heterosis ................................54

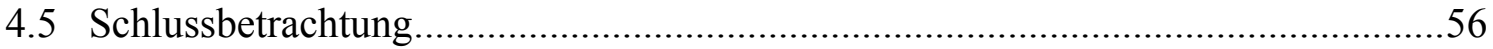

5 Zusammenfassung................................................................. 58



7 Literaturverzeichnis.............................................................. 62

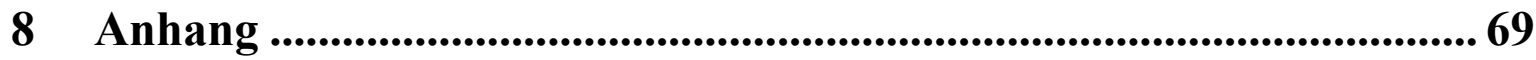




\section{Verzeichnis der Tabellen}

Tab. 1: Übersicht über die verwendeten Brassica rapa (A) und Brassica oleracea

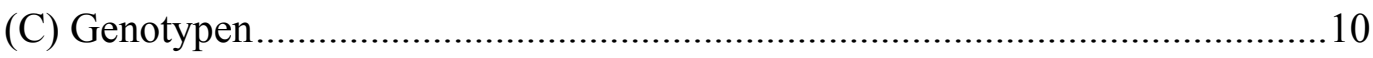

Tab. 2: Übersicht über die in den Diallel-Leistungsprüfungen verwendeten Eltern..........16

Tab. 3: Erfolgreich hergestellte Resynthesen.................................................................23

Tab. 4: Korrelationen zwischen Frischmasse-Gesamtertrag (FMGesamt) und anderen erfassten Merkmalen in den einzelnen Leistungsprüfungen ...................25

Tab. 5: Relative fixierte Elternmittel-Heterosis (\%) der Resynthesen und allgemeine Kombinationsfähigkeit (GCA) für fixierte EM-Heterosis der Elternlinien im Merkmal FMGesamt

Tab. 6: Relative fixierte Besserer-Elter-Heterosis (\%) der Resynthesen und allgemeine Kombinationsfähigkeit (GCA) für fixierte BE-Heterosis der Elternlinien im Merkmal FMGesamt

Tab. 7: Ergebnisse der Varianzanalyse für das Merkmal FMGesamt (Leistungsprüfung 1)

Tab. 8: Ergebnisse der Varianzanalyse für das Merkmal FMGesamt (Leistungsprüfung 2)

Tab. 9: Relative Elternmittel-Heterosis (\%) im Rübsen Diallel und allgemeine Kombinationsfähigkeit (GCA) für EM-Heterosis der Elternlinien im Merkmal FMGesamt.

Tab. 10: Ergebnisse der Varianzanalyse für das Merkmal FMGesamt (Leistungsprüfung 3)

Tab. 11: Relative Elternmittel-Heterosis (\%) im Kohl Diallel und allgemeine Kombinationsfähigkeit (GCA) für EM-Heterosis der Elternlinien im Merkmal FMGesamt.

Tab. 12: Ergebnisse der Varianzanalyse für das Merkmal FMGesamt (Leistungsprüfung 4).

Tab. 13: Relative Elternmittel-Heterosis (\%) im Resynthese Diallel 1 und allgemeine Kombinationsfähigkeit (GCA) für EM-Heterosis der Elternlinien im Merkmal FMGesamt.

Tab. 14: Ergebnisse der Varianzanalyse für das Merkmal FMGesamt (Leistungsprüfung 5).

Tab. 15: Relative Elternmittel-Heterosis (\%) im Resynthese Diallel 2 und allgemeine Kombinationsfähigkeit (GCA) für EM-Heterosis der Elternlinien im Merkmal FMGesamt

Tab. 16: Liste der für die RAPD Analyse verwendeten Primer

Tab. 17: Genetische Distanzen (Jaccard) zwischen den Rübsenlinien (a.), zwischen den Kohllinien (b.) und zwischen Rübsen- und Kohllinien (c.) 
Tab. 18: Übersicht über die Effizienz der interspezifischen Kreuzungen in den einzelnen Kreuzungskombinationen.

Tab. 19: Übersicht über die erfassten Frisch- und Trockenmasse-Erträge für die LP 1 Resynthesen und Eltern.

Tab. 20: Übersicht über die Frischmasse-Gesamterträge (g/Topf) und die allgemeine Kombinationsfähigkeit (GCA) in der LP 1 Resynthesen und Eltern.

Tab. 21: Übersicht über die erfassten Frisch- und Trockenmasse-Erträge für die LP 2 Rübsen Diallel

Tab. 22: Übersicht über die Frischmasse-Gesamterträge (g/Topf) und die allgemeine Kombinationsfähigkeit (GCA) in der LP 2 Rübsen Diallel.

Tab. 23: Übersicht über die erfassten Frisch- und Trockenmasse-Erträge für die LP 3 Kohl Diallel

Tab. 24: Übersicht über die Frischmasse-Gesamterträge (g/Topf) und die allgemeine Kombinationsfähigkeit (GCA) in der LP 3 Kohl Diallel. 77

Tab. 25: Übersicht über die erfassten Frisch- und Trockenmasse-Erträge für die LP 4 Resynthese Diallel 1 78

Tab. 26: Übersicht über die Frischmasse-Gesamterträge (g/Topf) und die allgemeine Kombinationsfähigkeit (GCA) in der LP 4 Resynthese Diallel 1

Tab. 27: Übersicht über die erfassten Frisch- und Trockenmasse-Erträge für die LP 5 Resynthese Diallel 2 79

Tab. 28: Übersicht über die Frischmasse-Gesamterträge (g/Topf) und die allgemeine Kombinationsfähigkeit (GCA) in der LP 5 Resynthese Diallel 2.

Tab. 29: Übersicht über die erfassten Frisch- und Trockenmasse-Erträge für die LP 6 Kältestress 


\section{Verzeichnis der Abbildungen}

Abb. 1: Entstehung von autopolyploiden und allopolyploiden Arten (Verändert nach LEITCH und BENNETT 2004) .

Abb. 2: Verwandtschaftsverhältnisse in der Gattung Brassica (verändert nach $U$ 1935)

Abb. 3: Benötigtes Material zur Unterscheidung der Effekte von Polyploidie und fixierter Heterosis bei resynthetisiertem Raps

Abb. 4: Temperaturverlauf in Gewächshaus und Klimakammer während der Leistungsprüfungen

Abb. 5: RAPD Bandenprofil von 14 B. rapa und 14 B. oleracea Genotypen mit dem Primer B 08

Abb. 6: Dendrogramm der genetischen Distanz von acht B. rapa (A) und acht B. oleracea $(\mathrm{C})$ Linien .22

Abb. 7: Effizienz der interspezifischen Kreuzung von B. rapa und B. oleracea...... .23

Abb. 8: Histogramme des relativen DNA Gehaltes für die Linien C47 und C47C47 ......24

Abb. 9: Beziehung zwischen Frischmasse und Trockenmasse bei tetraploiden Genotypen und deren Ausgangslinien

Abb. 10: Vergleich der Frischmasseerträge von tetraploiden Genotypen und ihren diploiden Ausgangslinien.

Abb. 11: Beziehung zwischen Elternmittel und dem Frischmasse-Gesamtertrag der Resynthesen

Abb. 12: Beziehung zwischen absoluter fixierter Elternmittel-Heterosis und dem Frischmasse-Gesamtertrag der Resynthesen.

Abb. 13: Beziehung zwischen genetischer Distanz und absoluter ElternmittelHeterosis im Rübsen Diallel

Abb. 14: Beziehung zwischen genetischer Distanz und absoluter ElternmittelHeterosis im Kohl Diallel

Abb. 15: Beziehung zwischen genetischer Distanz und absoluter ElternmittelHeterosis im Resynthese Diallel 1

Abb. 16: Vergleich der absoluten klassischen Heterosis bei sich entsprechenden Kreuzungen auf diploider und allotetraploider Stufe.

Abb. 17: Beziehung zwischen genetischer Distanz und absoluter ElternmittelHeterosis im Resynthese Diallel 1

Abb. 18: Vergleich der relativen fixierten Elternmittel-Heterosis unter Normalbedingungen und unter Kältestress .....

Abb. 19: Aufteilung der Leistung von heterozygoten Resynthesen in Elternmittel der Ursprungsarten, fixierte Heterosis und klassische Heterosis im Vergleich zur Aufteilung der Leistung von heterozygoten Kohl- und 
Rübsengenotypen in Elternmittel und klassische Heterosis (standardisierte Mittelwerte aus LP 1, 2, 3 und 5).

Abb. 20: Beziehung zwischen mittlerer absoluter fixierter Elternmittel-Heterosis der Elternlinien und absoluter klassischer Heterosis der Kreuzungen in den Resynthese Diallelen 1 und 2 .

Abb. 21: Beziehung zwischen mittlerer absoluter klassischer Elternmittel-Heterosis der Ausgangslinien im Rübsen und im Kohl Diallel und absoluter fixierter Heterosis der jeweiligen Resynthesen

Abb. 22: Skizze der Anordnung von Parzellen (1-100) und unvollständigen Blöcken (Teilblock) für die Leistungsprüfung fixierte Heterosis (LP 1) für zwei Wiederholungen.

Abb. 23: Skizze der Anordnung von Parzellen (1-36) und unvollständigen Blöcken (TB: Teilblock) für die Diallel Leistungsprüfungen (LP 2-5) für drei Wiederholungen (Wdh) 


\section{$1 \quad$ Einleitung}

\subsection{Polyploidie und Evolution}

Polyploidie bezeichnet das Vorhandensein von drei oder mehr Chromosomensätzen in einem Organismus (nach GRANT 1971). In der Natur sind Polyploide wahrscheinlich vor allem durch die Verschmelzung unreduzierter Gameten zustande gekommen (DE WET 1980). Für die Evolution der Pflanzen spielte Polyploidie vermutlich eine herausragende Rolle, da der größte Teil der heutigen Flora als polyploid angesehen wird. Schon MÜNTZING (1936) nahm an, dass etwa die Hälfte aller Bedecktsamer (Angiospermen) polyploiden Ursprungs sind. Anhand der Häufigkeit von Chromosomenzahlen schätzte LEWIS (1980) den Anteil polyploider Arten bei den Dikotyledonen auf 70-80\%. Durch einen Vergleich der Größe von Stomatazellen fossiler und heutiger Pflanzenarten kam MASTERSON (1994) zu der gleichen Einschätzung für alle Angiospermen. Neueste Untersuchungen der Genome von bisher eindeutig als diploid klassifizierten Arten zeigen außerdem, dass ein Großteil der Gene in diesen Genomen dupliziert vorliegen, was wiederum darauf hindeutet, dass auch diese Arten in ihrer Evolution mindestens ein Polyploidisierungsereignis aufweisen. Entsprechende Ergebnisse liegen zum Beispiel für Mais (HELENTJARIS et al. 1988), Reis (GOFF et al. 2002), schwarzen Senf (LAGERCRANTZ und LYDIATE 1996) und Arabidopsis thaliana (ARABIDOBSIS GENOME INITIATIVE 2000) vor. SOLTIS et al. (2004) bezweifeln daher, dass es überhaupt Pflanzenarten gibt, die wirklich diploid sind. Selbst für die Wirbeltiere finden sich deutliche Hinweise, dass es in ihrer frühen Evolution mindestens zwei aufeinander folgende Polyploidisierungsschritte gegeben hat (HOLLAND et al. 1994). Arten, bei denen das Polyploidisierungsereignis sehr weit zurück liegt, werden auch als Paleopolyploide bezeichnet (TATE et al. 2005).

Je nach Entstehung der polyploiden Arten unterscheidet man Autopolyploide und Allopolyploide. Während Autopolyploide durch eine Vervielfachung des Genoms einer Art entstehen, entstehen Allopolyploide durch die Verschmelzung der Genome verschiedener Arten (siehe Abb.1). Eine klare Abgrenzung zwischen Auto- und Allopolyploidie ist jedoch schwierig, da zum Beispiel die Verschmelzung der Genome von zwei entfernt verwandten Rassen einer Art formal Autopolyploidie ist, andererseits aber wie bei Allopolyploiden verschiedene Genome verschmelzen (STEBBINS 1947). Die Definition der Allopolyploidie ist also stark vom Artbegriff abhängig. 


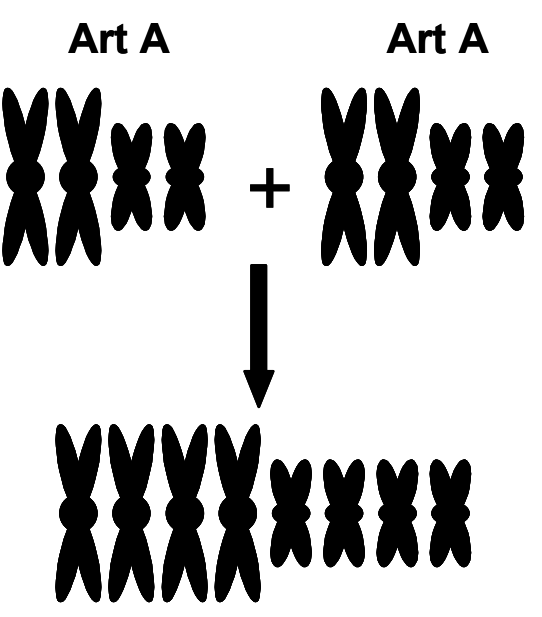

Autopolyploid



Allopolyploid

Abb. 1: Entstehung von autopolyploiden und allopolyploiden Arten (Verändert nach LEITCH und BENNETT 2004)

Ein weiteres Kriterium zur Unterscheidung von Auto- und Allopolyploiden ist die Form der Chromosomenpaarung in der Meiose und den daraus resultierenden Folgen für die Fertilität (GRANT 1971). Da in Autopolyploiden mehr als zwei homologe Chromosomen vorliegen, zeigen diese mit der Bildung von Multivalenten und Univalenten oft starke Störungen der Chromosomenpaarung. Dies geht im Allgemeinen mit einer verminderten Fertilität gegenüber den diploiden Formen einher (GOTTSCHALK 1976). Autopolyploide Arten sind daher häufig nicht alleine auf die Vermehrung über Samen angewiesen, sondern vermehren sich auch vegetativ oder sind perennierend. Bei autopolyploiden Kulturpflanzen (z. B. Kartoffeln, Knaulgras und Wiesenlieschgras) werden aus dem gleichen Grund meist nicht die Samen, sondern vor allem vegetative Pflanzenteile genutzt.

Allopolyploide weisen im Gegensatz zu Autopolyploiden eine geregelte Meiose auf, da sich die Chromosomen der Elternarten in der Regel so stark unterscheiden, dass eine Paarung der sich ähnelnden (homöologen) Chromosomen aus den verschiedenen Genomen nur selten zu Stande kommt. Somit sind Allopolyploide meist auch relativ fertil und verhalten sich genetisch wie diploide, so dass sie auch als Amphidiploide bezeichnet werden (GOTTSCHALK 1976). Allopolyploide sind unter den Kulturpflanzen weit verbreitet. So werden heute zum Beispiel Brotweizen, Hafer, Raps, Sojabohne, Baumwolle und Tabak als eindeutig allopolyploid eingestuft. Auch die Bedeutung der Allopolyploidie für die Evolution wird größer eingeschätzt als die der Autopolyploidie. So sehen STEBBINS 
(1947) und GRANT (1971) Autopolyploidie als extrem seltenes Ereignis. Neuere Untersuchungen messen der Autopolyploidie dagegen eine gewisse Bedeutung zu (SOLTIS et al. 2004).

Für den Erfolg polyploider Arten werden von TATE et al. (2005) sowohl Gründe angegeben, die langfristig einen Selektionsvorteil bedeuten, als auch Gründe, die sich direkt nach der Entstehung einer polyploiden Art positiv auswirken. Als ein langfristiger Vorteil wird angeführt, dass durch die Verdoppelung des Genoms alle Gene an zwei unabhängigen Loci codiert sind. Eine funktionsbeeinträchtigende Mutation von wichtigen Genen an einem Locus führt daher nicht automatisch zu einem Selektionsnachteil, da das homöologe Gen die Funktion des mutierten Gens übernehmen kann. Somit reagieren Polyploide unanfälliger auf Mutationen, was zum Beispiel für Hefe auch experimentell nachgewiesen werden konnte (GU et al. 2003).

Ein weiterer Vorteil ist, dass eine Kopie jedes Gens für Mutationen zur Verfügung steht und somit zufällig bereits durch leichte Veränderungen der DNA Sequenz eine neue Funktion übernehmen kann, während die andere Kopie des Gens die ursprüngliche Funktion erfüllt (KELLOG 2003). Polyploide hätten damit langfristig im evolutionären Zusammenspiel von Mutation und Selektion aufgrund vielfältigerer Entwicklungsmöglichkeiten einen Vorteil gegenüber diploiden Arten. Neben der Entwicklung von neuen Funktionen (Neofunktionalisierung) ist es auch denkbar, dass sich die homöologen Gene auf verschiedene Funktionen spezialisieren (Subfunktionalisierung). So zeigen zum Beispiel zwei homöologe Gene im Mais, die die Anthozyan-Biosynthese regeln, eine unterschiedliche Aktivität in verschiedenen Geweben (WENDEL 2000).

Neben diesen langfristigen Vorteilen von Polyploidie werden auch zwei Effekte für den Erfolg polyploider Arten angeführt, die sich schon direkt nach der Entstehung der Art auswirken: Zum einen eine direkte positive Auswirkung des höheren DNA-Gehaltes auf die Konkurrenzfähigkeit und zum anderen positive Interaktionen zwischen unterschiedlichen Allelen an homöologen Loci (fixierte Heterosis).

Ein direkter Effekt des DNA-Gehaltes, im folgenden als Ploidieeffekt bezeichnet, wurde vor allem für die Zellgröße beobachtet. So zeigen Hefezellen mit steigender Ploidiestufe auch ein steigendes Zellvolumen (GALITSKI et al. 1999). Ein Effekt der Ploidiestufe auf die Zellgröße wird auch bei Pflanzen beobachtet. Häufig geht dabei mit der Zunahme der Zellgröße auch eine Vergrößerung der gesamten Pflanze einher, was dann als Gigaswuchs bezeichnet wird und unter Umständen einen Selektionsvorteil bedeutet (STEBBINS 1950). 
So nimmt die Länge der Schließzellen nach einer Zusammenstellung von GOTTSCHALK (1976) bei Tetraploiden meist um 15-40\% gegenüber den diploiden Ausgangsformen zu. Eine Zunahme der Zellgröße liegt dabei nach BUTTERFASS (1987) bei künstlich hergestellten Autopolyploiden in der gleichen Größenordnung, wie bei künstlich hergestellten Allopolyploiden. Dagegen ist der Effekt einer höheren Ploidiestufe auf die Entwicklungsgeschwindigkeit tendenziell negativ, so dass der Einfluss der Ploidiestufe auf die Biomasseproduktion von Pflanzen stark von der untersuchten Art abhängt (GOTTSCHALK 1976). So beobachtet SCHWANITZ (1948) einen etwa 80\% höheren Ertrag von tetraploidem Rübsen gegenüber der diploiden Ausgangsform. In der gleichen Untersuchung stellt er dagegen bei tetraploidem Grünkohl einen Minderertrag von etwa $50 \%$ gegenüber der diploiden Ausgangsform fest.

Neben einem möglichen Ploidieeffekt können neu entstandene Polyploide auch von Interaktionen zwischen homöologen Genen der vereinigten Genome profitieren. Während Diploide über nur zwei Allele verfügen, können zum Beispiel bei Autotetraploiden vier Allele interagieren. Polyploide können also potenziell mehr Allele in sich vereinigen und somit einen höheren Heterozygotiegrad aufweisen. ALLARD et al. (1993) konnten so nachweisen, dass Populationen des autotetraploiden Grases Avena barbata eine wesentlich größere allelische Diversität für Allozyme aufweisen als Populationen ihrer diploiden Ursprungsart Avena hirtula. Ein ähnliches Ergebnis erhielten ROOSE und GOTTLIEB (1976) für den allotetraploiden Korbblütler Tragopogon mirus im Vergleich zu seinen diploiden Ursprungsarten T. dubius und T. porrifolius.

Bei Allopolyploiden kommt dabei die Besonderheit hinzu, dass die Heterozygotie zwischen den homöologen Loci der verschiedenen Genome (intergenomische Heterozygotie) durch Selbstbefruchtung nicht verloren geht, da sich die homöologen Chromosomen nicht paaren. Daher wird die intergenomische Heterozygotie auch als fixierte Heterozygotie bezeichnet (SOLTIS und SOLTIS 2000). Da Heterozygotie wiederum die Basis für Heterosis ist, wird im Folgenden eine Mehrleistung von allopolyploiden Pflanzen, die auf dieser intergenomischen beziehungsweise fixierten Heterozygotie beruht, wie bei ELLSTRAND und SCHIERENBECK (2000), als fixierte Heterosis bezeichnet.

SOLTIS und SOLTIS (2000) unterstreichen die Bedeutung von fixierter Heterosis insbesondere in der frühen Phase der Etablierung von allopolyploiden Arten. Da nach der Entstehung der Art zunächst nur einzelne und später wenige nah verwandte Individuen vorhanden sind, kommt es in dieser Phase zu starker Inzucht. Durch die Fixierung 
verschiedener Allele an den homöologen Loci können Allopolyploide jedoch einen gewissen Grad an allelischer Diversität erhalten und unterliegen damit einer geringeren Inzuchtdepression als ihre diploiden Ausgangsarten. Ein Anhaltspunkt für fixierte Heterosis findet sich zum Beispiel für das allopolyploide Schlickgras Spartina anglica, das erst Ende des 19. Jahrhunderts aus der Hybridisierung der Arten S. maritima und S. alterniflora entstanden ist und deren Einzelpflanzen kaum genetische Variation aufweisen. Trotz dieser genetischen Ähnlichkeit, die wahrscheinlich auf Inzucht beruht, erweist sich S. anglica als äußerst konkurrenzfähig, was GRAY et al. (1991) auf eine hohe intergenomische Heterozygotie zurückführen.

\subsection{Raps (Brassica napus) als Modell für neu entstandene allopolyploide Arten}

Die Gattung Brassica beinhaltet sowohl diploide als auch polyploide Arten. Durch Untersuchungen der Chromosomenpaarung in Artkreuzungen zwischen Arten mit hoher und niedriger Chromosomenzahl aus dieser Gattung wiesen MORINAGA (1934) und U (1935) den allopolyploiden Charakter der Arten B. carinata, B. juncea und B. napus nach. So beobachtete U (1935) in Artbastarden zwischen B. napus und B. oleracea die Bildung von neun Bivalenten und zehn Univalenten und in Artbastarden zwischen B. napus und B. rapa die Bildung von zehn Bivalenten und neun Univalenten. Daraus zog er den Schluss, dass B. napus eine allopolyploide Art ist, die aus den diploiden Arten B. rapa und B. oleracea entstanden ist. In gleicher Weise wurde die Entstehung von B. carinata (Genom BBCC) und B. juncea (Genom AABB) aus den Elternarten B. rapa (AA), B. nigra (BB) und B. oleracea (CC) nachgewiesen. Eine Übersicht der von U vorgeschlagenen Verwandtschaftsverhältnisse der erwähnten Arten und deren Chromosomengrundzahlen (n) sind in Abb. 2 dargestellt. Auch neuere molekularbiologische Untersuchungen bestätigen diese Beziehungen (z. B. HOSAKA et al. 1989, PARKIN et al. 1995). 


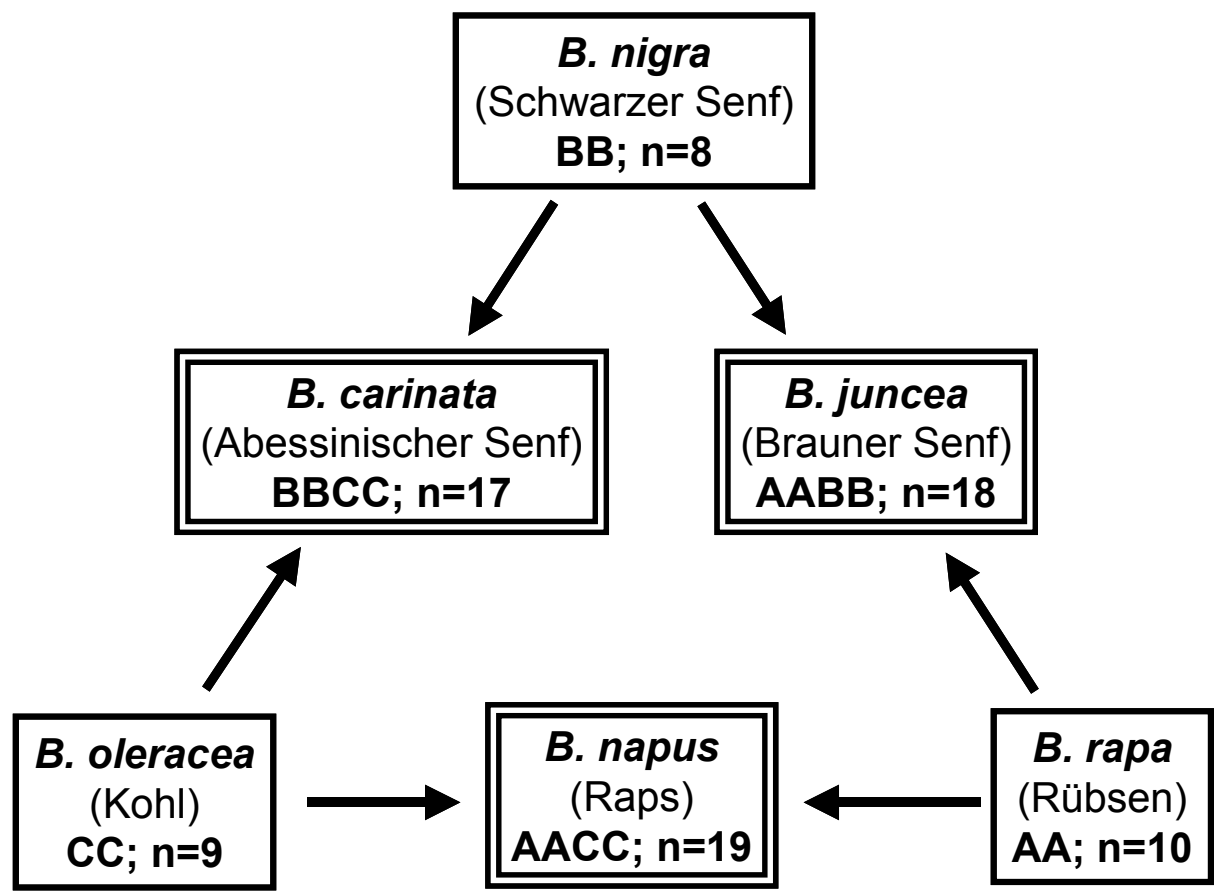

\section{Abb. 2: Verwandtschaftsverhältnisse in der Gattung Brassica (verändert nach $U$ 1935)}

Molekulargenetische Vergleiche der drei diploiden Arten legen außerdem nahe, dass sich diese aus einem gemeinsamen Urelter entwickelt haben, da die drei Genome starke Homologien aufweisen (TRUCO et al. 1996). Nach SONG et al. (1990) und LAGERCRANTZ und LYDIATE (1996) sind dabei die Homologien zwischen B. rapa und B. oleracea größer als zwischen diesen Arten und B. nigra. Daraus leiten sie die Vermutung ab, dass sich die Art B. nigra früher von den anderen Arten differenziert hat und sich die Arten B. rapa und B. oleracea erst relativ spät von einander getrennt haben. Diese Einschätzung wird auch durch die Analyse von Chloroplasten Genomen (WARWICK und BLACK 1991) und Untersuchungen zur Chromosomenpaarung bei haploiden Artbastarden zwischen diesen drei Arten (ATTIA und RÖBBELEN 1986) bestätigt.

Die Arten B. rapa und B. oleracea entwickelten sich wahrscheinlich im europäischen Mittelmeerraum und gelangten entweder über Mitteleuropa und die Mongolei oder über Indien nach Ostasien (NISHI 1980, SONG et al. 1990). Infolge der Domestikation der Wildformen in den verschiedenen Regionen entstanden zahlreiche kultivierte Unterformen. Während sich in Europa beim Rübsen vor allem Formen zur Öl- und zur Futternutzung entwickelten (ssp. oleifera und rapa), stand in Ostasien vor allem die Gemüsenutzung (ssp. pekinensis, chinensis und narinosa) und in Indien die Samennutzung (ssp. trilocularis) im Vordergrund. Beim Kohl entwickelten sich zum Teil in Ostasien (ssp. alboglabra) aber vor 
allem in Europa zahlreiche Gemüseformen (ssp. botrytis, italica, capitata, acephala und gongylodes) (GÓMEZ-CAMPO und PRAKASH 1999).

Die Art B. napus entstand vermutlich erst während des Mittelalters durch spontane Hybridisierung von Kohl und Rübsen in Gebieten in denen beide Arten nebeneinander genutzt wurden. Als Entstehungsgebiete werden hier vor allem der Mittelmeerraum und Nordwesteuropa genannt (KÖRBER-GROHNE 1994), wobei davon ausgegangen wird, dass die Hybridisierung zwischen Kohl und Rübsen kein einmaliges Ereignis war, sondern mehrfach stattgefunden hat (RUDORF 1951, SONG und OSBORN 1992).

Seit der Aufklärung der Verwandtschaftsverhältnisse durch MORINAGA und U wurde Raps in zahlreichen Arbeiten auch künstlich aus seinen Ursprungsarten hergestellt oder „resynthetisiert“. Dabei stand vor allem die Übertragung bestimmter Eigenschaften aus den diploiden Arten in den Raps im Vordergrund. So wurde resynthetisierter Raps zur Übertragung von Resistenzen (Kohlhernie: DIEDERICHSEN 1992), zur Verbesserung der Samenqualität (Glucosinolatgehalt: GLAND 1982, Gelbsamigkeit: CHEN et al. 1988) und zur Verbesserung agronomischer Eigenschaften (Frühreife: AKBAR 1989, Winterfestigkeit: HOFFMANN und PETERS 1958) hergestellt.

Die Resynthese von Raps durch interspezifische Kreuzung ist grundsätzlich auf zwei verschiedenen Wegen möglich (AKBAR 1987): Zum einen können zunächst Autotetraploide der Elternarten hergestellt werden. Die Verdoppelung des Chromosomensatzes wird dabei in den meisten Arbeiten durch eine Behandlung mit Colchizin erreicht, welches die Spindelbildung während der Mitose unterbindet (GOTTSCHALK 1976). Durch die Kreuzung der so hergestellten Autotetraploiden und die Verschmelzung ihrer diploiden Gameten entstehen daraufhin direkt fertile amphidiploide Artbastarde. Zum anderen können auch diploide Genotypen der Elternarten gekreuzt werden, so dass zunächst haploide Artbastarde entstehen, deren Chromosomensatz anschließend durch eine Behandlung mit Colchizin verdoppelt wird. Die Herstellung von resynthetisiertem Raps oder „Resynthesen“ war zunächst relativ ineffektiv (AKBAR 1989), da ein Großteil der Bastardembryonen aufgrund physiologischer Störungen zwischen Endosperm und Embryo abstirbt (NISHIYAMA et al. 1991). Erst durch die Kultivierung der Bastardembryonen auf geeigneten Nährmedien und die Optimierung dieser „embryo rescue“ Technik konnte der Kreuzungserfolg deutlich gesteigert werden (INOMATA 1985, DIEDERICHSEN und SACRISTAN 1994), so dass die Resynthese von Raps aus seinen Ursprungsarten heute relativ einfach ist. 
Durch die künstliche Herstellung von Raps ist auch ein direkter Vergleich dieser allopolyploiden Art mit seinen diploiden Ursprungsarten möglich. Diese Möglichkeit wurde vor allem für die Aufklärung der Vererbung spezieller Merkmale wie den Erucasäuregehalt (LÜHS 1996) und die Blütenblattgröße (LU et al. 2004) genutzt.

Zusammenfassend bietet sich Raps als Modell zur Untersuchung genetischer Effekte bei neu entstandenen allopolyploiden Arten an, weil

- beide Elternarten bekannt und in einer großen Variation verfügbar sind.

- die Resynthese von Raps aus den Elternarten relativ leicht möglich ist.

- die Genome der Elternarten ein hohes Maß an Homologien aufweisen, so dass zu erwarten ist, dass viele homöologe Gene interagieren können.

\subsection{Zielsetzung}

Obwohl seit der Entdeckung des allopolyploiden Charakters von B. napus zahlreiche Resynthesen hergestellt wurden, sind genaue Vergleiche der Leistungsfähigkeit von allopolyploidem Raps und seinen diploiden Ausgangsarten bisher kaum möglich. Dies liegt vor allem daran, dass die Elternarten B. rapa und B. oleracea vorwiegend Fremdbefruchter sind und daher überwiegend heterozygote Genotypen als Eltern für die Resynthese von Raps verwendet wurden. Für einen genauen Vergleich ist es aber zwingend notwendig, dass für die Resynthese vollständig homozygote Eltern verwendet werden, da das A- und das C-Genom in der entstehenden Resynthese auch vollständig homozygot vorliegen und somit ansonsten heterozygote mit homozygoten Genomen verglichen werden. Hinzu kommt, dass die heterozygoten Elterngenotypen nicht genetisch stabil über Samen vermehrt werden können und somit nicht für einen Vergleich mit der hergestellten Resynthese zur Verfügung stehen.

Wie in Abschnitt 1.1 erläutert wäre eine Mehrleistung von resynthetisiertem Raps, der im jeweiligen Genom genetisch seinen Elterngenotypen entspricht, durch einen Ploidieeffekt und den Effekt von fixierter Heterosis zu erklären. Abb. 3 zeigt schematisch ein Material, das nötig wäre, um beide Effekte von einander zu trennen. Hier werden neben einer Resynthese und ihren homozygoten diploiden Elterngenotypen (2x) auch Autotetraploide (4x) der Elterngenotypen benötigt. Durch einen Vergleich der Autotetraploiden mit den Diploiden kann so zunächst der Ploidieeffekt abgeschätzt werden. Durch einen Vergleich der Resynthese mit den Autotetraploiden erhält man dagegen den Effekt von Interaktionen 
zwischen den Genomen, also den Effekt der fixierten Heterosis. Um zu gewährleisten, dass die Resynthese in ihrer genetischen Zusammensetzung den Autopolyploiden entspricht, müssen dabei die Resynthesen und Autotetraploiden aus denselben vollständig homozygoten Elterngenotypen hergestellt werden.

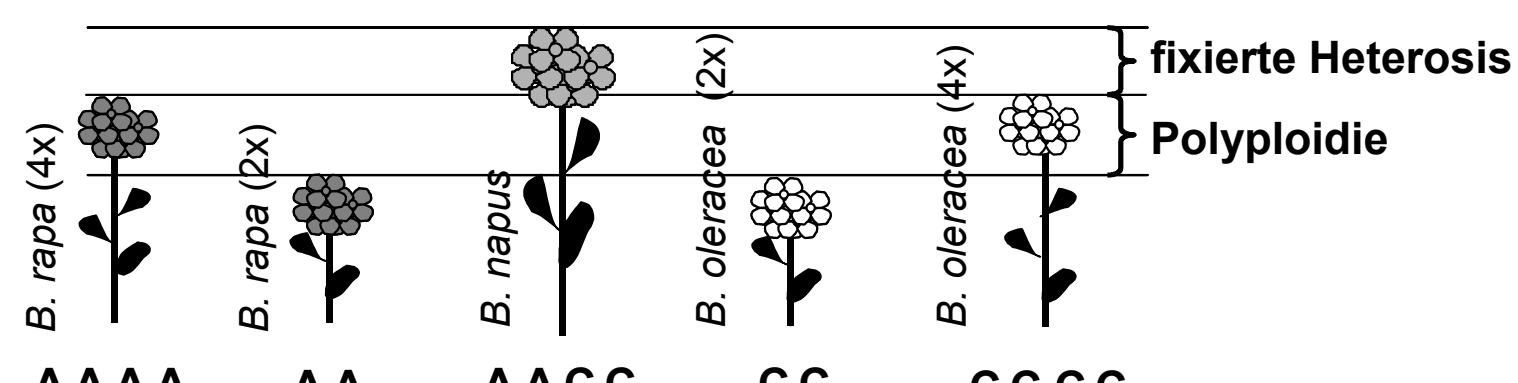
A A A A
A A
A ACC
C C
C C C C

AA und $C C$ bezeichnen vollständig homozygote Genotypen der Arten B. rapa und B. oleracea

\section{Abb. 3: Benötigtes Material zur Unterscheidung der Effekte von Polyploidie und fixierter Heterosis bei resynthetisiertem Raps}

Da auch für andere allopolyploide Arten keine genauen Vergleiche von Allopolyploiden mit ihren Eltern unter Berücksichtigung des Ploidieeffektes vorliegen und die Beziehung zwischen klassischer und fixierter Heterosis weitgehend unklar sind, waren die Ziele dieser Arbeit:

1. Ein genetisch balanciertes Material zu entwickeln, dass es ermöglicht, die Effekte von Polyploidie und fixierter Heterosis zu untersuchen (siehe Abb. 3).

2. Den Beitrag des Ploidieeffektes und der fixierten Heterosis zur Leistungsfähigkeit des Rapses zu quantifizieren.

3. Die Ausgangslinien molekulargenetisch zu charakterisieren und die Beziehung zwischen genetischen Distanzen und klassischer Heterosis bei Allopolyploiden und ihren Eltern zu untersuchen.

4. Den Einfluss fixierter Heterosis auf die klassische Heterosis bei Allopolyploiden zu untersuchen.

5. Eine Vorhersage des Ausmaßes der fixierten und klassischen Heterosis bei Allopolyploiden auf Basis des Ausmaßes der klassischen Heterosis bei ihren diploiden Eltern zu treffen. 


\section{Material und Methoden}

\subsection{Ausgangsmaterial}

Als Ausgangsmaterial wurden acht B. rapa (A_) und acht B. oleracea (C_) Genotypen aus verschiedenen Subspezies benutzt. Alle in dieser Untersuchung verwendeten Genotypen wurden aus diesen 16 Linien hergestellt. Eine Übersicht über die verwendeten Linien und deren Herkunft zeigt Tab. 1. Alle 16 Linien sind entweder Doppelthaploide- oder Inzuchtlinien und lassen sich somit genetisch stabil vermehren.

Tab. 1: Übersicht über die verwendeten Brassica rapa (A) und Brassica oleracea (C) Genotypen

\begin{tabular}{ccccc} 
Bezeichnung & Originalbezeichnung & Herkunft $^{1}$ & Subspezies & Typ $^{2}$ \\
\hline A4 & RO18 & John Innes Center (GB) & var. trilocularis & IL \\
A6 & $6748-21$ & Agri Food Canada (CA) & var. oleifera & DH \\
A7 & $6748-1430$ & Agri Food Canada (CA) & var. oleifera & DH \\
A8 & $6806-42$ & Agri Food Canada (CA) & var. trilocularis & DH \\
A9 & $7442-2942$ & Agri Food Canada (CA) & var. oleifera & DH \\
A13 & 03-A6-902 & Universität Wuhan (VC) & var. pekinensis & DH \\
A16 & S2YS-Pb24-2/1 & Genbank Gatersleben (D) & var. trilocularis & IL \\
A19 & S2 YS 50-1 & Danisco Seed (DN) & var. trilocularis & IL \\
& & & & \\
C34 & SW508 & Svalöf Weibull (S) & var. botrytis & DH \\
C36 & SW513 & Svalöf Weibull (S) & var. botrytis & DH \\
C37 & SW514 & Svalöf Weibull (S) & var. botrytis & DH \\
C38 & SW517 & Svalöf Weibull (S) & var. botrytis & DH \\
C42 & A12 & John Innes Center (GB) & var. alboglabra & DH \\
C46 & S2Bra165/83-3/1 & Genbank Gatersleben (D) & var. alboglabra & IL \\
C47 & S2C3-4-1 & CrGC (USA) & var. alboglabra & IL \\
C49 & S2Rah2-1 & Danisco Seed (DN) & var. alboglabra & IL \\
\hline
\end{tabular}

'CA: Kanada, D: Deutschland, DN: Dänemark, GB: Großbritannien, S: Schweden, VC: China; CrGC: Crucifer Genetic Cooperation; ${ }^{2}$ IL: Inzuchtlinie, DH: Doppelt Haploide

Die Ausgangslinien wurden untereinander sowohl interspezifisch zur Herstellung von Allopolyploiden (Resynthesen) als auch intraspezifisch zur Herstellung von $\mathrm{F}_{1}$-Hybriden gekreuzt. Außerdem wurden durch Colchizinierung Autotetraploide der Ausgangslinien erzeugt.

Die Bezeichnung der hergestellten Resynthesen und $\mathrm{F}_{1}$-Hybriden setzt sich aus den Bezeichnungen der diploiden Ausgangslinien zusammen. Die Resynthese aus der Kreuzung der Rübsenlinie A4 und der Kohllinie C34 wird somit zum Beispiel als Linie 
A4C34 bezeichnet. Entsprechend der Verdoppelung des Genoms werden die Autotetraploiden der Linie A4 zum Beispiel als Linie A4A4 bezeichnet.

\subsection{Molekulargenetische Untersuchungen}

\subsubsection{DNA Isolation}

Für die molekulargenetischen Untersuchungen wurden je zwei Pflanzen der verwendeten Genotypen im Gewächshaus angezogen und eine Blattmischprobe von $100 \mathrm{mg}$ genommen. Anschließend wurde unter Verwendung des Dneasy® Plant Mini Kit der Firma Qiagen (Deutschland) Gesamt-DNA aus den Proben isoliert und aufgereinigt. Die Isolierung erfolgte nach Anleitung des Herstellers. Schließlich wurde die Konzentration der extrahierten Gesamt-DNA mit einem VersaFluor ${ }^{\circledR}$ Fluorometer (Biorad, Deutschland) bestimmt und die Proben auf 25 ng DNA / $\mu$ l verdünnt.

\subsubsection{RAPD Analyse}

Für die RAPD Analyse wurden die in Tab. 16 (Anhang) aufgeführten 36 dekamer Oligonukleotide der Firma OperonTechnologies (Almada, USA) als Primer ausgewählt. Der Reaktionsansatz für die Polymerasekettenreaktion (PCR) enthielt 50 ng DNA, eine Einheit Taq-DNA-Polymerase (Fermentas, Litauen), 0,4 $\mu \mathrm{M}$ Primer, 0,2 $\mathrm{mM}$ dNTPs, 3 $\mathrm{mM} \mathrm{MgCl}_{2}$ und 2,5 $\mu 1$ 10x PCR-Puffer bei einem Gesamtvolumen von $25 \mu 1$. Die PCR erfolgte in einem PTC 100 Thermocycler (MJResearch, USA) mit einer ersten Denaturierung bei $94^{\circ} \mathrm{C}$ für 30 Sekunden gefolgt von 45 Zyklen von einer Minute bei $92^{\circ} \mathrm{C}$, einer Minute bei $35^{\circ} \mathrm{C}$ und zwei Minuten bei $72^{\circ} \mathrm{C}$, sowie einer abschließenden Elongation für fünf Minuten bei $72^{\circ} \mathrm{C}$.

Im Anschluss daran wurden die PCR Produkte auf einem 1,5\%igem Agarosegel elektrophoretisch getrennt und nach Färbung mit Ethidiumbromid unter UV-Licht sichtbar gemacht. Bilder der Bandenprofile wurden sowohl digital wie auch als Foto dokumentiert.

\subsubsection{Datenanalyse}

Für die weitere Verrechnung wurden die Bandenprofile in eine binäre Datenmatrix übersetzt (1 für Anwesenheit, 0 für Abwesenheit einer Bande). Die Schätzung der paarweisen genetischen Distanzen wurde unter Verwendung des Ähnlichkeitskoeffizienten nach Jaccard durchgeführt. Zur Gruppierung der Genotypen wurde anschließend eine 
Clusteranalyse nach der ,unweighted pair-group method with arithmetic means“ (UPGMA) durchgeführt und die Ergebnisse in einem Dendrogramm dargestellt. Die Verrechnung der Daten erfolgte mit dem Programm NTSYS-pc 2.1 (ROHLF 2000).

\subsection{Herstellung der Allopolyploiden}

\subsubsection{Anzucht der Elternpflanzen und interspezifische Kreuzungen}

Die Anzucht der acht B. rapa und acht B. oleracea Genotypen erfolgte im Gewächshaus bei $16 \mathrm{~h}$ Licht und $8 \mathrm{~h}$ Dunkelheit in $11 \times 11 \mathrm{~cm}$ Töpfen. Um zu gewährleisten, dass während der Kreuzungszeit stets genügend Knospen und Pollen für die interspezifischen Kreuzungen zur Verfügung standen, wurden alle Genotypen zeitversetzt in mehreren Chargen ausgesät. Die B. oleracea Genotypen der Subspezies botrytis wurden, nachdem sie Köpfe gebildet hatten, etwa vier Wochen bei $4^{\circ} \mathrm{C}$ vernalisiert. Damit sollte zum einen die Blütenbildung induziert und zum anderen durch die niedrige Temperatur die Gefahr einer Infektion der Köpfe mit Botrytis Graufäule (Botrytis cinerea) verringert werden.

Für die interspezifischen Kreuzungen wurde B. rapa immer als Mutterpflanze und B. oleracea immer als Vaterpflanze benutzt: Nach dem Aufblühen der ersten Blüten einer Mutterpflanze wurden zunächst die offenen Blüten und kleinere Knospen entfernt. Anschließend wurden die verbliebenen maximal zehn Knospen mit einer Pinzette geöffnet und alle Antheren entfernt. Direkt im Anschluss daran wurde frischer Pollen der Vaterpflanze auf die Narben der emaskulierten Knospen aufgetragen. Um eine spätere Fremdbestäubung zu verhindern, wurden die bestäubten Triebe in Pergamintüten gesteckt. Nach etwa sieben Tagen wurden die Pergamintüten wieder entfernt.

Für jede der 64 Kreuzungskombination (acht B. rapa x acht B. oleracea) wurden mindestens 20 Knospen bestäubt. Alle interspezifischen Kreuzungen wurden zwischen Oktober 2003 und Mai 2004 durchgeführt.

\subsubsection{Embryo Rescue und in vitro Kultur}

Die Überführung der Samenanlagen in in vitro Kultur erfolgte 12-14 Tage nach der Kreuzung. Hierzu wurden die sich entwickelnden Schoten von der Mutterpflanze abgenommen und für eine Minute in 96\%igem Alkohol sterilisiert. Anschließend wurden die Schoten in einer Sterilbank unter dem Binokular mit einem Skalpell längs aufgeschnitten und die Samenanlagen in sterile Petrischälchen auf festes Nährmedium 
überführt. Als Nährmedium wurde MS-Medium nach MURASHIGE und SKOOG (1962) mit 2\% Saccharose und 1\% Agarose verwendet. Anschließend wurden die Petrischälchen mit atmungsaktivem Klebeband versiegelt und in einem Klimaschrank bei $24^{\circ} \mathrm{C}$ und Dauerlicht aufbewahrt.

Sobald aus den kultivierten Samenanlagen Embryonen auswuchsen, wurden diese gezählt und auf neues MS-Medium umgesetzt. Die sich entwickelnden Embryonen und daraus entstandenes Kallusgewebe wurden alle drei Wochen auf neues MS-Medium umgesetzt. Sprosse wurden vom Kallusgewebe getrennt und weiterkultiviert bis sich Wurzeln bildeten. Bewurzelte Sprosse wurden schließlich in $7 \times 7 \mathrm{~cm}$ Töpfen in Komposterde verpflanzt und in einer Klimakammer bei $15^{\circ} \mathrm{C}, 75 \%$ Luftfeuchtigkeit und 16 Stunden Licht weitergezogen. Für jede Kreuzungskombination wurden bis zu fünf Sprosse in Erde überführt.

\subsubsection{Colchizinierung und Anzucht der Allopolyploiden}

Zur Verdoppelung des Chromosomensatzes der haploiden interspezifischen Hybriden erfolgte etwa 14 Tage nach der Überführung in die Klimakammer eine Colchizinierung. Hierfür wurden die Pflanzen, sobald sie wieder ein deutliches Wachstum zeigten, ausgetopft und ihre Wurzeln von Erde freigewaschen und auf $7 \mathrm{~cm}$ eingekürzt. Anschließend wurden 10-20 Pflanzen gemeinsam bis zum Hypokotyl in eine wässrige Lösung mit 0,33\% Colchizin (Duchefa, Niederlande) getaucht. Nach drei Stunden Behandlungsdauer bei Dauerlicht wurden die Pflanzen wieder aus dem Tauchbad genommen, kurz in Leitungswasser gewaschen und wieder in Komposterde gepflanzt. Nach weiteren 14 Tagen in einer Klimakammer wurden die Pflanzen in das Gewächshaus überführt und in $11 \times 11 \mathrm{~cm}$ Töpfe umgetopft.

Bei Erreichen der Blüte wurden fertile Triebe zur Selbstbestäubung eingetütet. Bei Pflanzen die trotz Pollenbildung keinen Ansatz zeigten wurde zusätzlich eine Knospenbestäubung mit Pollen derselben Pflanze durchgeführt, um eine mögliche Selbstinkompatibilität zu überwinden. Pflanzen, die keine Pollenbildung zeigten, wurden zunächst zweimal zurückgeschnitten und dann erneut mit Colchizin behandelt, um den Chromosomensatz zu verdoppeln. 


\subsubsection{Datenanalyse}

Um den Erfolg der interspezifischen Kreuzungen $\mathrm{zu}$ bewerten, wurde für jede der Mutterlinien und der Vaterlinien die Kreuzungseignung als Anzahl gewonnener Embryonen je bestäubter Blüte berechnet. Für die Berechnung der Grenzdifferenz wurden dabei die Bestäubungen mit den acht verschiedenen Vaterlinien als Wiederholungen für die jeweilige Mutterlinie angesehen. Entsprechend wurden die Bestäubungen der acht verschiedenen Mutterlinien als Wiederholungen für die jeweiligen Vaterlinien angesehen.

\subsection{Herstellung der Autopolyploiden}

Zur Verdoppelung des Chromosomensatzes der diploiden Elternpflanzen wurden deren Samen zunächst auf Filterpapier bei $25^{\circ} \mathrm{C}$ und Dauerlicht angekeimt. Nach dem Aufbrechen der Samenschale wurden die Keimlinge für zwei Stunden vollständig in eine wässrige Lösung mit $0,075 \%$ Colchizin (B.rapa) beziehungsweise 0,15\% Colchizin (B. oleracea) getaucht. Anschließend wurden sie kurz in Leitungswasser gewaschen, in ein Komposterde-Sand-Torf-Gemisch $(2: 1: 1)$ gepflanzt und in einer Klimakammer bei $15^{\circ} \mathrm{C}$, 75\% Luftfeuchtigkeit und 16 Stunden Licht weitergezogen.

Bei Pflanzen, welche die Colchizinierung überlebt hatten, wurde nach etwa vier Wochen am dritten Laubblatt die Ploidiestufe bestimmt. Hierfür wurde die DNA der Zellen mit dem fluoreszierenden Kernfarbstoff 4‘,6-Diamidino-2-phenylindol (DAPI) angefärbt und anschließend der relative DNA Gehalt der Zellen mit einem PA1 Durchflusszytometer (Partec, Deutschland) geschätzt und mit dem der diploiden Ausgangslinien verglichen. Tetraploide Pflanzen beziehungsweise Pflanzen mit einem hohen Anteil tetraploider Zellen wurden in 11x11 cm Töpfe umgetopft und ins Gewächshaus überführt. Bei Erreichen der Blüte wurden die Pflanzen eingetütet und eine Knospenbestäubung mit Pollen derselben Pflanze durchgeführt. Die aus der Selbstbestäubung entstandenen Samen wurden erneut im Gewächshaus ausgesät und am dritten Laubblatt mit dem Durchflusszytometer auf ihre Ploidiestufe hin überprüft. Um den Untersuchungsaufwand zu reduzieren, wurde hier eine morphologische Vorselektion auf Pflanzen mit einem kleineren Längen-Breiten-Verhältnis der Blätter durchgeführt.

\subsection{Biomasseversuche}

Die Leistungsfähigkeit der Genotypen wurde am Merkmal oberirdische Biomasseproduktion an jungen Pflanzen bestimmt. Zu diesem Zweck wurden zwischen 
März und August 2005 Ertragsversuche im Gewächshaus durchgeführt. Das gesamte Saatgut für die Ertragsversuche wurde zwischen Oktober 2004 und Mai 2005 im Gewächshaus erzeugt.

\subsubsection{Beschreibung der Leistungsprüfungen}

Insgesamt wurden sechs verschiedene Leistungsprüfungen (LP) mit folgenden Genotypen durchgeführt:

LP 1 Resynthesen und Eltern: Zur Bestimmung der fixierten Heterosis wurden 64 Resynthesen im Vergleich mit ihren acht Rübsen- und acht Kohleltern aus Tab. 1, sowie den daraus hergestellten Autotetraploiden geprüft.

LP 2 Rübsen Diallel: Zur Bestimmung der klassischen Heterosis bei Rübsen wurde ein Diallel mit den acht Elternlinien aus Tab. 1 geprüft.

LP 3 Kohl Diallel: Zur Bestimmung der klassischen Heterosis bei Kohl wurde ein Diallel mit den acht Elternlinien aus Tab. 1 geprüft.

LP 4 Resynthese Diallel 1: Zur Bestimmung der klassischen Heterosis bei resynthetisiertem Raps wurde ein Diallel mit acht Resyntheselinien als Eltern geprüft. Hier wurden vier Resyntheselinien ausgewählt, die den gleichen Rübsenelter (A7) haben und sich somit nur im C-Genom unterscheiden. Entsprechend dazu wurden fünf Resynthesen ausgewählt, die den gleichen Kohlelter (C47) haben und sich nur im A-Genom unterscheiden (siehe Tab. 2).

LP 5 Resynthese Diallel 2: Zur Bestimmung der klassischen Heterosis bei resynthetisiertem Raps wurde ein Diallel mit acht Resyntheselinien als Eltern geprüft. Die Resyntheselinien für dieses Diallel wurden so ausgewählt, dass jede Rübsen- und jede Kohllinie aus Tab. 1 jeweils einmal Elter dieser Resynthesen ist (siehe Tab. 2). Somit entspricht die genetische Zusammensetzung dieses Diallels im jeweiligen Genom der aus den Leistungsprüfungen 2 und 3.

LP 6 Kältestress: Zur Bestimmung der fixierten Heterosis bei Kältestress wurden die Rübsenlinien A4 und A19, die Kohllinien C34 und C46 sowie die vier daraus hergestellten Resynthesen in einer Klimakammer bei $7^{\circ} \mathrm{C}$ und $16 \mathrm{~h}$ Licht geprüft. 


\begin{tabular}{|c|c|c|c|}
\hline $\begin{array}{l}\text { LP } 2 \text { Rübsen } \\
\text { Diallel }\end{array}$ & $\begin{array}{l}\text { LP } 3 \text { Kohl } \\
\text { Diallel }\end{array}$ & $\begin{array}{c}\text { LP } 4 \text { Resynthese } \\
\text { Diallel } 1\end{array}$ & $\begin{array}{c}\text { LP } 5 \text { Resynthese } \\
\text { Diallel } 2\end{array}$ \\
\hline A4 & C34 & A7C37 & A4C34 \\
\hline A6 & C36 & A7C38 & $\mathrm{A} 6 \mathrm{C} 42$ \\
\hline A7 & C37 & A7C46 & A7C49 \\
\hline A8 & C38 & A7C47 & A8C46 \\
\hline A9 & $\mathrm{C} 42$ & $\mathrm{~A} 4 \mathrm{C} 47$ & A9C38 \\
\hline A13 & C46 & A6C47 & A13C36 \\
\hline A16 & $\mathrm{C} 47$ & A9C47 & A16C37 \\
\hline A19 & C49 & A16C47 & A19C47 \\
\hline
\end{tabular}

Als Versuchsanlage wurde für die Leistungsprüfungen jeweils eine Gitteranlage gewählt, um Unterschieden in Temperatur- und Lichtverteilung im Gewächshaus Rechnung zu tragen. In der Leistungsprüfung Resynthesen und Eltern wurden insgesamt 100 Genotypen in vier quadratischen Dreisatzuntergittern (12 Wiederholungen mit 10x10 Prüfgliedern) geprüft. Die Diallel Leistungsprüfungen umfassten jeweils 36 Prüfglieder (PG) und wurden jeweils als drei quadratische Dreisatzuntergitter (9 Wiederholungen mit 6x6 PG) angelegt. Die Leistungsprüfung Kältestress wurde aufgrund der geringen Anzahl Prüfglieder (8) als Blockversuch mit 12 Wiederholungen angelegt. Die Randomisierung der Versuche erfolgte mit dem Programm Plabplan (UTZ 1994). Um Randeffekte zu minimieren, wurde um die Versuche jeweils eine Reihe der Sommerrapssorte Korall (LP 1 und 4-6) als Rand ausgesät. In der LP 2 wurde hierfür die Linie A7 und in der LP 3 die Linie C47 verwendet. Skizzen der Gitteranlagen finden sich in Abb. 22 und Abb. 23 im Anhang.

\subsubsection{Versuchsdurchführung}

Die Prüfung der Genotypen erfolgte in Parzellen mit jeweils 18 Pflanzen. Die Aussaat erfolgte in quadratischen Parzellen mit jeweils neun 7x7 cm Töpfen, die mit Fruhstorfer Erde Typ „T 25 (fein)“ gefüllt waren. Je Topf wurden zwei Samen ausgelegt, so dass je Parzelle drei Reihen mit jeweils sechs Pflanzen entstanden. Nach der Aussaat, sowie nach dem Auflaufen der Pflanzen, wurden die Versuche mit Wasser besprüht, um die Erde zu befeuchten. Im Anschluss daran wurden die Versuche zweimal wöchentlich im Anstauverfahren bewässert, um eine möglichst gleichmäßige Durchfeuchtung des Bodens zu gewährleisten. Hierzu wurden die Tische, auf denen die Versuche standen, für drei Stunden 2-3 cm hoch mit Wasser befüllt. Um eine ausreichende Nährstoffversorgung zu 
gewährleisten, wurde dem Gießwasser der NPK-Dünger HaKaPhos ${ }^{\circledR}$ blau (Compo, Deutschland) in einer Konzentration von $0,5 \mathrm{~g}$ je Liter Gießwasser zugesetzt. Zusätzlich zum Tageslicht wurde jeder Tisch für 16 Stunden mit zwei 400 Watt SON-T-Agro Natriumdampflampen (Philips/Niederlande) beleuchtet.

Nach 20 und 26 Tagen wurde die Frischmasse des Aufwuchses bestimmt. Dazu wurde nach 20 Tagen aus jedem Topf eine Pflanze geerntet (1. Ernte) und die geernteten Pflanzen einer Parzelle gemeinsam gewogen. Die Ernte der übrigen Pflanzen erfolgte 26 Tage nach der Aussaat (2. Ernte). Die Trockenmasse wurde nach Trocknung bei $75^{\circ} \mathrm{C}$ für 48 Stunden erfasst. Die Ernte der LP 6 erfolgte aufgrund des langsameren Wachstums bei niedrigen Temperaturen nach 40 und 52 Tagen.

Aufgrund des Umfanges der Versuche wurden die zwölf Wiederholungen der LP 1 an sechs Terminen ausgesät. LP 2-5 wurden jeweils zu drei unterschiedlichen Terminen ausgesät und die LP 6 wurde zu zwei Terminen ausgesät. Der Temperaturverlauf während der Leistungsprüfungen, sowie Aussaat- und 2. Erntetermine sind Abb. 4 zu entnehmen. 


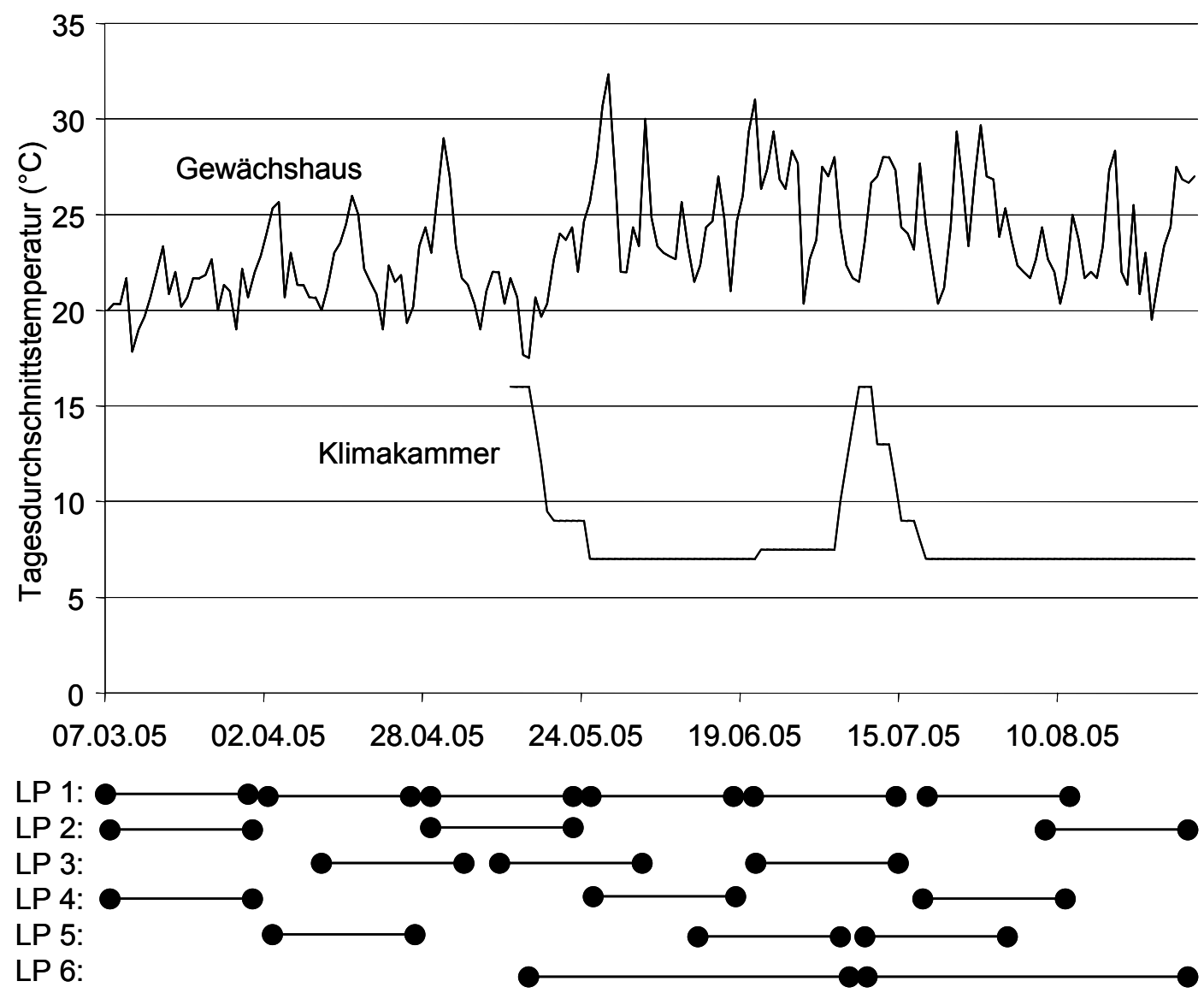

\section{Abb. 4: Temperaturverlauf in Gewächshaus und Klimakammer während der Leistungsprüfungen}

\subsubsection{Datenanalyse}

Zunächst wurden aus den Erträgen je Parzelle und der Anzahl geernteter Pflanzen die Frisch- und Trockenmasseerträge je Pflanze berechnet. Außerdem wurde der FrischmasseZuwachs zwischen den Ernteterminen und der Frischmasse-Gesamtertrag je Topf berechnet. Somit ergaben sich folgende sechs Merkmale für die statistische Auswertung:

FM 1: Oberirdischer Frischmasseertrag je Pflanze 20 Tage nach der Aussaat

TM 1: Oberirdischer Trockenmasseertrag je Pflanze 20 Tage nach der Aussaat

FM 2: Oberirdischer Frischmasseertrag je Pflanze 26 Tage nach der Aussaat

TM 2: Oberirdischer Trockenmasseertrag je Pflanze 26 Tage nach der Aussaat

FMZuwachs: Zuwachs der oberirdischen Frischmasse zwischen Tag 20 und Tag 26 nach der Aussaat (FM 2 - FM 1) 
FMGesamt: Oberirdischer Frischmasseertrag je Topf (FM 1 + FM 2)

Zur statistischen Verrechnung wurde für die einzelnen Untergitter zunächst getrennt eine Gitterkorrektur vorgenommen. Die um die Effekte der unvollständigen Blöcke korrigierten Parzellenwerte bildeten dann die Datengrundlage für eine Verrechnung der einzelnen Leistungsprüfungen als vollständig randomisierte Blockanlage. Aus den Mittelwerten der Prüfglieder wurden schließlich sowohl die relative als auch die absolute ElternmittelHeterosis und die Heterosis gegenüber dem besseren Elter für klassische und fixierte Heterosis wie folgt ermittelt:

absolute Elternmittel-Heterosis: $\quad \mathrm{absH}_{\mathrm{EM}}=\mathrm{h}_{\mathrm{ij}}-0,5\left(\mathrm{p}_{\mathrm{i}}+\mathrm{p}_{\mathrm{j}}\right)$

relative Elternmittel-Heterosis: $\quad \operatorname{relH}_{\mathrm{EM}}=100\left[\mathrm{~h}_{\mathrm{ij}}-0,5\left(\mathrm{p}_{\mathrm{i}}+\mathrm{p}_{\mathrm{j}}\right)\right] /\left[0,5\left(\mathrm{p}_{\mathrm{i}}+\mathrm{p}_{\mathrm{j}}\right)\right]$

absolute Heterosis (besserer Elter): $a b s H_{B E}=h_{i j}-p_{i}$

relative Heterosis (besserer Elter): $\operatorname{relH}_{\mathrm{BE}}=100\left(\mathrm{~h}_{\mathrm{ij}}-\mathrm{p}_{\mathrm{i}}\right) / \mathrm{p}_{\mathrm{i}}$

, wobei

$\mathrm{h}_{\mathrm{ij}}:$ der Mittelwert einer Kreuzung der i-ten Mutter mit dem j-ten Vater

$\mathrm{p}_{\mathrm{i}}$ : der Mittelwert des besseren Elter $\mathrm{i}$

$\mathrm{p}_{\mathrm{j}} \quad$ : der Mittelwert des schlechteren Elter $\mathrm{j}$

Allgemeine Kombinationsfähigkeit (GCA) und spezielle Kombinationsfähigkeit (SCA) wurden nach dem folgenden Modell berechnet:

$$
X_{i j}=\mu+g_{i}+g_{j}+s_{i j}
$$

,wobei

$\mathrm{X}_{\mathrm{ij}}$ : der Mittelwert einer Kreuzung der i-ten Mutter mit dem j-ten Vater

$\mu$ : der allgemeine Mittelwert des Versuchs

$\mathrm{g}_{\mathrm{i}}:$ der Effekt der GCA der i-ten Mutter

$\mathrm{g}_{\mathrm{j}} \quad$ : der Effekt der GCA des j-ten Vaters

$s_{i j}:$ der Effekt der SCA zwischen der i-ten Mutter und dem j-ten Vater 
Gitterkorrektur, die Auswertung der Blockversuche, sowie die Diallel-Analyse wurden mit den Programmen Plabstat (UTZ 1992) und PZ14 (UTZ 1989) durchgeführt.

Da alle Eltern der Diallel-LPs auch in LP 1 geprüft wurden, wurden diese für Vergleiche zwischen den Leistungsprüfungen als Standards herangezogen. Dadurch konnten alle Diallel-LPs auf den Mittelwert der jeweiligen Standards in LP 1 standardisiert werden.

Für den Vergleich der autotetraploiden Linien mit ihren diploiden Ausgangslinien wurde jeweils ein t-Test für den Vergleich von Paardifferenzen durchgeführt. 


\section{Ergebnisse}

\subsection{Molekulargenetische Untersuchungen}

Mit den 36 ausgewählten Primern konnten insgesamt 261 RAPD Loci ausgewertet werden. Das entspricht einem Mittel von 7,25 Loci je Primer. Die B. rapa Linien produzierten an 184 der ausgewerteten Loci eine Bande von denen 159 einen Polymorphismus zeigten. Bei B. oleracea waren dagegen nur 87 der 135 produzierten Banden polymorph. Tab. 16 im Anhang zeigt eine Übersicht über die Anzahl der auswertbaren polymorphen Banden der verwendeten Primer in den jeweiligen Arten. Ein Beispiel für das RAPD Bandenprofil mit dem Primer B 08 zeigt Abb. 5.

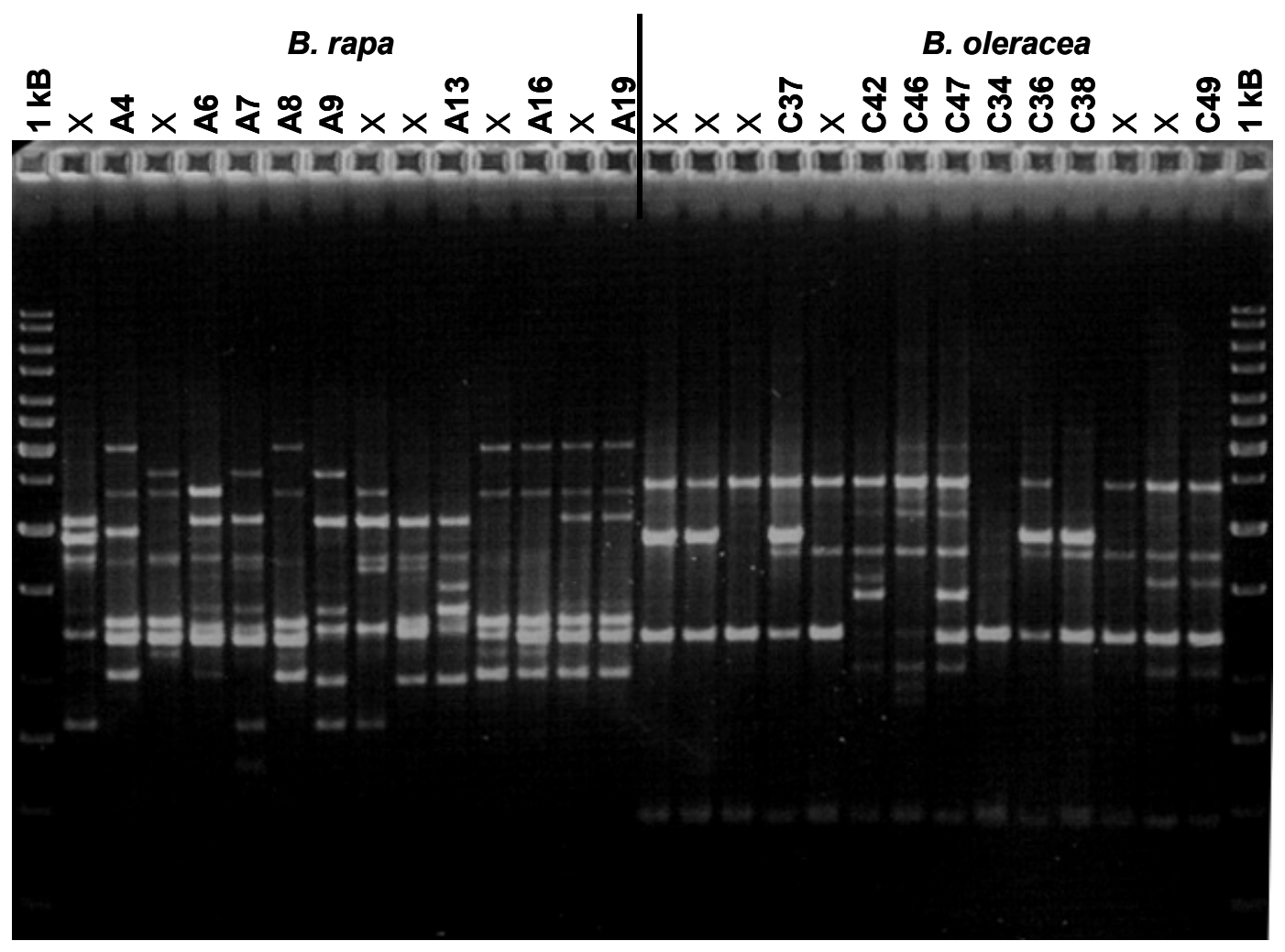

1kB: DNA Größenstandard (Fermentas gene ruler® $1 \mathrm{kB}$ Leiter)

links: $B$. rapa; rechts: $B$. oleracea; angegeben sind nur die Genotypen aus Tab. 1

Abb. 5: RAPD Bandenprofil von 14 B. rapa und 14 B. oleracea Genotypen mit dem Primer B 08

Ebenfalls im Anhang in Tab. 17 finden sich die aus den Bandenprofilen berechneten genetischen Distanzen zwischen den Genotypen. Das auf Grundlage dieser Distanzen in einer Clusteranalyse ermittelte Dendrogramm ist in Abb. 6 dargestellt. In der Clusteranalyse bildeten sowohl die Arten B. rapa und B. oleracea als auch deren 
Subspezies deutlich abgrenzbare Gruppen. Insgesamt variierten die genetischen Distanzen innerhalb der Art B. rapa zwischen 0,11 und 0,77 und innerhalb B. oleracea zwischen 0,01 und 0,49 .



\section{Abb. 6: Dendrogramm der genetischen Distanz von acht $B$. rapa (A) und acht B. oleracea $(\mathrm{C})$ Linien}

Die größte genetische Ähnlichkeit zeigten die vier Kohllinien der Subspezies botrytis (C34, C36, C37, C38) mit einer mittleren genetischen Distanz von 0,10. Die Subspezies alboglabra (C42, C46, C47, C49) wies hingegen eine mittlere genetische Distanz von 0,33 auf. Zwischen beiden Gruppen wurde eine genetische Distanz von 0,45 ermittelt. Bei Rübsen zeigte die Subspezies trilocularis (A4, A8, A16, A19) innerhalb der Gruppe mit 0,18 im Verhältnis zur Subspezies oleifera (A6, A7, A9) mit 0,39 eine vergleichsweise geringe mittlere genetische Distanz. Die Distanz zwischen den beiden Gruppen lag bei 0,73. Die mittlere genetische Distanz der Linie A13 (var. pekinensis) zu den anderen Rübsenlinien betrug 0,64 .

\subsection{Herstellung der Allopolyploiden}

Für die Herstellung aller 64 möglichen Resynthesen wurden insgesamt 1873 Knospen der acht Rübsenlinien mit Pollen der acht Kohllinien bestäubt. Aus den sich entwickelnden Schoten konnten 5556 Samenanlagen in die in vitro Kultur überführt werden. Aus diesen Samenanlagen wuchsen schließlich 866 Embryonen aus. Somit konnten aus jeder 
bestäubten Knospe im Durchschnitt 0,46 Embryonen gewonnen werden. Der Erfolg der Kreuzungen hing dabei jedoch hoch signifikant von der als Mutter verwendeten Rübsenlinie ab. Die interspezifische Kreuzungseignung der Rübsenlinien variierte zwischen 0,13 und 1,22 Embryonen pro bestäubter Knospe im Mittel über alle verwendeten B. oleracea Väter. Welche Kohllinie als Vater verwendet wurde hatte dagegen keinen signifikanten Einfluss auf den Kreuzungserfolg. Die mittlere Kreuzungseignung der einzelnen Genotypen ist in Abb. 7 dargestellt. Die Erfolgsraten der einzelnen Kreuzungskombinationen finden sich im Anhang in Tab. 18.

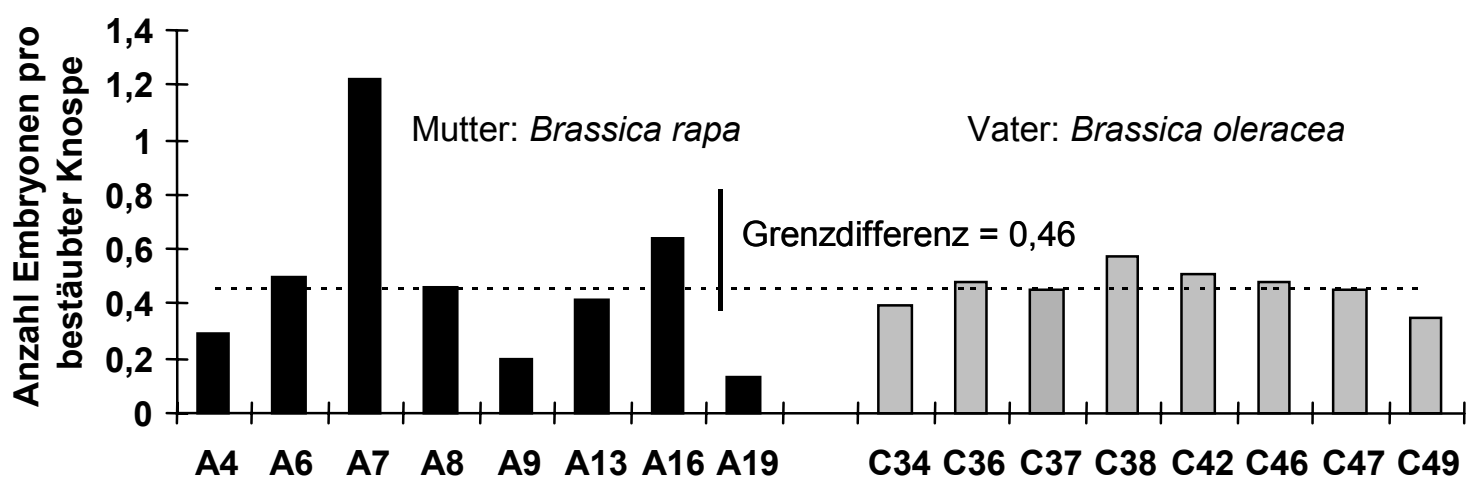

\section{Abb. 7: $\quad$ Effizienz der interspezifischen Kreuzung von B. rapa und B. oleracea}

Aus der in vitro Kultur konnten alle 64 Resynthesen ins Gewächshaus überführt werden. Die Resynthesen A4C38, A13C34 und A13C47 zeigten jedoch auch nach mehrfacher Colchizinierung keine Pollenbildung, so dass für die weiteren Versuche nur 61 Resynthesen zur Verfügung standen. Eine Übersicht über die erfolgreich hergestellten Resynthesen zeigt Tab. 3.

Tab. 3: Erfolgreich hergestellte Resynthesen

\begin{tabular}{lcccccccc} 
& A4 & A6 & A7 & A8 & A9 & A13 & A16 & A19 \\
\hline C34 & X & $X$ & $X$ & $X$ & $X$ & -- & $X$ & $X$ \\
C36 & $X$ & $X$ & $X$ & $X$ & $X$ & $X$ & $X$ & $X$ \\
C37 & $X$ & $X$ & $X$ & $X$ & $X$ & $X$ & $X$ & $X$ \\
C38 & --- & $X$ & $X$ & $X$ & $X$ & $X$ & $X$ & $X$ \\
C42 & $X$ & $X$ & $X$ & $X$ & $X$ & $X$ & $X$ & $X$ \\
C46 & $X$ & $X$ & $X$ & $X$ & $X$ & $X$ & $X$ & $X$ \\
C47 & $X$ & $X$ & $X$ & $X$ & $X$ & --- & $X$ & $X$ \\
C49 & $X$ & $X$ & $X$ & $X$ & $X$ & $X$ & $X$ & $X$ \\
\hline
\end{tabular}

X: Kombination (Resynthese) verfügbar; ---: Resynthese nicht verfügbar 


\subsection{Herstellung der Autopolyploiden}

Nach der Colchizinierung der Samen konnten in allen Ausgangslinien Pflanzen mit tetraploiden Zellen gefunden werden. Die Nachkommen aus der Selbstbestäubung dieser Pflanzen waren hingegen wieder zu einem großen Teil vollständig diploid oder bildeten keinen Pollen.

Insgesamt konnten so nur für die fünf Rübsenlinien A7, A8, A13, A16, und A19 sowie für die beiden Kohllinien C46 und C47 autotetraploide Linien erzeugt werden. Als Beispiel für die Ploidiebestimmung mit einem Durchflusszytometer sind in Abb. 8 die Histogramme für die diploide Ausgangslinie C47 (a.) und die hergestellte tetraploide Linie C47C47 (b.) dargestellt. Hier zeigt sich deutlich, dass die Zellkerne der tetraploiden Linie etwa den doppelten relativen DNA Gehalt aufweisen, wie die der diploiden Linie.

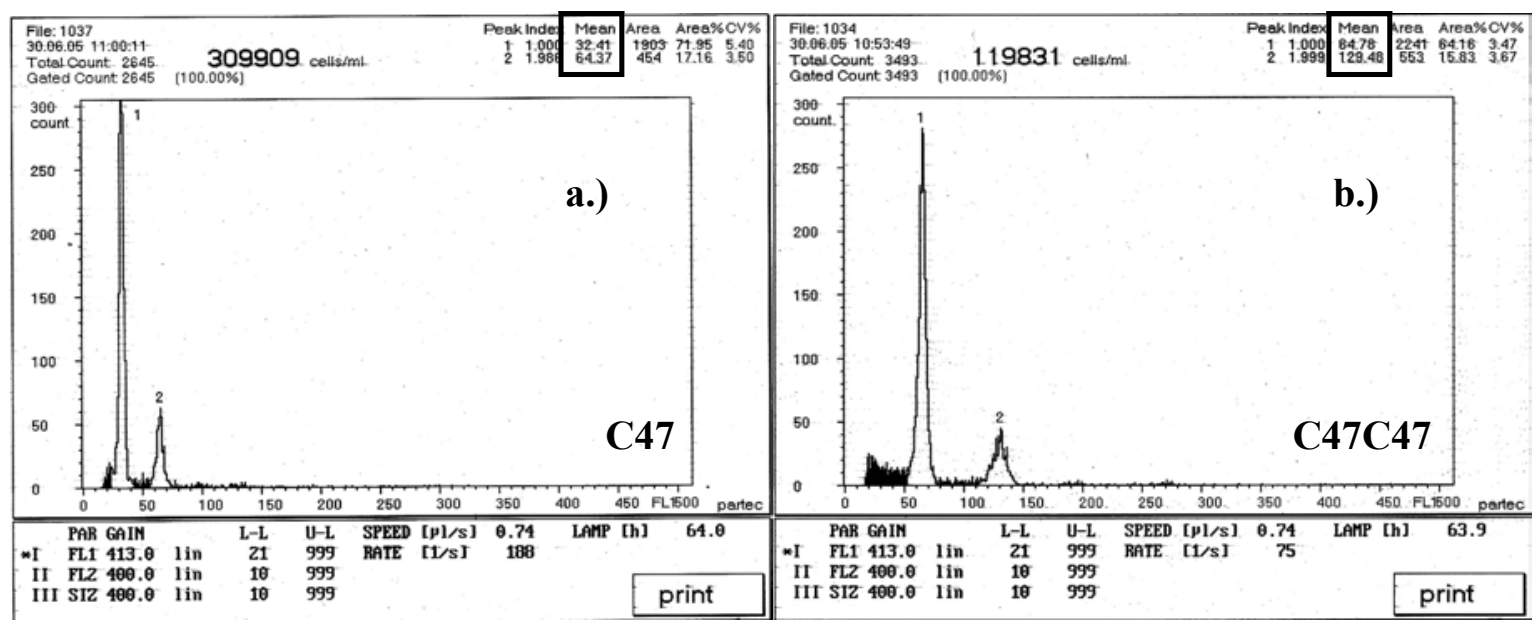

x-Achse: relativer DNA Gehalt (Kanalnummer), y-Achse: Anzahl Zellkerne

Abb. 8: Histogramme des relativen DNA Gehaltes für die Linien C47 und C47C47

\subsection{Biomasseversuche}

\subsubsection{Korrelationen zwischen den erfassten Merkmalen}

In Tab. 4 sind die Korrelationskoeffizienten zwischen dem Frischmasse-Gesamtertrag und den anderen Merkmalen für die einzelnen Leistungsprüfungen aufgeführt. Die erfassten Merkmale waren unter einander hoch korreliert. Zur Vereinfachung der Darstellung werden daher im Folgenden nur die Ergebnisse zu einem Merkmal erläutert. Soweit nicht anders angegeben, werden die Werte für den Frischmasse-Gesamtertrag (FMGesamt) dargestellt, da für dieses Merkmal der zu erwartende Messfehler am kleinsten ist. Für jedes Prüfglied sind die Mittelwerte aller erfassten Merkmale im Anhang in Tab. 19, 
Tab. 21, Tab. 23, Tab. 25, Tab. 27 und Tab. 29 aufgeführt.

Tab. 4: Korrelationen zwischen Frischmasse-Gesamtertrag (FMGesamt) und anderen erfassten Merkmalen in den einzelnen Leistungsprüfungen

\begin{tabular}{cccccc} 
& FM1 & TM1 & FM2 & TM2 & FMZuwachs \\
\hline LP 1 & 0,99 & 0,94 & 1,00 & 0,95 & 0,97 \\
LP 2 & 0,99 & 0,97 & 1,00 & 0,93 & 0,93 \\
LP 3 & 0,98 & 0,97 & 0,99 & 0,99 & 0,98 \\
LP 4 & 0,89 & 0,84 & 0,97 & 0,93 & 0,73 \\
LP 5 & 0,96 & 0,92 & 0,99 & 0,95 & 0,80 \\
LP 6 & 0,96 & 0,93 & 1,00 & 1,00 & 0,97 \\
\hline
\end{tabular}

Abb. 9 zeigt die Beziehung zwischen Trocken- und Frischmasse-Gesamtertrag für die 16 diploiden Ausgangslinien und die aus ihnen hergestellten tetraploiden Linien. Hier zeigt sich, dass auch die Ploidiestufe keinen Einfluss auf den prozentualen Trockenmassegehalt hatte. Die Rübsenlinie A13 und die daraus hergestellte tetraploide Linie A13A13 aus der Subspezies pekinensis zeigten dagegen mit 5,2\% einen geringeren Trockenmassegehalt als die übrigen Linien mit einem Mittel von 7,0\%. Auch die aus dieser Linie hergestellten Resynthesen wiesen mit 6,4\% einen geringeren Trockenmassegehalt auf als die übrigen Resynthesen (7,2\%). Die angegebenen Frischmasseerträge der aus der Linie A13 hergestellten Genotypen sind somit im Verhältnis zum Trockenmasseertrag leicht überschätzt.

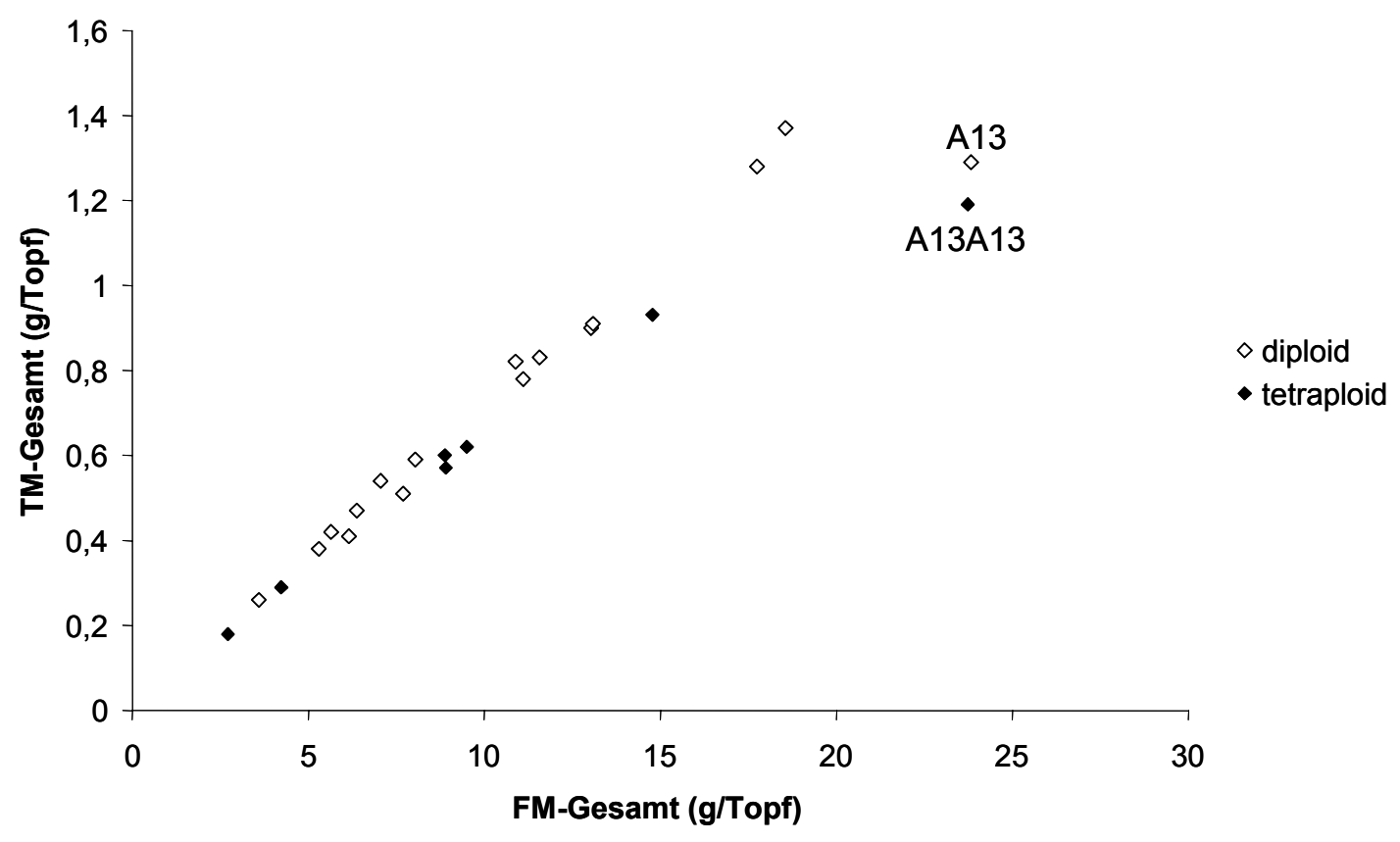

Abb. 9: Beziehung zwischen Frischmasse und Trockenmasse bei tetraploiden Genotypen und deren Ausgangslinien 


\subsubsection{Leistungsprüfung 1: Resynthesen und Eltern}

Zur Darstellung des Ploidieeffektes sind in Abb. 10 die Erträge der tetraploiden Linien den Erträgen ihrer diploiden Ausgangslinien gegenübergestellt. Entgegen der Erwartung zeigten die autotetraploiden Linien keine höheren Erträge als ihre diploiden Ausgangsformen. Bei den beiden Kohllinien C46 und C47 sowie bei zwei der Rübsenlinien aus der Subspezies trilocularis waren dagegen sogar signifikante Mindererträge der tetraploiden Linien $\mathrm{zu}$ beobachten. Auch die Linien A7A7 (var. oleifera) und A8A8 (var. trilocularis) zeigten geringere Erträge, wobei die Unterschiede jedoch nicht signifikant waren. Bei der Linie A13 (var. pekinensis) hatte die Ploidiestufe dagegen keinen Einfluss auf den Frischmasseertrag.

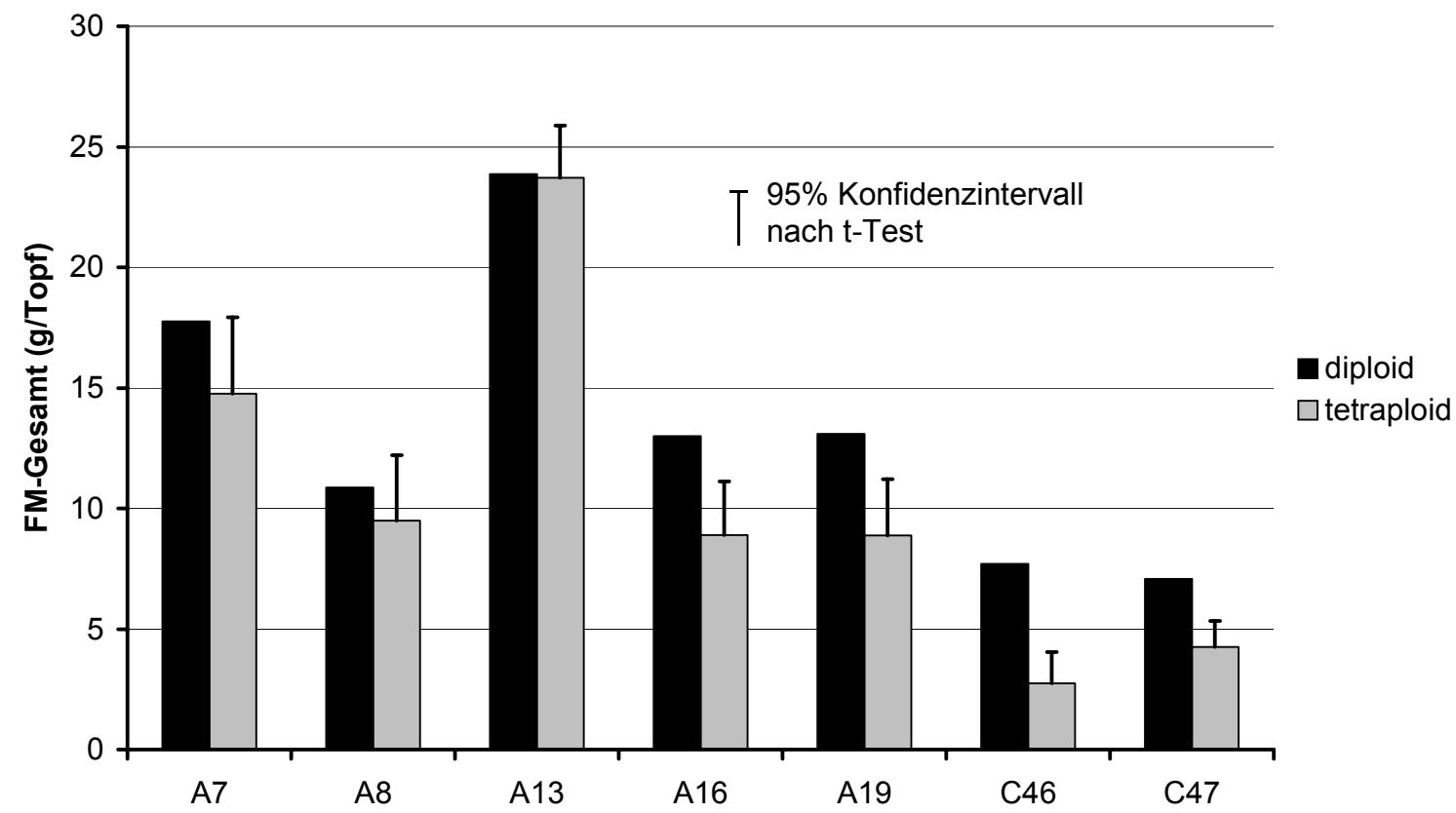

\section{Abb. 10: Vergleich der Frischmasseerträge von tetraploiden Genotypen und ihren diploiden Ausgangslinien}

Da nicht alle tetraploiden Linien vorhanden waren, werden im Folgenden als Eltern-Basis für die Berechnung der fixierten Heterosis nicht die Erträge der tetraploiden, sondern die der diploiden Ausgangsformen einer Resynthese angesehen. Durch dieses Vorgehen wird die fixierte Heterosis aufgrund des negativen Ploidieeffektes tendenziell unterschätzt.

Tab. 5 zeigt eine Übersicht der relativen fixierten Elternmittel-Heterosis auf Basis des Elternmittels der diploiden Ausgangslinien. Im Mittel lag der Frischmasse-Gesamtertrag etwa 50\% über dem Elternmittel, wobei die Größe der fixierten Heterosis zwischen -17,3\% und 124\% lag. Vier der 61 untersuchten Resynthesen wiesen eine negative fixierte 
Heterosis auf. Die allgemeine Kombinationsfähigkeit für fixierte Heterosis der diploiden Ausgangslinien schwankte bei den Rübsenlinien zwischen $-13,8 \%$ und 22,6\% und bei den Kohllinien zwischen $-27,5 \%$ und 40,9\%. Im Vergleich der beiden Erntezeitpunkte ergab sich für die erste Ernte mit $66 \%$ eine höhere fixierte EM-Heterosis als für den die zweite Ernte (45\%).

Tab. 5: Relative fixierte Elternmittel-Heterosis (\%) der Resynthesen und allgemeine Kombinationsfähigkeit (GCA) für fixierte EM-Heterosis der Elternlinien im Merkmal FMGesamt

\begin{tabular}{ccccccccccc} 
& A4 & A6 & A7 & A8 & A9 & A13 & A16 & A19 & Mittel & GCA \\
\hline C34 & 118,9 & 61,4 & 70,4 & 124,0 & 103,3 & $(76,2)$ & 66,1 & 110,2 & $\mathbf{9 1 , 3}$ & 40,9 \\
C36 & 74,6 & 65,5 & 32,9 & 62,5 & 46,9 & 38,6 & 42,7 & 50,2 & $\mathbf{5 1 , 7}$ & 1,3 \\
C37 & 57,2 & 66,2 & 55,4 & 85,2 & 57,2 & 41,3 & 47,3 & 61,7 & $\mathbf{5 9 , 0}$ & 8,5 \\
C38 & $(50,4)$ & 48,8 & 44,5 & 37,2 & 37,1 & 23,4 & 40,8 & 52,9 & $\mathbf{4 1 , 9}$ & $-8,5$ \\
C42 & 70,5 & 21,2 & 61,0 & 86,8 & 25,1 & 58,9 & 24,2 & 70,0 & $\mathbf{5 2 , 2}$ & 1,8 \\
C46 & 20,8 & $-17,3$ & $-5,9$ & 68,7 & 5,0 & 49,9 & 36,5 & 25,5 & $\mathbf{2 2 , 9}$ & $-27,5$ \\
C47 & 49,9 & $-2,7$ & 53,1 & 67,5 & 23,6 & $(42,7)$ & 59,9 & 24,2 & $\mathbf{3 9 , 8}$ & $-10,6$ \\
C49 & 46,1 & 49,2 & 47,6 & 52,8 & 56,9 & 67,0 & 37,4 & $-1,8$ & $\mathbf{4 4 , 4}$ & $-5,9$ \\
\hline Mittel & $\mathbf{6 1 , 1}$ & $\mathbf{3 6 , 5}$ & $\mathbf{4 4 , 9}$ & $\mathbf{7 3 , 1}$ & $\mathbf{4 4 , 4}$ & $\mathbf{4 9 , 8}$ & $\mathbf{4 4 , 4}$ & $\mathbf{4 9 , 1}$ & $\mathbf{5 0 , 4}$ & \\
GCA & 10,6 & $-13,8$ & $-5,5$ & 22,6 & $-6,0$ & $-0,6$ & $-6,0$ & $-1,2$ & & \\
\hline
\end{tabular}

( ) fehlende Werte wurden rechnerisch ergänzt

Beim Vergleich der Resynthesen mit ihrem besseren Elter ergab sich ein Mittelwert von 8,3\% für die fixierte Besserer-Elter (BE) -Heterosis (Tab. 6). Hier wiesen noch 41 der 61 untersuchten Resynthesen einen höheren Ertrag auf als ihr besserer Elter. Die Höhe der fixierten BE-Heterosis variierte zwischen $-41,5 \%$ und $48,9 \%$.

Tab. 6: Relative fixierte Besserer-Elter-Heterosis (\%) der Resynthesen und allgemeine Kombinationsfähigkeit (GCA) für fixierte BE-Heterosis der Elternlinien im Merkmal FMGesamt

\begin{tabular}{ccccccccccc} 
& A4 & A6 & A7 & A8 & A9 & A13 & A16 & A19 & Mittel & GCA \\
\hline C34 & 44,9 & $-3,7$ & 2,4 & 48,9 & 33,2 & $(1,4)$ & 5,9 & 33,9 & $\mathbf{2 0 , 9}$ & 12,58 \\
C36 & 31,6 & 7,9 & $-12,4$ & 23,3 & 9,3 & $-14,3$ & 2,2 & 7,5 & $\mathbf{6 , 9}$ & $-1,41$ \\
C37 & 16,2 & 6,9 & 1,0 & 37,7 & 14,7 & $-13,6$ & 3,7 & 13,7 & $\mathbf{1 0 , 0}$ & 1,74 \\
C38 & $(18,4)$ & $-0,1$ & $-1,8$ & 8,7 & 6,3 & $-21,8$ & 4,8 & 13,7 & $\mathbf{3 , 5}$ & $-4,76$ \\
C42 & 32,4 & $-19,3$ & 8,3 & 46,1 & $-4,2$ & $-0,1$ & $-8,7$ & 24,9 & $\mathbf{9 , 9}$ & 1,63 \\
C46 & 2,3 & $-41,5$ & $-32,6$ & 43,9 & $-12,5$ & $-0,9$ & 8,5 & $-0,4$ & $\mathbf{- 4 , 2}$ & $-12,46$ \\
C47 & 22,7 & $-32,8$ & 7,0 & 38,1 & $-0,4$ & $(-7,5)$ & 23,3 & $-4,4$ & $\mathbf{5 , 8}$ & $-2,54$ \\
C49 & 25,9 & 7,0 & 7,3 & 32,8 & 33,0 & 11,7 & 11,1 & $-20,7$ & $\mathbf{1 3 , 5}$ & 5,21 \\
\hline Mittel & $\mathbf{2 4 , 3}$ & $\mathbf{- 9 , 5}$ & $\mathbf{- 2 , 6}$ & $\mathbf{3 5 , 0}$ & $\mathbf{9 , 9}$ & $\mathbf{- 5 , 6}$ & $\mathbf{6 , 4}$ & $\mathbf{8 , 5}$ & $\mathbf{8 , 3}$ & \\
GCA & 16,0 & $-17,7$ & $-10,8$ & 26,6 & 1,6 & $-13,9$ & $-1,9$ & 0,2 & & \\
\hline
\end{tabular}

( ) fehlende Werte wurden rechnerisch ergänzt

Eine Übersicht über die absoluten Frischmasse-Gesamterträge der Resynthesen und ihrer Eltern finden sich im Anhang in Tab. 20. Die Ergebnisse der Varianzanalyse für den Frischmasse-Gesamtertrag in der Leistungsprüfung 1 sind in Tab. 7 dargestellt. Aufgrund des Ausmaßes der fixierten Heterosis ist der Mehrertrag der Resynthesen gegenüber ihren 
Eltern hoch signifikant. Auch Wiederholungen und Prüfglieder haben einen hoch signifikanten Einfluss auf den Frischmasse-Gesamtertrag. Auf die Leistung der Resynthesen haben sowohl die GCA des Rübsenelters als auch die GCA des Kohlelters und die spezielle Kombinationsfähigkeit beider Eltern einen signifikanten Einfluss. Beim Vergleich der Varianzkomponenten fällt jedoch auf, dass zwar die GCA des Rübsenelters (Mutter) großen Einfluss auf die Leistung der Resynthese hat, die GCA des Kohlelters (Vater) im Verhältnis zur SCA aber eine untergeordnete Rolle spielt.

Tab. 7: Ergebnisse der Varianzanalyse für das Merkmal FMGesamt (Leistungsprüfung 1)

\begin{tabular}{lrrrrr} 
Varianzursache & FG & SQ & MQ & F-Wert & Var.cp. \\
\hline Wiederholungen & 11 & 16199 & 1472,6 & $80,5^{* *}$ & \\
Prüfglieder & 76 & 17875 & 235,2 & $25,8^{* *}$ & \\
$\quad$ Eltern & 15 & 5638 & 375,9 & $34,7^{* *}$ & \\
$\quad$ Eltern vs. Resynthesen & 1 & 2303 & 2303,3 & $212,7^{* *}$ & \\
$\quad$ Resynthesen & 60 & 9933 & 165,6 & & \\
$\quad$ GCA Mutter & 7 & 6561 & 937,2 & $86,6^{* *}$ & 9,66 \\
$\quad$ GCA Vater & 7 & 801 & 114,4 & $10,6^{* *}$ & 1,09 \\
$\quad$ SCA & 46 & 2572 & 55,9 & $5,2^{* *}$ & 3,86 \\
Fehler & 385 & 4168 & 10,8 & &
\end{tabular}

${ }^{* *}$ signifikant bei $p \leq 0,01$

Der Ertrag der Resynthesen ist sowohl mit dem Elternmittel (Abb. 11) als auch mit der absoluten fixierten Heterosis (Abb. 12) signifikant korreliert. Elternmittel und absolute fixierte Heterosis waren dagegen untereinander nicht signifikant korreliert $(r=0,06)$.

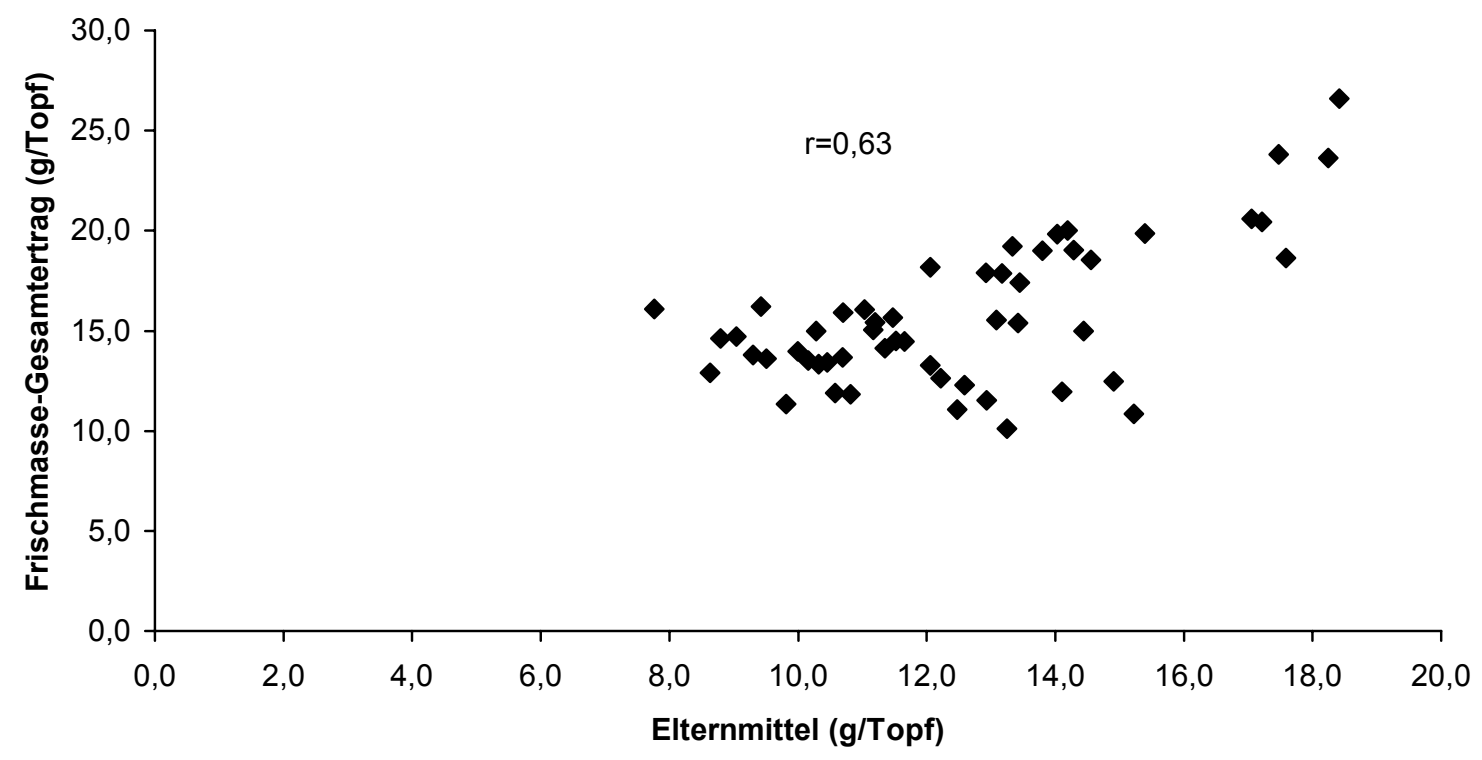


Abb. 11: Beziehung zwischen Elternmittel und dem Frischmasse-Gesamtertrag der Resynthesen

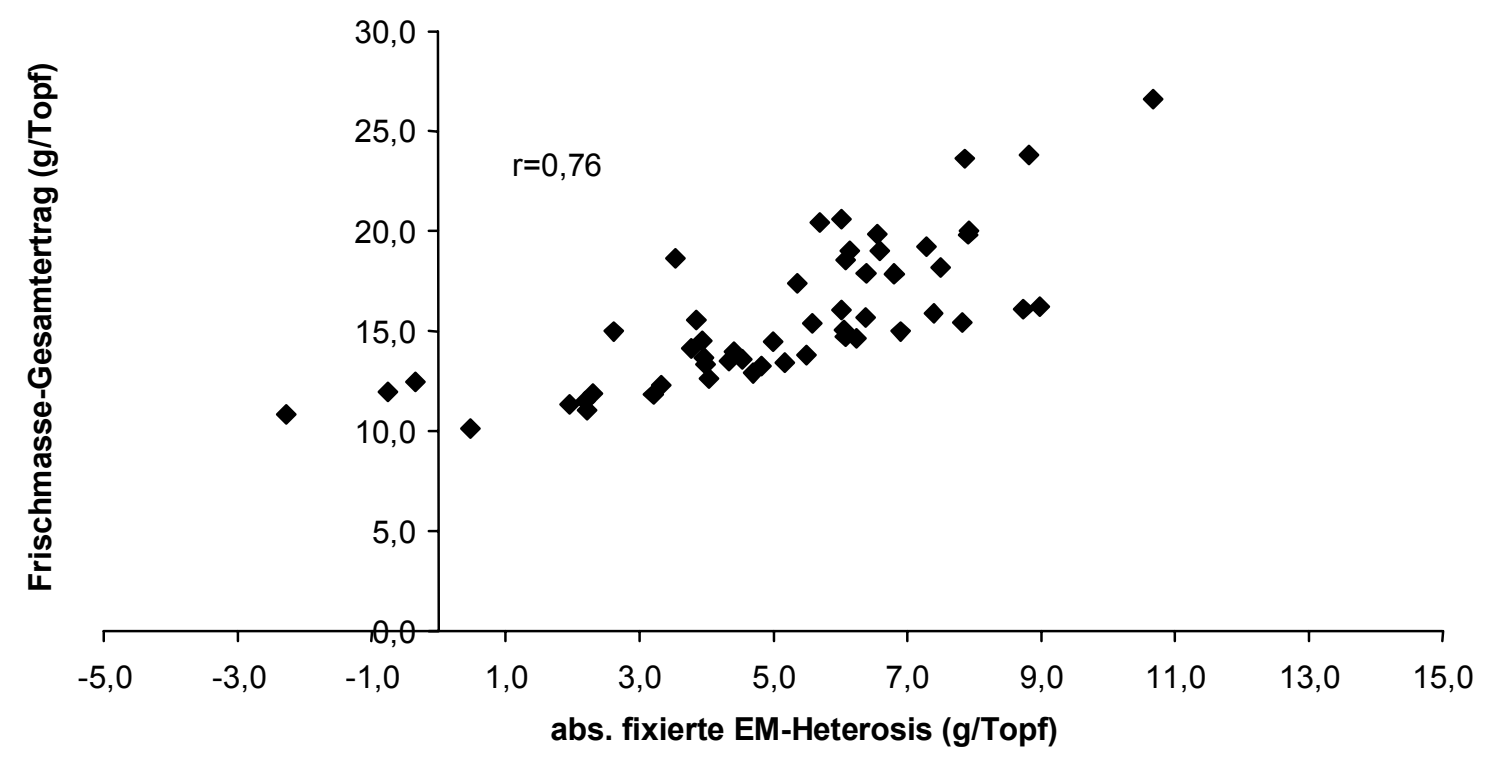

Abb. 12: Beziehung zwischen absoluter fixierter Elternmittel-Heterosis und dem Frischmasse-Gesamtertrag der Resynthesen

\subsubsection{Leistungsprüfung 2: Rübsen Diallel}

In Tab. 8 sind die Ergebnisse der Varianzanalyse für den Frischmasse-Gesamtertrag im Rübsen Diallel aufgeführt. Hier zeigt sich eine hoch signifikante Mehrleistung der Kreuzungen gegenüber ihren homozygoten Eltern. Auch Wiederholungen, Prüfglieder und GCA und SCA hatten einen hoch signifikanten Einfluss wobei die Varianzkomponente für die GCA größer ist als für die SCA.

Eine Übersicht über die absoluten Frischmasse-Gesamterträge für das Rübsen Diallel findet sich im Anhang in Tab. 22. 
Tab. 8: Ergebnisse der Varianzanalyse für das Merkmal FMGesamt (Leistungsprüfung 2)

\begin{tabular}{lrrrrr} 
Varianzursache & FG & SQ & MQ & F-Wert & Var.cp. \\
\hline Wiederholungen & 8 & 10395 & 1299,4 & $111,9^{* *}$ & \\
Prüfglieder & 35 & 8655 & 247,3 & $21,3^{* *}$ & \\
$\quad$ Eltern & 7 & 1711 & 244,5 & $21,1^{* *}$ & \\
$\quad$ Eltern vs. Kreuzungen & 1 & 2518 & 2517,5 & $216,8^{* *}$ & \\
$\quad$ Kreuzungen & 27 & 4426 & 163,9 & & \\
$\quad$ GCA & 7 & 3966 & 566,6 & $48,8^{* *}$ & 90,6 \\
$\quad$ SCA & 20 & 460 & 23,0 & $2,0^{* *}$ & 11,4 \\
Fehler & 280 & 3251 & 11,6 & & \\
${ }^{* *}$ signifikant bei $p \leq 0,01$ & & & & &
\end{tabular}

Eine Übersicht über die relative Elternmittel-Heterosis im Rübsen Diallel zeigt Tab. 9. Im Mittel lag der Frischmasse-Gesamtertrag der Kreuzungen 62,2\% über dem Elternmittel. Das Ausmaß der Heterosis variierte dabei zwischen 6,7\% und 155,9\%. Die allgemeine Kombinationsfähigkeit für die relative EM-Heterosis der acht Elternlinien lag zwischen $-28,8 \%$ und $35,3 \%$.

Im Vergleich $\mathrm{zu}$ ihrem besseren Elter wiesen die Kreuzungen im Mittel noch eine Mehrleistung von 33,1\% auf, wobei fünf Kreuzungen einen geringeren Ertrag hatten als ihr besserer Elter (siehe Tab. 22 im Anhang).

Tab. 9: Relative Elternmittel-Heterosis (\%) im Rübsen Diallel und allgemeine Kombinationsfähigkeit (GCA) für EM-Heterosis der Elternlinien im Merkmal FMGesamt

\begin{tabular}{cccccccccc} 
& A4 & A6 & A7 & A8 & A9 & A13 & A16 & A19 & Mittel \\
\hline A4 & & & & & & & & & \\
A6 & 80,2 & & & & & & & & \\
A7 & 93,1 & 49,7 & & & & & & & \\
A8 & 53,8 & 58,8 & 67,6 & & & & & & \\
A9 & 153,8 & 75,8 & 94,5 & 73,6 & & & & & \\
A13 & 28,6 & 33,8 & 51,8 & 42,2 & 58,7 & & & & \\
A16 & 17,3 & 43,2 & 42,8 & 6,7 & 70,7 & 9,1 & & & \\
A19 & 61,1 & 66,0 & 83,5 & 77,0 & 155,9 & 48,3 & 43,8 & & \\
\hline Mittel & $\mathbf{6 9 , 7}$ & $\mathbf{5 8 , 2}$ & $\mathbf{6 9 , 0}$ & $\mathbf{5 4 , 2}$ & $\mathbf{9 7 , 6}$ & $\mathbf{3 8 , 9}$ & $\mathbf{3 3 , 4}$ & $\mathbf{7 6 , 5}$ & $\mathbf{6 2 , 2}$ \\
GCA & $\mathbf{7 , 4}$ & $-3,9$ & $\mathbf{6 , 8}$ & $-\mathbf{7 , 9}$ & $\mathbf{3 5 , 3}$ & $-23,2$ & $-28,8$ & 14,3 & \\
\hline
\end{tabular}

Die Unterschiede in der Höhe der Heterosis lassen sich dabei zu einem großen Teil mit der genetischen Distanz zwischen den Eltern erklären. In Abb. 13 ist die Beziehung zwischen genetischer Distanz der Eltern und der absoluten Elternmittel-Heterosis dargestellt. Hier zeigt sich, dass die absolute Elternmittel-Heterosis bei Kreuzungen innerhalb der Subspezies trilocularis und oleifera mit steigender genetischer Distanz fast linear zunimmt 
$(\mathrm{r}=0,90)$. Bei Kreuzungen zwischen den Subspezies besteht dagegen kein eindeutiger Zusammenhang zwischen genetischer Distanz und Heterosis $(r=0,27)$. Für alle Kreuzungen ergibt sich ein Korrelationskoeffizient von 0,52.

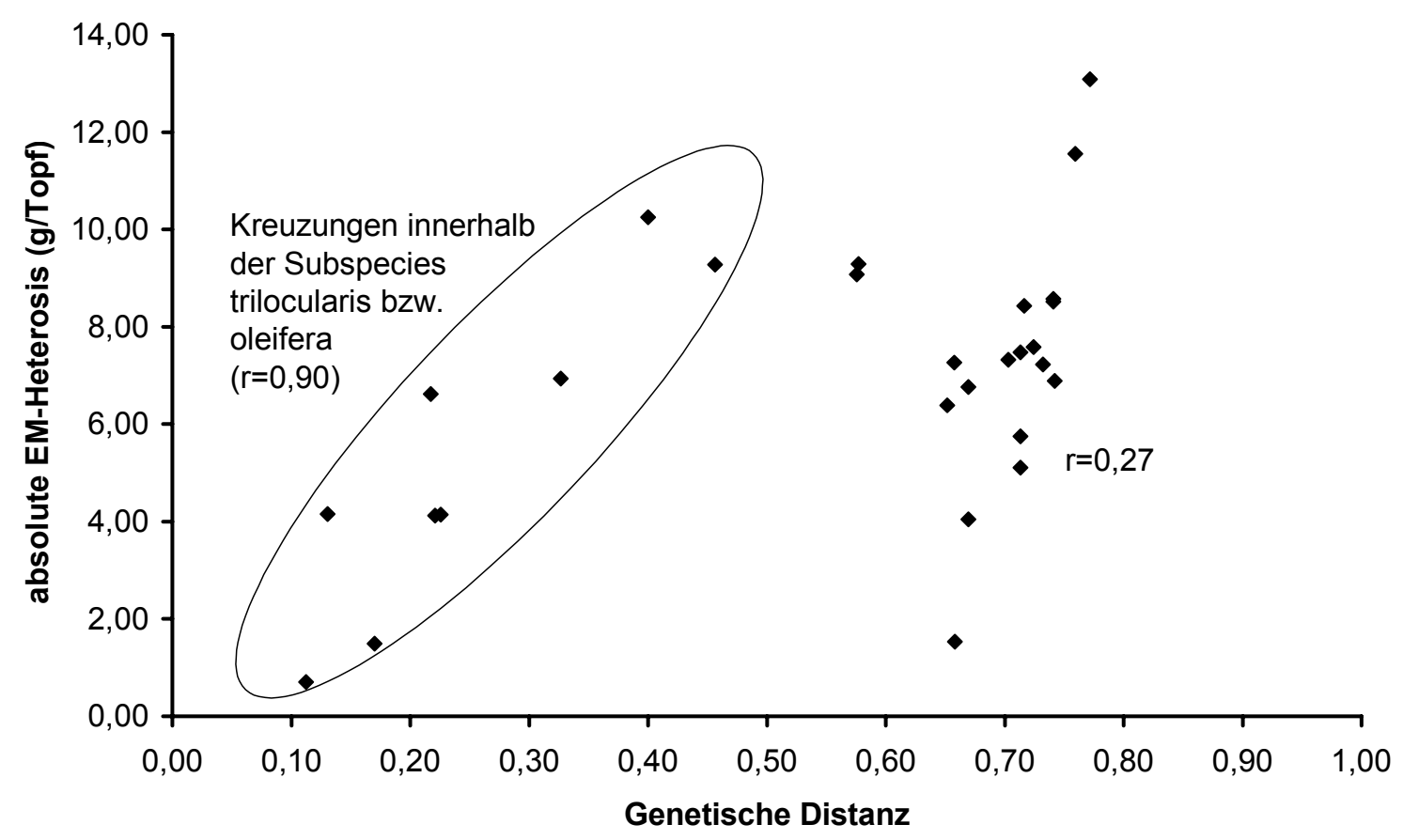
Abb. 13: Beziehung zwischen genetischer Distanz und absoluter Elternmittel-
Heterosis im Rübsen Diallel

\subsubsection{Leistungsprüfung 3: Kohl Diallel}

In Tab. 10 sind die Ergebnisse der Varianzanalyse für den Frischmasse-Gesamtertrag im Kohl Diallel aufgeführt. Auch hier zeigt sich eine hoch signifikante Mehrleistung der Kreuzungen gegenüber ihren homozygoten Eltern. Wiederholungen, Prüfglieder und GCA und SCA der Elternlinien hatten ebenso einen hoch signifikanten Einfluss. Im Unterschied zum Rübsen Diallel unterscheiden sich die Elternlinien selbst jedoch nicht signifikant voneinander. Auch die GCA spielt im Kohl Diallel im Verhältnis zur SCA eine untergeordnete Rolle.

Eine Übersicht über die absoluten Frischmasse-Gesamterträge für das Kohl Diallel findet sich im Anhang in Tab. 24. 
Tab. 10: Ergebnisse der Varianzanalyse für das Merkmal FMGesamt (Leistungsprüfung 3)

\begin{tabular}{lrrrrr} 
Varianzursache & FG & SQ & MQ & F-Wert & Var.cp. \\
\hline Wiederholungen & 8 & 2882 & 360,2 & $61,2^{* *}$ & \\
Prüfglieder & 35 & 4503 & 128,7 & $21,9^{\star *}$ & \\
$\quad$ Eltern & 7 & 67 & 9,6 & 1,6 & \\
$\quad$ Eltern vs. Kreuzungen & 1 & 2520 & 2519,8 & $428,1^{\text {** }}$ & \\
$\quad$ Kreuzungen & 27 & 1917 & 71,0 & & \\
$\quad$ GCA & 7 & 720 & 102,9 & $17,5^{\star *}$ & 7,2 \\
$\quad$ SCA & 20 & 1196 & 59,8 & $10,2^{* *}$ & 55,3 \\
Fehler & 280 & 1648 & 5,9 & & \\
** signifikant bei $p \leq 0,01$ & & & & &
\end{tabular}

Im Mittel lag der Frischmasse-Gesamtertrag der Kreuzungen im Kohl Diallel 90,0\% über dem Elternmittel. Eine Übersicht über die relative Elternmittel-Heterosis im Rübsen Diallel zeigt Tab. 11. Das Ausmaß der Heterosis lag bei den einzelnen Kreuzungen zwischen $16,0 \%$ und $137,3 \%$ und die allgemeine Kombinationsfähigkeit für die relative EM-Heterosis der acht Elternlinien schwankte zwischen -19,7\% und 17,4\%.

Im Vergleich zu ihrem besseren Elter wiesen die Kreuzungen im Mittel eine Mehrleistung von $75 \%$ auf, wobei die BE-Heterosis zwischen 10,9\% und 110,3\% variierte (siehe Tab. 24 im Anhang).

Tab. 11: Relative Elternmittel-Heterosis (\%) im Kohl Diallel und allgemeine Kombinationsfähigkeit (GCA) für EM-Heterosis der Elternlinien im Merkmal FMGesamt

\begin{tabular}{cccccccccc} 
& C34 & C36 & C37 & C38 & C42 & C46 & C47 & C49 & Mittel \\
\hline C34 & & & & & & & & & \\
C36 & 33,3 & & & & & & & & \\
C37 & 66,8 & 16,0 & & & & & & & \\
C38 & 52,5 & 49,0 & 46,6 & & & & & & \\
C42 & 137,3 & 115,2 & 100,8 & 130,7 & & & & & \\
C46 & 128,8 & 88,2 & 69,2 & 122,8 & 65,7 & & & & \\
C47 & 136,9 & 123,2 & 104,0 & 108,7 & 98,4 & 21,1 & & & \\
C49 & 125,8 & 113,2 & 89,0 & 118,4 & 104,0 & 65,4 & 89,8 & & \\
\hline Mittel & $\mathbf{9 7 , 4}$ & $\mathbf{7 6 , 9}$ & $\mathbf{7 0 , 3}$ & $\mathbf{8 9 , 8}$ & $\mathbf{1 0 7 , 4}$ & $\mathbf{8 0 , 1}$ & $\mathbf{9 7 , 4}$ & $\mathbf{1 0 0 , 8}$ & $\mathbf{9 0 , 0}$ \\
GCA & $\mathbf{7 , 3}$ & $-13,2$ & $-19,7$ & $-0,2$ & 17,4 & $-9,9$ & $\mathbf{7 , 4}$ & 10,8 & \\
\hline
\end{tabular}

In Abb. 14 ist die Beziehung zwischen genetischer Distanz der Eltern und der absoluten Elternmittel-Heterosis dargestellt. Auch hier nimmt die absolute Elternmittel-Heterosis bei Kreuzungen innerhalb der Subspezies alboglabra und botrytis ähnlich wie im Rübsen Diallel mit steigender genetischer Distanz zu $(\mathrm{r}=0,62)$. Eine Ausnahme bildet die Kreuzung zwischen den Linien C46 und C47, die trotz relativ großer genetischer Distanz eine 
vergleichsweise geringe Heterosis aufweist. Für Kreuzungen zwischen den Subspezies ergibt sich auch hier kein signifikanter Zusammenhang $(r=0,20)$. Der Korrelationskoeffizient für alle Kreuzungen liegt dabei bei 0,82 .

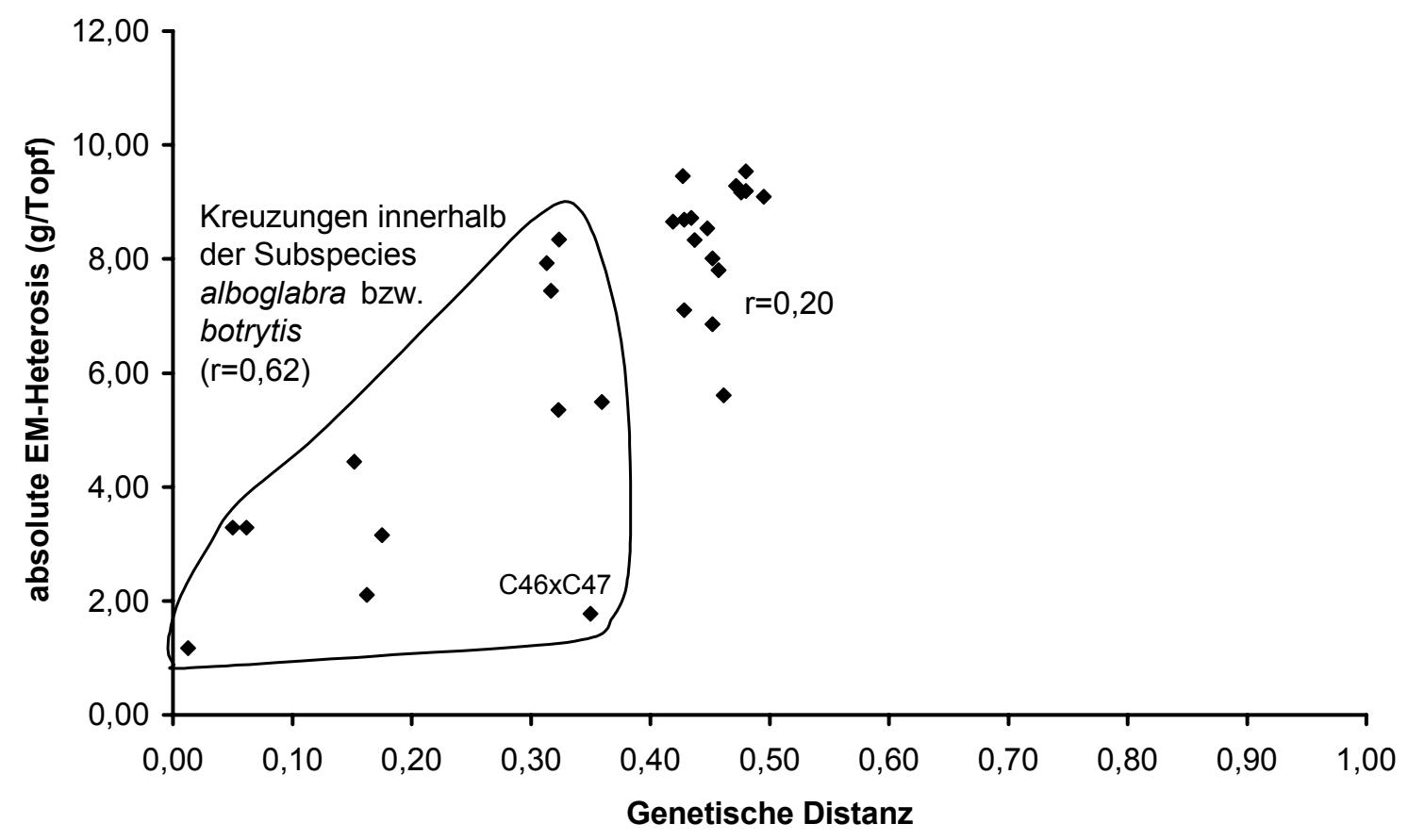

\section{Abb. 14: Beziehung zwischen genetischer Distanz und absoluter Elternmittel- Heterosis im Kohl Diallel}

\subsubsection{Leistungsprüfung 4: Resynthese Diallel 1}

Auch in der Varianzanalyse für den Frischmasse-Gesamtertrag des Resynthese Diallels 1 zeigt sich eine hoch signifikante Mehrleistung der Kreuzungen gegenüber ihren homozygoten Eltern. Wiederholungen, Prüfglieder und GCA und SCA der Elternlinien hatten auch hier einen signifikanten Einfluss. Die Varianzkomponenten für GCA und SCA liegen dabei in der gleichen Größenordnung.

Eine Übersicht über die absoluten Frischmasse-Gesamterträge für das Rübsen Diallel 1 findet sich im Anhang in Tab. 26. 
Tab. 12: Ergebnisse der Varianzanalyse für das Merkmal FMGesamt (Leistungsprüfung 4)

\begin{tabular}{lrrrrr} 
Varianzursache & FG & SQ & MQ & F-Wert & Var.cp. \\
\hline Wiederholungen & 8 & 1815 & 226,9 & $33,7^{* *}$ & \\
Prüfglieder & 35 & 949 & 27,1 & $4,0^{* *}$ & \\
$\quad$ Eltern & 7 & 151 & 21,6 & $3,2^{* *}$ & \\
$\quad$ Eltern vs. Kreuzungen & 1 & 222 & 222,3 & $33,0^{* *}$ & \\
$\quad$ Kreuzungen & 27 & 576 & 21,3 & & \\
$\quad$ GCA & 7 & 329 & 47,0 & $7,0^{* *}$ & 5,8 \\
$\quad$ SCA & 20 & 247 & 12,3 & $1,8^{*}$ & 5,6 \\
Fehler & 280 & 1884 & 6,7 & & \\
$*^{* *}$ signifikant bei $p \leq 0,05 / 0,01$ & & & & &
\end{tabular}

Eine Übersicht über die relative Elternmittel-Heterosis im Resynthese Diallel 1 zeigt Tab. 13. Im Mittel lag der Frischmasse-Gesamtertrag der Kreuzungen 15,2\% über dem Elternmittel, wobei das Ausmaß der Heterosis zwischen -9,3\% und 48,1\% variierte. Die allgemeine Kombinationsfähigkeit für die relative EM-Heterosis lag dabei zwischen $12,2 \%$ und $14,2 \%$.

Im Vergleich zu ihrem besseren Elter wiesen die Kreuzungen im Mittel eine Mehrleistung von $8,0 \%$ auf, wobei sechs Kreuzungen einen geringeren Ertrag hatten als ihr besserer Elter (siehe Tab. 26 im Anhang).

Tab. 13: Relative Elternmittel-Heterosis (\%) im Resynthese Diallel 1 und allgemeine Kombinationsfähigkeit (GCA) für EM-Heterosis der Elternlinien im Merkmal FMGesamt

$\begin{array}{llllllllll}\text { A4C47 } & \text { A6C47 } & \text { A7C37 } & \text { A7C38 } & \text { A7C46 } & \text { A7C47 } & \text { A9C47 A16C47 } & \text { Mittel }\end{array}$

\begin{tabular}{cccccccccc}
\hline A4C47 & & & & & & & & & \\
A6C47 & 27,6 & & & & & & & & \\
A7C37 & $-6,6$ & 8,0 & & & & & & & \\
A7C38 & $-9,3$ & 14,0 & 7,7 & & & & & & \\
A7C46 & 19,5 & 38,8 & 18,1 & 11,5 & & & & & \\
A7C47 & 7,6 & 21,1 & 9,7 & 3,4 & 36,4 & & & & \\
A9C47 & 29,8 & 24,2 & 20,6 & $-8,0$ & 48,1 & 4,5 & & & \\
A16C47 & 15,7 & 13,7 & 0,4 & 1,7 & 33,9 & 12,8 & 21,4 & & \\
\hline Mittel & $\mathbf{1 2 , 0}$ & $\mathbf{2 1 , 0}$ & $\mathbf{8 , 3}$ & $\mathbf{3 , 0}$ & $\mathbf{2 9 , 5}$ & $\mathbf{1 3 , 6}$ & $\mathbf{2 0 , 1}$ & $\mathbf{1 4 , 2}$ & $\mathbf{1 5 , 2}$ \\
GCA & $-3,1$ & 5,8 & $-6,9$ & $-12,2$ & 14,2 & $-1,5$ & 4,8 & $-0,9$ & \\
\hline
\end{tabular}

In Abb. 15 ist die Beziehung zwischen genetischer Distanz der Eltern und der absoluten Elternmittel-Heterosis im Resynthese Diallel 1 dargestellt. Im Gegensatz zum Rübsen und zum Kohl Diallel wurde hier keine signifikante Beziehung beobachtet. 


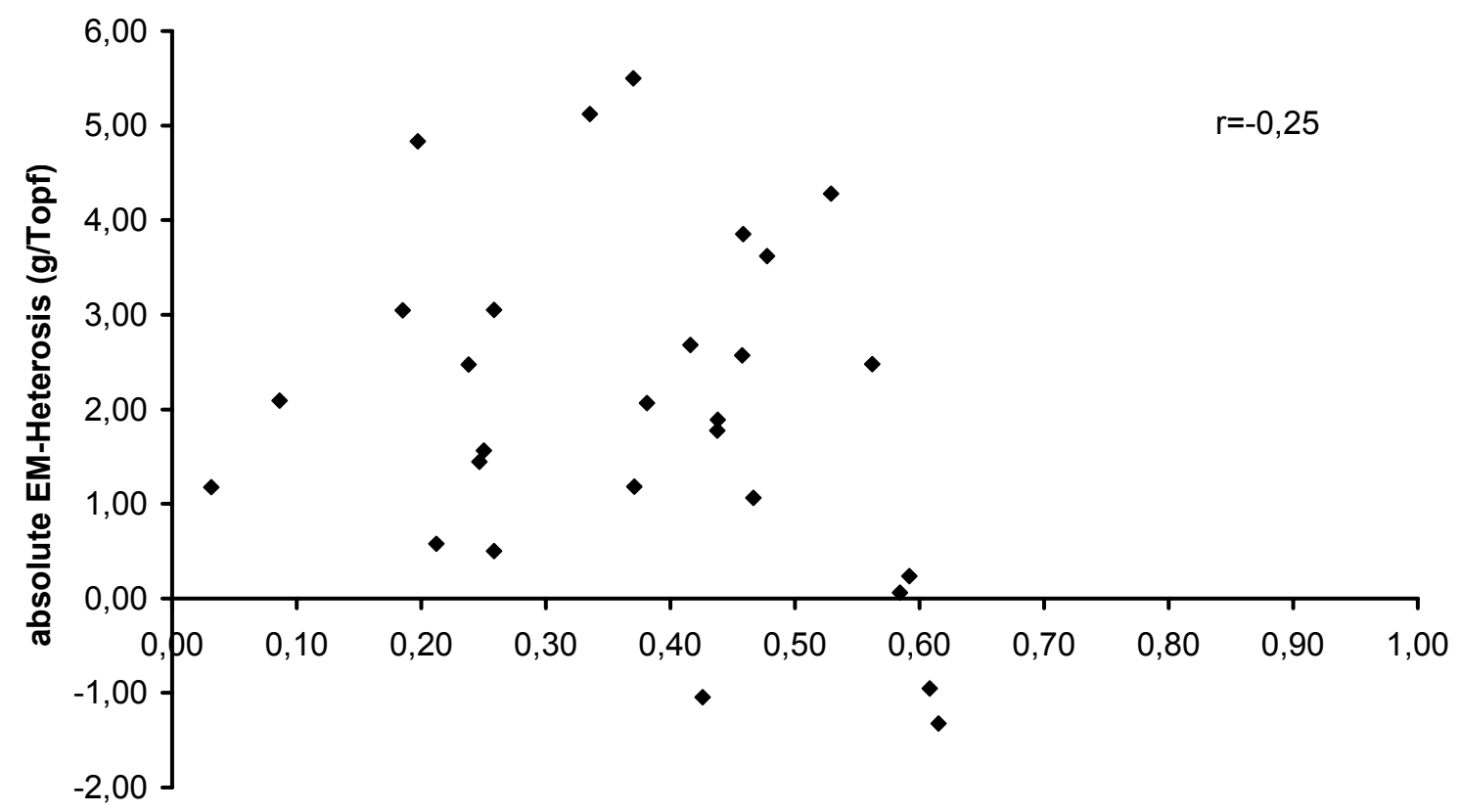

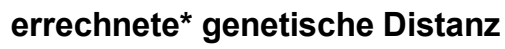

* Die genetischen Distanzen der Resynthesen wurden aus den Daten der diploiden Eltern errechnet

Abb. 15: Beziehung zwischen genetischer Distanz und absoluter ElternmittelHeterosis im Resynthese Diallel 1

Die Eltern für das Resynthese Diallel 1 wurden so ausgewählt, dass sich fünf Elternlinien nur im A-Genom (A_C47) und vier Elternlinien nur im C-Genom unterscheiden (A7C_). Im Diallel gab es somit Kreuzungen, die nur für das A-Genom beziehungsweise nur für das C-Genom heterozygot waren. In Abb. 16 wird die absolute klassische Heterosis, die diese Kreuzungen zeigten mit der verglichen, die entsprechende Kreuzungen aus dem Rübsen und dem Kohl Diallel zeigten. So wird beispielsweise die Kreuzung A4C47*A16C47 mit der Kreuzung A4*A16 verglichen. Bei diesen Vergleichen zeigt sich zum einen, dass die klassische Heterosis auf allotetraploider Stufe im Mittel kleiner ist als auf diploider Stufe. Zum anderen wird deutlich, dass die Höhe der klassischen Heterosis auf diploider und allotetraploider Stufe nicht signifikant korreliert sind. 




Abb. 16: Vergleich der absoluten klassischen Heterosis bei sich entsprechenden Kreuzungen auf diploider und allotetraploider Stufe

\subsubsection{Leistungsprüfung 5: Resynthese Diallel 2}

Wie beim Resynthese Diallel 1 zeigt sich auch in der Varianzanalyse für den FrischmasseGesamtertrag des Resynthese Diallels 2 eine hoch signifikante Mehrleistung der Kreuzungen gegenüber ihren homozygoten Eltern. Auch Wiederholungen, Prüfglieder und GCA und SCA der Elternlinien hatten einen hoch signifikanten Einfluss. Die Varianzkomponente für die GCA ist dabei größer als die für die SCA.

Eine Übersicht über die absoluten Frischmasse-Gesamterträge für das Rübsen Diallel 2 findet sich im Anhang in Tab. 28.

Tab. 14: Ergebnisse der Varianzanalyse für das Merkmal FMGesamt (Leistungsprüfung 5)

\begin{tabular}{lrrrrr} 
Varianzursache & FG & SQ & MQ & F-Wert & Var.cp. \\
\hline Wiederholungen & 8 & 1130 & 141,2 & $141,2^{* *}$ & \\
Prüfglieder & 35 & 1291 & 36,9 & $36,9^{* *}$ & \\
$\quad$ Eltern & 7 & 456 & 65,1 & $65,1^{* *}$ & \\
$\quad$ Eltern vs. Kreuzungen & 1 & 146 & 146,5 & $146,5^{* *}$ & \\
$\quad$ Kreuzungen & 27 & 689 & 25,5 & & \\
$\quad$ GCA & 7 & 523 & 74,7 & $74,7^{* *}$ & 11,1 \\
$\quad$ SCA & 20 & 167 & 8,3 & $8,3^{* *}$ & 4,6 \\
Fehler & 280 & 1051 & 3,8 & &
\end{tabular}

** signifikant bei $p \leq 0,01$ 
Tab. 15 zeigt eine Übersicht über die relative Elternmittel-Heterosis im Resynthese Diallel 2. Im Mittel lag der Frischmasse-Gesamtertrag der Kreuzungen 19,1\% über dem Elternmittel, wobei das Ausmaß der Heterosis zwischen $-18,9 \%$ und $89 \%$ variierte. Die allgemeine Kombinationsfähigkeit für die relative EM-Heterosis der acht Elternlinien lag zwischen $-21,9 \%$ und $29,4 \%$.

Im Vergleich zu ihrem besseren Elter wiesen die Kreuzungen im Mittel eine Mehrleistung von 3,9\% auf, wobei 13 Kreuzungen einen geringeren Ertrag hatten als ihr besserer Elter (siehe Tab. 28 im Anhang).

Tab. 15: Relative Elternmittel-Heterosis (\%) im Resynthese Diallel 2 und allgemeine Kombinationsfähigkeit (GCA) für EM-Heterosis der Elternlinien im Merkmal FMGesamt

A4C34 A6C42 A7C49 A8C46 A9C38 A13C36 A16C37 A19C47 Mittel

\begin{tabular}{cccccccccc}
\hline A4C34 & & & & & & & & & \\
A6C42 & 15,6 & & & & & & & & \\
A7C49 & $-11,5$ & $-12,5$ & & & & & & & \\
A8C46 & 26,4 & 23,3 & 15,0 & & & & & & \\
A9C38 & 26,3 & 23,2 & $-18,9$ & 83,2 & & & & & \\
A13C36 & $-11,2$ & 6,2 & $-11,4$ & 21,0 & 1,6 & & & & \\
A16C37 & 2,1 & 12,1 & $-8,7$ & 21,8 & 6,3 & $-14,7$ & & & \\
A19C47 & 39,1 & 49,0 & 28,4 & 89,0 & 74,3 & 21,6 & 37,8 & & \\
\hline Mittel & $\mathbf{1 2 , 4}$ & $\mathbf{1 6 , 7}$ & $\mathbf{- 2 , 8}$ & $\mathbf{4 0 , 0}$ & $\mathbf{2 8 , 0}$ & $\mathbf{1 , 9}$ & $\mathbf{8 , 1}$ & $\mathbf{4 8 , 5}$ & $\mathbf{1 9 , 1}$ \\
GCA & $-6,7$ & $-2,4$ & $-21,9$ & 20,9 & 8,9 & $-17,2$ & $-10,9$ & 29,4 & \\
\hline
\end{tabular}

Im Resynthese Diallel 2 konnte wie im Resynthese Diallel 1 keine signifikante Korrelation zwischen genetischer Distanz der Eltern und der absoluten Elternmittel-Heterosis nachgewiesen werden (Abb. 17). 


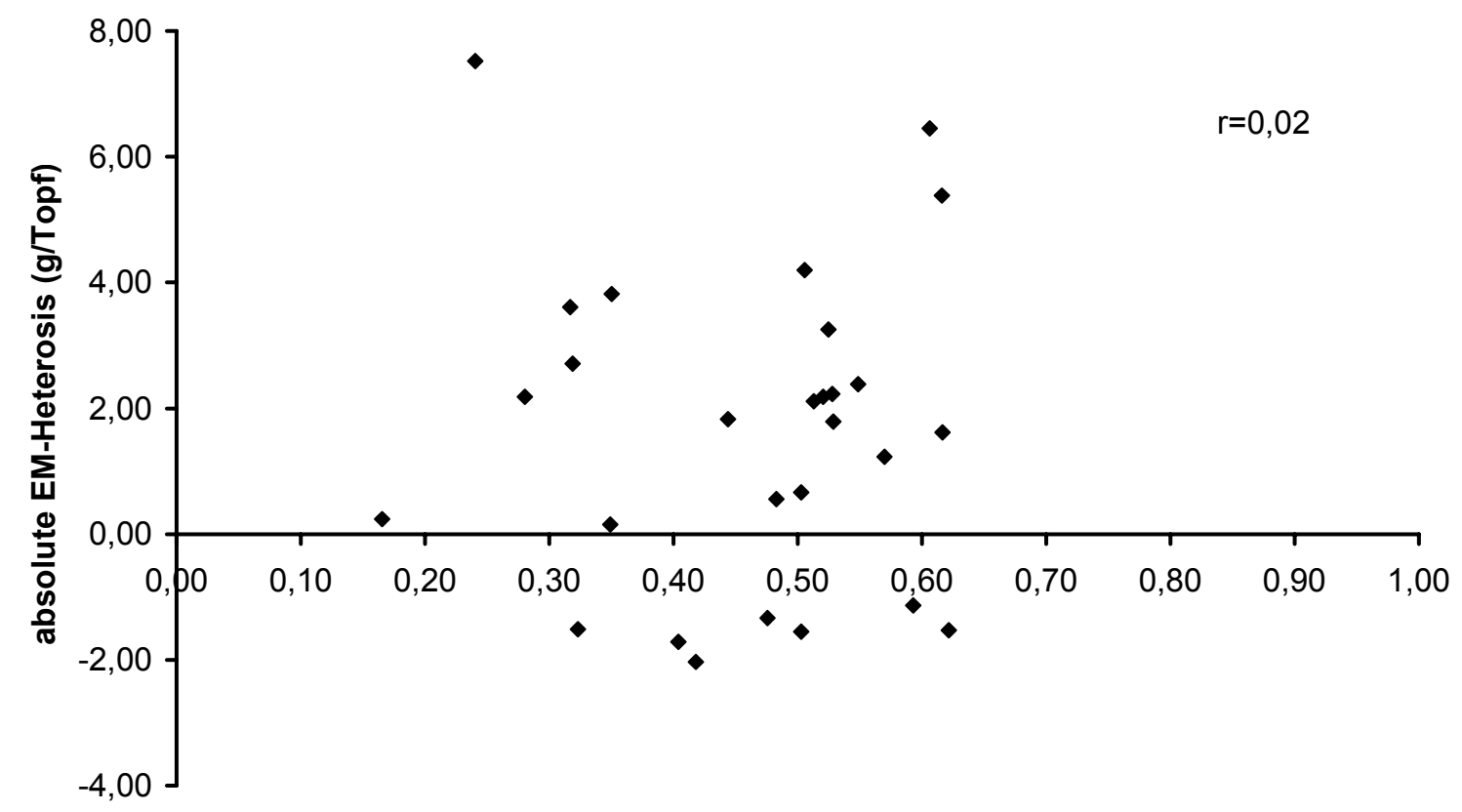

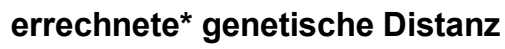

* Die genetischen Distanzen der Resynthesen wurden aus den Daten der diploiden Eltern errechnet

Abb. 17: Beziehung zwischen genetischer Distanz und absoluter ElternmittelHeterosis im Resynthese Diallel 1

\subsubsection{Leistungsprüfung 6: Kältestress}

Ein Vergleich des Ausmaßes der relativen fixierten EM-Heterosis unter Normalbedingungen im Gewächshaus und unter Kältestress ist in Abb. 18 für vier Resynthesen dargestellt. Alle Resynthesen, die unter Gewächshausbedingungen eine positive fixierte Heterosis aufwiesen zeigten unter Kältestress eine noch höhere fixierte Heterosis als im Gewächshaus. Für die Resynthesen A7C34 und A19C46 waren diese Unterschiede signifikant. Die Resynthese A7C46 zeigte hingegen unter Kältestress eine signifikant größere Minderleistung gegenüber ihren diploiden Eltern als dies im Gewächshaus der Fall war. 


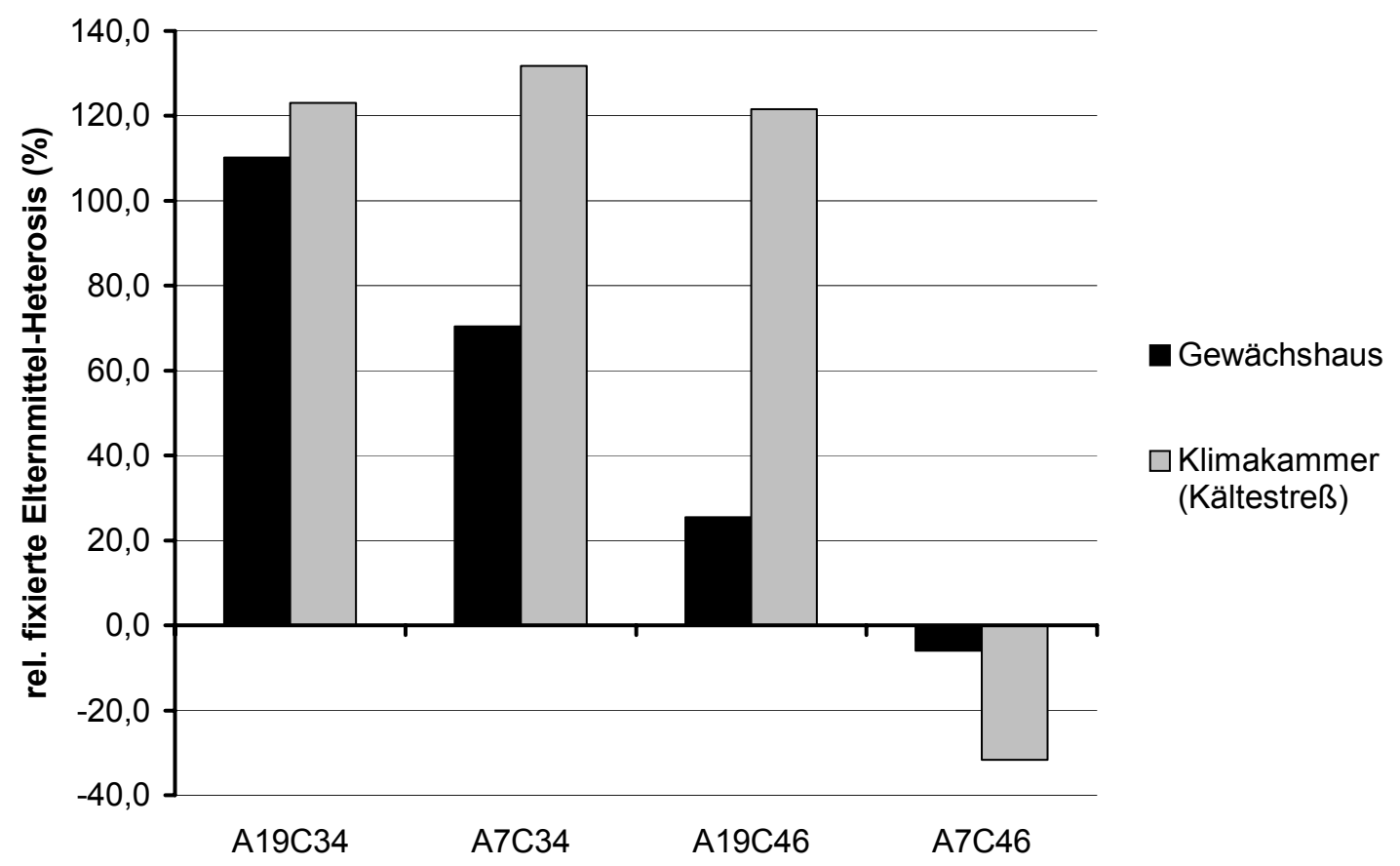

Abb. 18: Vergleich der relativen fixierten Elternmittel-Heterosis unter
Normalbedingungen und unter Kältestress

\subsubsection{Beziehung zwischen klassischer und fixierter Heterosis}

Die Leistungsprüfungen 1, 2, 3 und 5 sind in den jeweiligen Genomen genetisch balanciert. Vergleicht man die Ergebnisse dieser Leistungsprüfungen miteinander (Abb. 19), so zeigen die homozygoten Resynthesen im Mittel aufgrund der fixierten Heterosis (schraffierte Säulen) eine höhere Leistung als ihre homozygoten Elternlinien (schwarze Säulen). Das Ausmaß der klassischen Heterosis (graue Säulen) ist jedoch bei den Resynthesen, deren Leistung zu einem Teil auf fixierter Heterosis beruht, deutlich geringer (19\%) als bei den diploiden Arten (62\% und 90\%). Die Gesamtleistung der heterozygoten Resynthesen liegt dabei niedriger als die der heterozygoten Rübsengenotypen. 


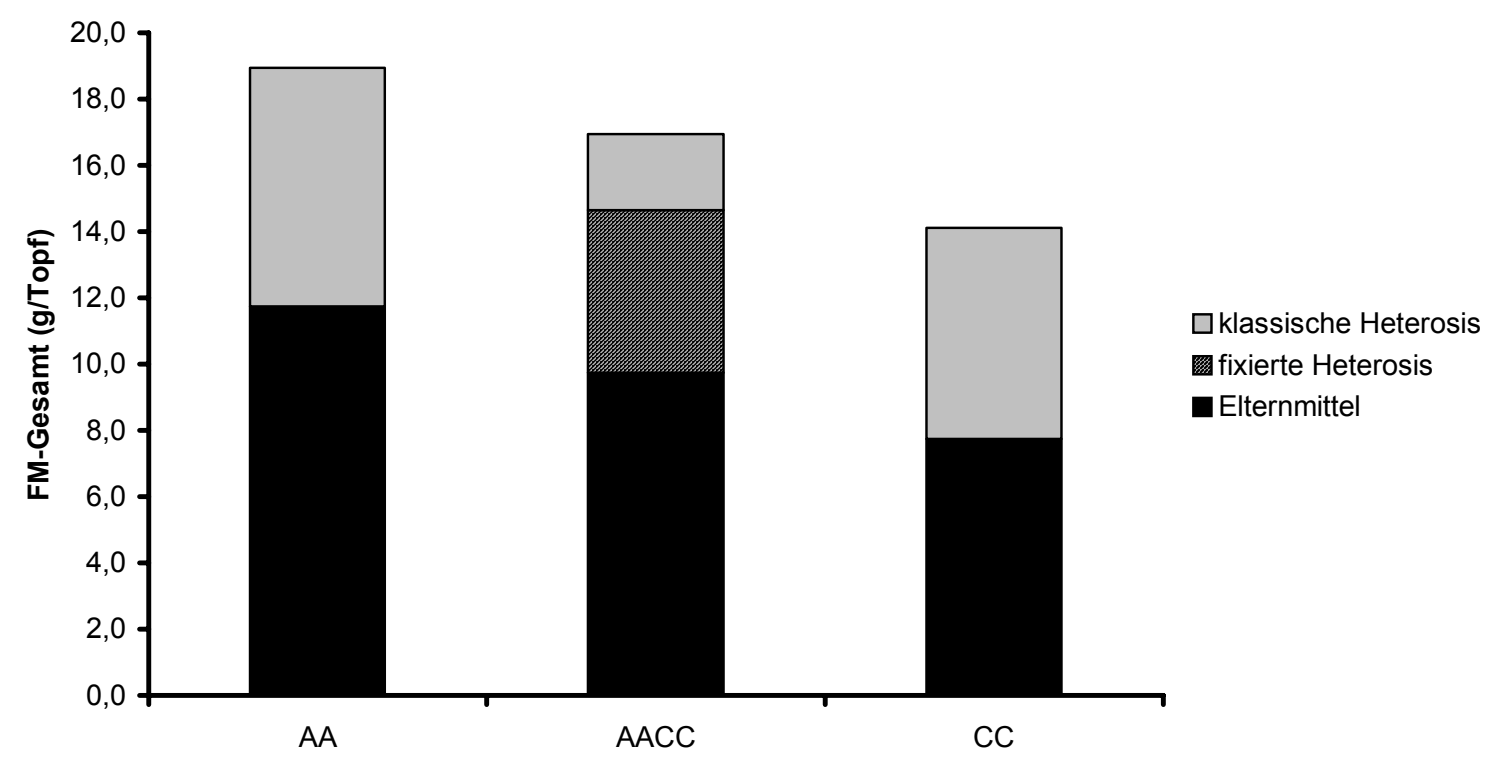

Abb. 19: Aufteilung der Leistung von heterozygoten Resynthesen in Elternmittel der Ursprungsarten, fixierte Heterosis und klassische Heterosis im Vergleich zur Aufteilung der Leistung von heterozygoten Kohl- und Rübsengenotypen in Elternmittel und klassische Heterosis (standardisierte Mittelwerte aus LP 1, 2, 3 und 5)

Ein Zusammenhang zwischen der Höhe von fixierter Heterosis und klassischer Heterosis bei Resynthesen ist auch erkennbar, wenn einzelne Kreuzungen betrachtet werden. Abb. 20 zeigt den Zusammenhang zwischen absoluter klassischer Heterosis von Kreuzungen zwischen Resynthesen und der mittleren fixierten Heterosis, die die beiden Resyntheseeltern der Kreuzungen gegenüber ihren Kohl- und Rübseneltern zeigen. Hier ist ein hoch signifikant negativer Zusammenhang zwischen fixierter und klassischer Heterosis erkennbar. Somit zeigten solche Resynthesen, deren Leistung zu einem großen Anteil auf fixierter Heterosis beruht, wenig klassische Heterosis. 


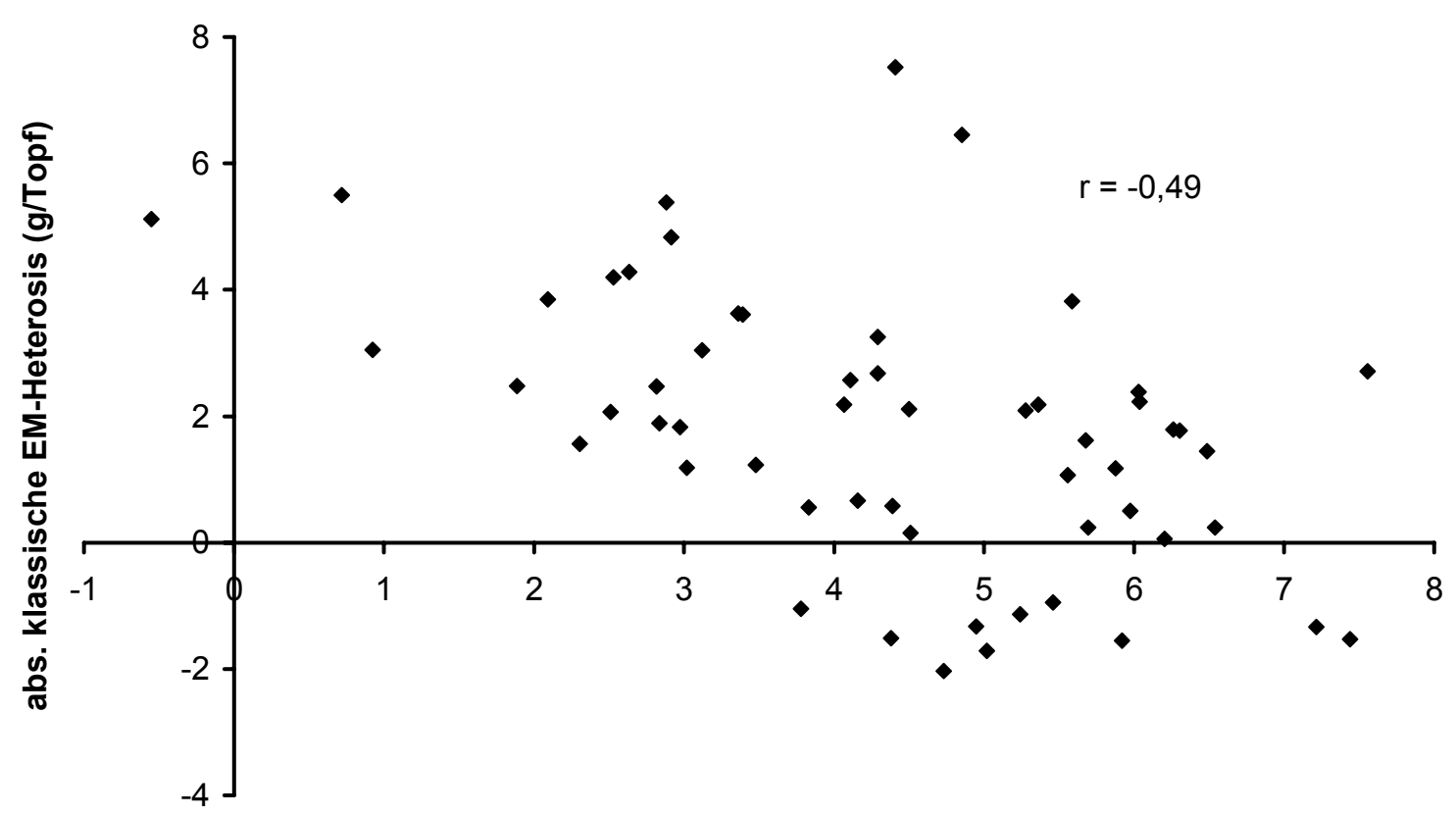

mittlere abs. fixierte EM-Heterosis (g/Topf)

Abb. 20: Beziehung zwischen mittlerer absoluter fixierter Elternmittel-Heterosis der Elternlinien und absoluter klassischer Heterosis der Kreuzungen in den Resynthese Diallelen 1 und 2

Eine Vorhersage über die Höhe der fixierten Heterosis aus der Kombinationsfähigkeit der Eltern in den Kohl und Rübsen Diallelen scheint dagegen nicht möglich zu sein. Abb. 21 zeigt den Zusammenhang zwischen mittlerer absoluter klassischer Elternmittel-Heterosis der Ausgangslinien im Rübsen und im Kohl Diallel und absoluter fixierter Heterosis der jeweiligen Resynthesen. Mit einem Korrelationskoeffizienten von $-0,07$ bestand hier kein Zusammenhang. 


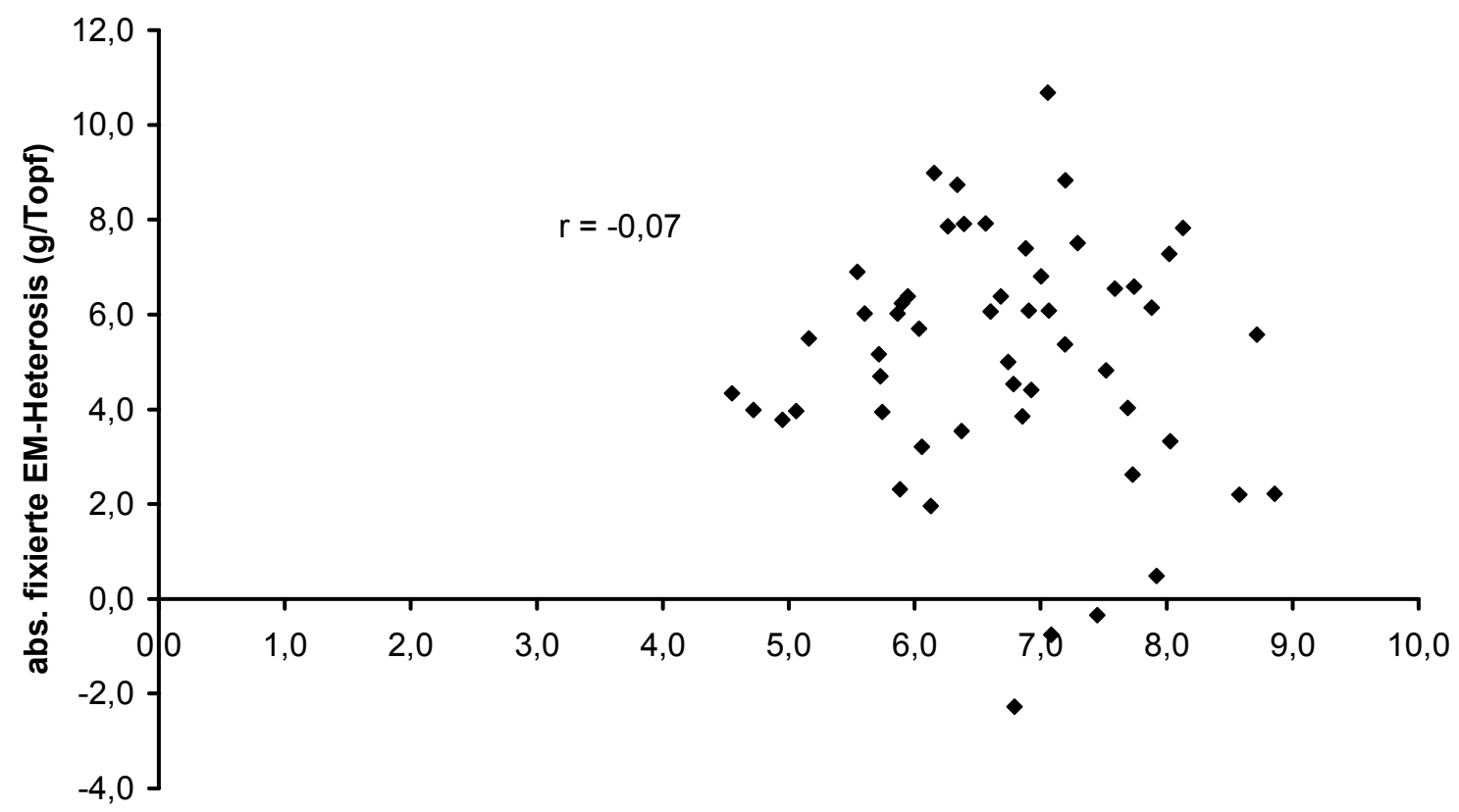

mittlere abs. klassische EM-Heterosis (g/Topf)

Abb. 21: Beziehung zwischen mittlerer absoluter klassischer Elternmittel-Heterosis der Ausgangslinien im Rübsen und im Kohl Diallel und absoluter fixierter Heterosis der jeweiligen Resynthesen 


\section{Diskussion}

\subsection{Modellsystem Brassica napus}

\subsubsection{Ausgangsmaterial}

Wie in Abschnitt 1.3 erläutert war es für die vorliegende Fragestellung unabdingbar, die Resynthese von Raps mit vollständig homozygoten Genotypen durchzuführen. Erst durch dieses Vorgehen sind die Resynthesen und ihre Elterngenotypen in bezug auf die beteiligten Gene beziehungsweise Allele vollständig balanciert und werden damit vergleichbar. Daher wurden anders als in anderen Arbeiten nur Doppelthaploidebeziehungsweise Inzuchtlinien der Elternarten $B$. rapa und $B$. oleracea für diese Untersuchung ausgewählt. Anfänglich wurden so $21 \mathrm{~B}$. rapa und 16 B. oleracea zur Herstellung von Resynthesen ausgewählt, wobei für 197 der 336 möglichen Kreuzungskombinationen Resynthesen hergestellt werden konnten (ABEL et al. 2005). Für die Ertragsversuche war es jedoch notwendig, die Anzahl der Genotypen zu reduzieren. Außerdem war es für die genetische Balancierung der Versuche und für die Analyse der allgemeinen Kombinationsfähigkeit für Heterosis vorteilhaft, ein möglichst vollständiges Set von Resynthesen zu untersuchen. Daher wurden für die weiteren Versuche acht Rübsen- und acht Kohllinien ausgewählt, für die 61 der möglichen 64 Kreuzungskombinationen vorlagen. Die vorliegende Arbeit beschränkt sich daher in der Darstellung auf diese 16 Ausgangslinien.

\subsubsection{Herstellung der Allopolyploiden}

Der Erfolg der Resynthese von Raps aus seinen Ursprungsarten wird durch viele Faktoren beeinflusst. Neben einer Reihe von Umweltfaktoren (Anzuchtbedingungen der Mutterpflanze, Temperatur, Luftfeuchtigkeit und Zeitpunkt der Bestäubung; siehe RÖBBELEN 1960 und HOFFMANN und PETERS 1958) spielt vor allem die Kreuzungsrichtung eine entscheidende Rolle. In einer Mehrzahl der Arbeiten war dabei der Kreuzungserfolg erheblich höher, wenn $B$. rapa als mütterlicher Elter verwendet wurde (Übersicht bei DIEDERICHSEN 1992 und NISHIYAMA et al. 1991). LU et al. (2001) konnten so für Kreuzungen mit B. rapa als Mutter einen Kreuzungserfolg (Embryonen je bestäubter Knospe) von 0,25 erreichen, während der Kreuzungserfolg in der reziproken Kreuzung nur 
bei 0,07 lag. Ein dem entsprechendes Ergebnis erhielt LÜHS 1996 mit Kreuzungserfolgen von 0,77 beziehungsweise 0,03 .

Den größten Einfluss auf den Kreuzungserfolg bei der Resynthese von Raps hat aber sicherlich die Anwendung der ,embryo-rescue“ Technik. Bevor diese Technik Anwendung fand lag der Erfolg interspezifischer Kreuzungen zwischen den diploiden Arten Kohl und Rübsen meist bei weit weniger als einem lebensfähigem Embryo je 100 Bestäubungen (NISHIYAMA et al. 1991). Auch die Kreuzung zwischen autotetraploiden Genotypen dieser Arten führten nur zu einer geringfügig verbesserten Kreuzungseffizienz. So erzielten OLSSON (1960) und AKBAR (1987) bei der Kreuzung tetraploider Rübsen und Kohle nur einen interspezifischen Kreuzungserfolg von 0,011 beziehungsweise 0,004 Samen je Bestäubung. Durch die Nutzung der „embryo-rescue“ Technik konnten die Kreuzungserfolge dagegen deutlich gesteigert werden (INOMATA 1985). Dabei werden entweder isolierte Embryonen, die ganzen Samenanlagen oder komplette Ovarien auf geeigneten Nährmedien kultiviert. Nach einer Literaturübersicht über die Effizienz dieser drei Methoden der Embryokultur von DIEDERICHSEN (1992) erweist sich die Samenanlagenkultur als die erfolgreichste Methode. In einigen Kreuzungskombinationen konnte DIEDERICHSEN so unter Verwendung der Samenanlagenkultur bis $\mathrm{zu} 3,75$ Embryonen je bestäubter Knospe gewinnen.

Das Ziel dieser Arbeit bestand weniger in methodischen Fragestellungen, sondern vor allem darin, ein geeignetes Material für die Untersuchung der fixierten Heterosis herzustellen. Daher wurde eine Vorgehensweise ausgewählt, die in den oben beschriebenen Arbeiten die höchsten Kreuzungserfolge aufwiesen. So wurde B. rapa ausschließlich als Mutter benutzt und nach der Kreuzung eine in vitro Kultur der Samenanlagen durchgeführt. Durch dieses Vorgehen konnte im Durchschnitt eine Kreuzungseffizienz von 0,46 Embryonen je bestäubter Knospe erreicht werden. Dieser Wert liegt zwischen den Werten vergleichbarer Arbeiten mit ähnlicher Vorgehensweise (LU et al. 2001: 0,25; DIEDERICHSEN 1992: 0,73 und LÜHS 1996: 0,77).

Des Weiteren konnten für die verwendeten mütterlichen B. rapa Genotypen genotypische Unterschiede in der interspezifischen Kreuzungseignung nachgewiesen werden. So variierte die Kreuzungseignung der acht Rübsenlinien zwischen 0,13 und 1,22 Embryonen pro bestäubter Knospe. Dies bestätigt die Beobachtungen von OLSSON (1960) und LU et al. (2001), die ebenfalls signifikante Unterschiede in der Kreuzungseignung verschiedener Genotypen nachweisen konnten. Bei heterozygoten Herkünften wurde darüber hinaus eine 
unterschiedliche Eignung einzelner Individuen beobachtet (GLAND 1982), was sich sicherlich dadurch erklären lässt, dass sich die Individuen genotypisch unterschieden. Der maternale Einfluss auf die Kreuzungseignung wird auch durch die Beobachtung von DIEDERICHSEN (1992) bestätigt, nach der sich Klone von Pflanzen mit guter und schlechter Kreuzungseignung wie ihre Ursprungspflanzen verhalten, wobei in dieser Arbeit ein maternaler Einfluss auf den Kreuzungserfolg sowohl für B. rapa Mütter als auch für B. oleracea Mütter nachgewiesen werden konnte.

In einigen Untersuchungen zur Resynthese von Raps wurde außerdem das häufige Auftreten von matromorphen Pflanzen beobachtet (RÖBBELEN 1966, AKBAR 1987). In diesen Arbeiten wurde die ,embryo-rescue“ Technik jedoch nicht angewendet, so dass nur sehr wenige interspezifische Embryonen gefunden wurden und sich somit die Wahrscheinlichkeit des Auftretens matromorpher Pflanzen erhöhte. In neueren Arbeiten mit einer höheren Kreuzungseffizienz (DIEDERICHSEN 1992, LÜHS 1996) konnten dagegen, wie in der vorliegenden Untersuchung, keine matromorphen Pflanzen beobachtet werden, wenn die Samenanlagenkultur und B. rapa als mütterlicher Elter verwendet wurden. Eine phänotypische Unterscheidung der matromorphen Pflanzen wäre leicht möglich gewesen.

\subsubsection{Herstellung der Autopolyploiden}

Seit der Entdeckung der polyploidisierenden Wirkung von Colchizin bei Pflanzen durch NEBEL (1937) wurde diese Verbindung bei einer großen Zahl von Pflanzen angewendet, um polyploide Organismen herzustellen. Die Anwendung erfolgt dabei meistens entweder an gequollenen Samen, durch Applikation auf die Sprossspitzen oder über die Wurzeln junger Pflanzen, wobei die Konzentration des Colchizins, der Behandlungszeitpunkt und die Behandlungsdauer in verschiedenen Versuchen stark variieren und häufig andere Chemikalien zugesetzt werden, um die Wirksamkeit zu erhöhen (GOTTSCHALK 1976). Der Nachteil der Samenbehandlung liegt dabei darin, dass auch die Keimwurzeln mit dem Colchizin in Kontakt kommen und dadurch stark geschädigt werden. Der Nachteil der Sprossspitzenbehandlung liegt hingegen darin, dass meist nur kleine Segmente der Pflanzen tetraploide Zellen aufweisen. Die Applikation über die Wurzeln junger Pflanzen vereint die Nachteile beider Methoden, so dass diese Methode vorwiegend zur Verdoppelung des Chromosomensatzes haploider Pflanzen (zum Beispiel bei der Herstellung von Resynthesen) verwendet wird, bei denen keine Samen für die 
Samenbehandlung zur Verfügung stehen und diploide Segmente durch die Bildung von Pollen leicht von haploiden Segmenten zu unterscheiden sind.

In der vorliegenden Arbeit wurde eine Behandlung von gequollenen Samen durchgeführt, da hier wie beschrieben tendenziell eher große Teile der Pflanze eine einheitliche Ploidiestufe aufweisen und die Behandlung technisch einfacher durchzuführen ist. Diese Vorgehensweise führte jedoch nur bei fünf Rübsenlinien und zwei Kohllinien zu autotetraploiden Nachkommen. Eine gute Alternative hätte sicherlich die von AKBAR (1987) vorgestellte Behandlung von Keimlingen dargestellt. Diese Methode hat den Vorteil, dass das Colchizin auf den Vegetationskegel aufgetropft wird und somit anders als bei der Samenbehandlung die Wurzel nicht geschädigt wird. Beim Vergleich der Effizienz beider Methoden konnte AKBAR (1987) so bei Rübsen mit der Keimlingsbehandlung eine Polyploidisierungsrate von bis $\mathrm{zu} 43 \%$ erzielen, während er für die Samenbehandlung maximal $8,7 \%$ erhielt. Auch in dieser Untersuchung erwies sich die Herstellung tetraploider Linien bei Kohl mit maximalen Polyploidisierungsraten von 25\% und 4\% für beide Methoden schwieriger als beim Rübsen.

Grundsätzlich ist ein Vergleich der Ergebnisse aus verschiedenen Arbeiten jedoch aufgrund der Vielzahl der verwendeten Methoden und des unterschiedlichen Pflanzenmaterials kaum möglich. Hinzu kommt, dass die Effizienz von Colchzinierungsexperimenten diploider Pflanzen in der Literatur selten dokumentiert ist, sondern häufig nur die Eigenschaften von diploiden und den daraus hergestellten polyploiden Pflanzen verglichen werden (zum Beispiel SCHWANITZ 1948).

Auch in der vorliegenden Arbeit konnte der Behandlungserfolg der Colchizinierung nicht dokumentiert werden. Dies liegt zum einen daran, dass vor der Bestimmung der Ploidiestufe eine phänotypische Vorselektion auf tetraploide Pflanzen durchgeführt wurde, um den Untersuchungsaufwand $\mathrm{zu}$ reduzieren. Zum anderen hatten die durch Colchizinbehandlung erhaltenen Pflanzen meist einen chimären Charakter, bestanden also zum Teil aus diploiden und zum Teil aus tetraploiden Zellen. Da auch hier die Herstellung des Materials und keine methodischen Fragen im Vordergrund standen, wurden daraufhin nicht alle Pflanzen weiter kultiviert, sondern nur diejenigen, die nach der Untersuchung mit dem Durchflusszytometer einen hohen Anteil tetraploider Zellen aufwiesen und somit die höchste Wahrscheinlichkeit hatten, auch tetraploide Nachkommen zu erzeugen. Somit wurde nur ein kleiner Teil der Nachkommenschaften der behandelten Pflanzen auf ihre Ploidiestufe hin untersucht. Eine Einschätzung des Behandlungserfolges wäre daher wenig 
aussagekräftig. Das Ziel, für alle 16 Rübsen- und Kohllinien Autotetraploide herzustellen, konnte mit der hier angewendeten Methode nicht erreicht werden. Hierbei muss jedoch berücksichtigt werden, dass die in dieser Arbeit mit Colchizin behandelten Linien vollständig homozygot sind und die erfolgreich hergestellten Autotetraploiden sehr schwachwüchsig waren (siehe Abschnitt 3.4.2) und zum Teil kaum Samenansatz zeigten.

\subsubsection{Merkmalserfassung}

Heterosis tritt bei einer Vielzahl von Merkmalen wie Wuchshöhe, Samenertrag und Biomasseproduktion auf. Heterosis wird dabei vor allem für Merkmale erwartet, an deren Ausprägung eine Vielzahl von Genen beteiligt sind. Für die vorliegende Untersuchung waren jedoch nicht alle dieser Merkmale zur Erfassung der Heterosis geeignet. Insbesondere für den Samenertrag ergab sich das Problem, dass vor allem bei den Autotetraploiden mit Fertilitätsstörungen durch Unregelmäßigkeiten in der Meiose zu rechen war, die den Samenertrag stark beeinflussen. Die Wuchshöhe schied dagegen als Merkmal aus, weil die verwendeten Blumenkohllinien zunächst Köpfe bilden und daher eine Bestimmung der Wuchshöhe nicht sinnvoll ist. Hinzu kommt, dass die vegetativen und generativen Entwicklungszeiten der untersuchten Arten sehr verschieden sind, was eine Vergleichbarkeit späterer Phasen der Pflanzenentwicklung fraglich erscheinen läßt. Als Merkmal wurde daher die vegetative Biomasseproduktion junger Pflanzen ausgewählt. Da einige Rübsenlinien bereits nach etwa vier Wochen in die generative Phase übertraten, musste dabei die letzte Ernte spätestens zu diesem Zeitpunkt erfolgen.

Um einen Einfluss des Erntezeitpunktes auf das Ausmaß der Heterosis zu untersuchen, wurde die Biomasse zu zwei unterschiedlichen Zeitpunkten festgestellt. MEYER et al. (2004) konnten bei Arabidopsis thaliana zwischen dem 15. und dem 25. Tag nach der Aussaat bei niedrigen und mittleren Lichtintensitäten keine signifikanten Unterschiede in der Höhe der Elternmittel-Heterosis feststellen. Bei hohen Lichtintensitäten $\left(240 \mu \mathrm{mol} \mathrm{s} \mathrm{m}^{-1}\right)$ zeigten Hybriden nach 25 Tagen dagegen eine höhere prozentuale Elternmittel-Heterosis als nach 15 Tagen. In der vorliegenden Arbeit zeigte sich dagegen 26 Tage nach der Aussaat eine geringere fixierte Elternmittel-Heterosis als 20 Tage nach der Aussaat. 


\subsection{Genetische Distanzen}

\subsubsection{Bestimmung genetischer Distanzen mit RAPD Markern}

Für die Untersuchung genetischer Distanzen stehen heute verschiedene Typen molekularer Marker zur Verfügung. Hier sind vor allem RFLP (restriction fragment length polymorhism), RAPD (random amplified polymorphic DNA), AFLP (amplified fragment length polymorphism) und SSR (simple sequence repeats) Marker zu nennen. Zunächst wurden vor allem RFLPs zur Bestimmung genetischer Distanzen herangezogen (zum Beispiel BECKER et al. 1995 und KNAAK 1996). Da diese Technik jedoch sehr zeitaufwendig ist und eine umfangreiche Laboraustattung benötigt, werden seit Anfang der 90er Jahre vermehrt PCR basierte Markertypen wie RAPD, AFLP und SSR eingesetzt. Da die RAPD Technik sehr einfach und relativ kostengünstig durchzuführen ist und keine Sequenzinformationen benötigt werden, erlangte dieser Markertyp eine große Bedeutung für Diversitätsstudien (zum Beispiel JAIN et al. 1994 und KRESOVICH et al. 1992) und wurde auch in dieser Untersuchung für die Bestimmung genetischer Distanzen eingesetzt.

RAPD Marker gelten jedoch als wenig reproduzierbar (RAFALSKI und TINGEY 1993). So führten zum Beispiel HALLDÉN et al. (1996) eine RAPD Analyse unter zwei verschiedenen Reaktionsbedingungen durch und berichten, dass 6,25\% aller Banden nur unter einer der beiden Reaktionsbedingungen beobachtet werden konnten. In der gleichen Studie konnte außerdem nachgewiesen werden, dass es bei Mischungen der DNA von zwei Genotypen nicht in allen Fällen zu dem erwarteten RAPD Bandenmuster kommt, da es eine Konkurrenzbeziehung zwischen einzelnen RAPD Banden gibt. Dies erklärt auch die Beobachtung von HEUN und HELENTJARIS (1993), dass $\mathrm{F}_{1}$-Hybriden von Mais in einigen Fällen nicht alle RAPD Banden ihrer Eltern aufweisen. Aufgrund dieser Befunde und aus Gründen der Arbeitsersparnis wurden die Resynthesen in der vorliegenden Arbeit nicht molekulargenetisch untersucht. Stattdessen wurden die genetischen Distanzen der Resynthesen aus den Daten ihrer Elterngenotypen errechnet (Abschnitt 3.4.5 und 3.4.6).

Trotz der problematischen Reproduzierbarkeit einzelner RAPD Marker unter verschiedenen Bedingungen haben sich RAPDs für Diversitätsstudien in vielen Untersuchungen als sehr gut geeignet erwiesen, da die Schätzung genetischer Distanzen auf vielen Markern beruht und sich somit Fehler bei einzelnen Marker kaum auf die geschätzten Distanzen auswirken. So zeigen die Daten von RAPD und RFLP Markern eine sehr gute Übereinstimmung und ein ähnliches Auflösungsvermögen bei der 
Unterscheidung von Genotypen verschiedener Brassica Arten (DOS SANTOS et al. 1994, HALLDÉN et al. 1994 und THORMANN et al. 1994). Nach KRESOVICH et al. (1992) und HALLDÉN et al. (1994) reichen dabei bereits 60-75 polymorphe RAPD Marker aus, um die genetischen Beziehungen zwischen den Genotypen widerzuspiegeln. In der vorliegenden Arbeit wurden bei Kohl 87 und bei Rübsen 159 polymorphe Banden für die Schätzung der genetischen Distanzen herangezogen, so dass diese die Verwandtschaftsbeziehungen des verwendeten Materials recht gut wiedergeben sollten. Hierfür spricht auch die klare Gruppierung der einzelnen Subspezies im gezeigten Dendrogramm (Abb. 1).

\subsubsection{Beziehung zwischen genetischen Distanzen und klassischer Heterosis}

In vielen Arbeiten konnte eine enge Beziehung zwischen genetischer Distanz und klassischer Heterosis beobachtet werden. So fanden beispielsweise DIERS et al. (1996), KNAAK (1996) und RIAZ et al. (2001) eine positive Korrelation von 0,58, 0,72 beziehungsweise 0,64 zwischen genetischer Distanz und dem Samenertrag von $F_{1^{-}}$ Hybriden bei Raps und SMITH et al. (1990) eine Korrelation von 0,87 für Einfachkreuzungen bei Mais. Andere Autoren konnten dagegen keine eindeutige Beziehung zwischen genetischer Distanz und Heterosis feststellen (JAIN et al. 1994, MEYER et al. 2004 und YU et al. 2005). Insbesondere Kreuzungen zwischen Genotypen mit sehr großer genetischer Distanz zeigen dabei häufig nur wenig Heterosis (MOLL et al. 1965), so dass sich in den meisten Fällen nur Korrelationen ergeben, wenn Kreuzungen zwischen nah verwandten Genotypen in die Untersuchungen einbezogen sind (KNAAK 1996).

MELCHINGER (1999) zog daher für den Zusammenhang von genetischen Distanzen und Heterosis den Schluss, dass es a.) eine enge Beziehung für Kreuzungen zwischen relativ nah verwandten Genotypen, b.) ein schwache Beziehung für Kreuzungen zwischen nicht verwandten Genotypen aus dem selben Genpool und c.) keine Beziehung für Kreuzungen zwischen Genotypen aus verschiedenen Genpools gibt. Diese Einschätzung wird auch durch die Beziehung zwischen genetischer Distanz und Heterosis für die in der vorliegenden Arbeit verwendeten Rübsen und Kohl Diallele bestätigt (Abb. 13 und Abb. 14). Auch hier beruht die Korrelation nur auf Kreuzungen zwischen nah verwandten Linien der gleichen Subspezies, während sich für Kreuzungen zwischen den Subspezies keine Korrelation ergab.

Für die Resynthese Diallele ergab sich dagegen auch dann keine Korrelation zwischen genetischer Distanz und Heterosis, wenn nur Kreuzungen mit relativ kleiner genetischer 
Distanz $(<0,3)$ betrachtet wurden (Abb. 15 und Abb. 17). Es ergab sich also auch dann keine Korrelation, wenn Resynthesen gekreuzt wurden, deren entsprechende Kohl- und Rübsenkreuzungen eine enge Korrelation zwischen genetischer Distanz und Heterosis aufwiesen. Andere Untersuchungen zur Beziehung zwischen genetischer Distanz und Heterosis bei Kreuzungen zwischen Resynthesen liegen bisher nicht vor. Für Kreuzungen zwischen Resynthesen und natürlichem Raps liegen dagegen Ergebnisse vor (GIRKE et al. 2000, GIRKE 2002). Diese zeigen, dass auch hier kein signifikanter Zusammenhang zwischen genetischer Distanz und Heterosis besteht.

\subsection{Ploidieeffekt}

Eine höhere Ploidiestufe führt bei Pflanzen in den meisten Fällen zu größeren Zellen, dickeren und breiteren Blättern und größeren Blüten (GOTTSCHALK 1976). Einige morphologische Eigenschaften wie die Pollengröße (SPECKMANN et al. 1967) und die Stomatagröße (SCHWANITZ 1952) werden daher auch zur Selektion autotetraploider Pflanzen eingesetzt. Auch in der vorliegenden Arbeit wurde anhand der Blattform eine Vorselektion auf autotetraploide Pflanzen durchgeführt. Die Beobachtung, dass Polyploide meist vergrößerte Organe aufweisen, führte vor allem zu Beginn der Ploidiezüchtung zu der Vorstellung, dass Polyploide auch einen allgemeinen Gigaswuchs mit einer erhöhten Biomasseproduktion aufweisen. Bereits SCHWANITZ (1948), der sich mit den Auswirkungen der Polyploidie bei zahlreichen Kulturpflanzen beschäftigt hat, schreibt jedoch: „Dieser Glaube an eine höhere Stoffproduktion der Polyploiden dürfte vor allem auf subjektive Eindrücke zurückgehen ...“, da mit der Vergrößerung der Organe meist auch eine Verringerung der Entwicklungsgeschwindigkeit und der Blatt- und Blütenzahl einhergeht.

Die Auswirkung einer höheren Ploidiestufe auf die Gesamtbiomasse sind daher bei verschiedenen Pflanzen sehr unterschiedlich (ausführliche Übersicht bei GOTTSCHALK 1976), wobei auch Untersuchungen, die sich mit den selben Arten beschäftigen, zu sehr unterschiedlichen Ergebnissen kommen. Auch in der Gattung Brassica wurde so neben einer höheren auch eine geringere Biomasseproduktion von tetraploiden gegenüber ihren diploiden Ausgangspflanzen gefunden. So beobachtete SCHWANITZ (1948) einen etwa 80\% höheren Ertrag von tetraploidem Rübsen gegenüber der diploiden Ausgangsform. In der

gleichen Untersuchung stellte er dagegen bei tetraploidem Grünkohl einen Minderertrag von etwa 50\% gegenüber der diploiden Ausgangsform fest. Auch VON SENGBUSCH (1941) 
beobachtete eine schnellere Jugendentwicklung von tetraploiden Stoppelrüben (B. rapa), während GOWERS (1977) bei der selben Art einen um 40\% geringeren Trockenmasseertrag der Tetraploiden gegenüber den diploiden Ausgangssorten ermitteln konnte.

In der vorliegenden Arbeit wurde ein eindeutig negativer Einfluss einer höheren Ploidiestufe auf die Biomasseproduktion festgestellt. Die verschiedenen Subspezies reagierten jedoch auch hier sehr unterschiedlich. So zeigte die Subspezies trilocularis im Durchschnitt eine Ertragsreduktion von 26\% während die Linie A13 der Subspezies pekinensis nur eine sehr geringe Ertragsreduktion beim Übergang von der diploiden auf die tetraploide Stufe zeigte (Abb. 10). Den stärksten Ertragsrückgang zeigten dabei jedoch die beiden Kohllinien C46 und C47 mit einem mittleren Ertragsrückgang von 53\%.

Anders als in anderen Arbeiten wurden dabei die Autotetraploiden aus vollständig homozygoten diploiden Linien hergestellt. Dies ist deshalb wichtig, weil die Leistung von Genotypen der Arten B. rapa und B. oleracea ganz erheblich von ihrem Heterozygotiegrad beeinflusst wird (siehe Abschnitt 3.4.3 und 3.4.4). Der Heterozygotiegrad von diploiden und daraus hergestellten tetraploiden Populationen ist jedoch nicht vergleichbar, wenn eine heterozygote Ausgangspopulation verwendet wird. Dies liegt zum einen daran, dass die colchizinierten Pflanzen zur Selektion von Autopolyploiden in den meisten Fällen mindestens einmal geselbstet werden. Die resultierenden Autopolyploiden weisen somit einen geringeren Heterozygotiegrad und schon aus diesem Grund eine geringere Leistung auf als die diploiden Ausgangspopulationen, die meist als Vergleichsbasis herangezogen werden. In diesem Zusammenhang ist insbesondere die Arbeit von GOWERS (1977) interessant. In dieser Untersuchung wurden bei Rübsen sowohl fünf diploide Sorten wie auch fünf daraus entwickelte tetraploide Genotypen diallel gekreuzt. Auf diploider Stufe lag die durchschnittliche Heterosis für den Trockenmasseertrag dabei nur bei 6,3\%, was auf einen hohen Heterozygotiegrad der diploiden Sorten hindeutet. Auf tetraploider Stufe wurde dagegen eine durchschnittliche Heterosis von $48 \%$ beobachtet, was auch damit erklärt werden könnte, dass die tetraploiden Genotypen einen niedrigeren Heterozygotiegrad aufwiesen. Dafür spricht auch die um 40\% geringere Leistung der Tetraploiden gegenüber den diploiden Ausgangssorten.

Zum anderen ermöglicht die Polyploidie jedoch auch einen höheren Heterozygotiegrad von autotetraploiden gegenüber diploiden Genotypen, wenn verschiedene autotetraploide Genotypen erzeugt und diese miteinander als zufallspaarende Population vermehrt werden. In diesem Fall können Autotetraploide, wie bereits in Abschnitt 1.1 geschildert, vier 
verschiedene Allele in sich vereinigen, während diploide nur maximal zwei verschiedene Allele besitzen können. Bei Autotetraploiden führt dabei eine schrittweise Erhöhung des Heterozygotiegrades bis zur maximalen Heterozygotie $\mathrm{zu}$ einer stetigen Leistungssteigerung. So zeigen sowohl bei tetraploidem Mais (LEVINGS et al. 1967) als auch bei tetraploider Luzerne (GROOSE et al. 1989) Zweifachkreuzungen eine höhere Leistung als Einfachkreuzungen. Bei zufallspaarenden Populationen von tetraploiden Fremdbefruchtern kommt dabei noch hinzu, dass bei gleichen Frequenzen aller Allele und jeweils vier Allelen je Locus nur 1,6\% aller Loci vollständig homozygot vorliegen (BINGHAM 1980), während bei diploiden unter gleichen Bedingungen 25\% aller Loci homozygot besetzt sind.

Dieser Umstand ist wohl auch ein wichtiger Grund dafür, dass es sowohl bei Rübsen als auch bei Markstammkohl autotetraploide Sorten gibt, die diploide Sorten in ihrer Leistung übertreffen (OLSSON und ELLERSTRÖM 1980), obwohl die Ergebnisse der vorliegenden Arbeit nahe legen, dass der Einfluss der Polyploidie auf die Leistungsfähigkeit beider Arten eher negativ ist. Der große Einfluss der Heterozygotie auf die Leistungsfähigkeit dieser Sorten deutet sich dabei schon dadurch an, dass die erfolgreiche tetraploide Rübsensorte Svalöf Sirius nach OLSSON und ELLERSTRÖM (1980) eine synthetische Sorte aus drei verschiedenen tetraploiden Populationen ist und die ebenfalls erfolgreiche tetraploide Futterrübsensorte Perko PVH aus einer Kreuzung zwischen den sehr unterschiedlichen Subspezies pekinensis und oleifera hervorgegangen ist (HERTZSCH und PLARRE 1970).

Ein Einfluss der Ploidiestufe auf den prozentualen Trockensubstanzgehalt konnte in der vorliegenden Arbeit nicht festgestellt werden (Abb. 9). Auch OLSSON und ELLERSTRÖM (1980) konnten keinen signifikanten Unterschied im Trockenmassegehalt zwischen diploidem und tetraploidem Markstammkohl ermitteln. Dies widerlegt die ursprüngliche Einschätzung von SCHLÖSSER (1936), dass Polyploide ,... nur stärker mit Wasser aufgeblähte diploide Ausgangsformen ..." seien.

\subsection{Fixierte Heterosis}

\subsubsection{Ausmaß der fixierten Heterosis}

Die Tatsache, dass Allopolyploide die Genome und damit die Allele beider Elternarten in sich vereinen und dass daraus Vorteile für die Anpassungsfähigkeit und Leistungsfähigkeit von allopolyploiden Arten entstehen können, wurde häufig als wichtiger Grund für den 
Erfolg dieser Arten angeführt (GRANT 1971, MAC KEY 1974). Diese Einschätzung beruht dabei auf der theoretischen Überlegung, dass homöologe Loci in den elterlichen Genomen einer getrennten disomen Vererbung unterliegen und dass somit auch bei steter Selbstbefruchtung noch verschiedene Allele an den homöologen Loci vorliegen können. Diese Überlegung wird dabei auch durch Beobachtungen untermauert, dass Allopolyploide eine höhere allelische Diversität aufweisen als Diploide (zum Beispiel ROOSE und GOTTLIEB 1976 und BROCHMANN et al. 2004). Die allelische Diversität zwischen homöologen Loci wird dabei auch als intergenomische oder fixierte Heterozygotie bezeichnet (SOLTIS und SOLTIS 2000). Während es für intergenomische Heterozygotie auch einige experimentelle Belege gibt, wurde der Effekt dieser intergenomischen oder fixierten Heterozygotie auf die Leistungsfähigkeit allopolyploider Arten (fixierte Heterosis) bisher nicht untersucht. In der vorliegenden Arbeit ist es daher erstmals gelungen, den Effekt der fixierten Heterosis zu quantifizieren.

Anders als zunächst vorgesehen wurde als Bezugsbasis zur Berechnung der fixierten Heterosis dabei nicht die Leistung der Autotetraploiden sondern die Leistung der diploiden Elterngenotypen herangezogen. Dies hatte zum einen den Grund, dass nur ein Teil der autotetraploiden Linien hergestellt werden konnten. Zum anderen konkurrieren neu entstandene allopolyploide Arten in der Evolution in erster Linie mit ihren diploiden Ursprungsarten und nicht mit deren Autotetraploiden, zumal die in dieser Arbeit erfolgreich hergestellten Autotetraploiden auch anders als zunächst angenommen eine geringere Leistung aufwiesen als ihre diploiden Ausgangsgenotypen. Aus diesen Gründen erschien es zumindest aus evolutionsbiologischer Sicht sinnvoller, die diploiden Genotypen als Vergleichsbasis heranzuziehen. Da der negative Ploidieeffekt jedoch nicht berücksichtigt ist, ist der in dieser Untersuchung ermittelte durchschnittliche Effekt der fixierten Heterosis von etwa $50 \%$ eher noch unterschätzt.

\subsubsection{Fixierte Heterosis bei Kältestress}

In vielen Fällen wird beobachtet, dass Inzuchtlinien empfindlicher auf ungünstige Wachstumsbedingungen reagieren als daraus hergestellte Hybriden. Die Ausprägung der Heterosis ist in diesen Fällen unter Stressbedingungen also höher als unter günstigeren Wachstumsbedingungen. So beobachteten beispielsweise BETRÁN et al. (2003) bei Mais eine höhere Heterosis unter Trockenstress und SARAWAT et al. (1994) bei Erbsen eine höhere Heterosis auf Standorten mit einem geringen Ertragsniveau. Im Gegensatz dazu 
berichten MEYER et al. (2004) bei Arabidopsis thaliana von einer geringeren Heterosis bei niedrigen Lichtintensitäten.

In der Leistungsprüfung Kältestress sollte daher die Frage geklärt werden, ob auch die Ausprägung von fixierter Heterosis durch suboptimale Wachstumsbedingungen verstärkt wird. Da jedoch nur vier Resynthesen geprüft wurden und eine dieser Resynthesen eine noch stärker negative Heterosis als unter Gewächshausbedingungen zeigte, konnte diese Fragestellung nicht eindeutig beantwortet werden. Es liegt aber die Vermutung nahe, dass die diploiden Ausgangsarten stärker auf die ungünstigen Wachstumsbedingungen reagieren als die Resynthesen, da alle drei Resynthesen, die unter Gewächshausbedingungen eine positive fixierte Heterosis zeigten, unter Kältestress eine noch höhere fixierte Heterosis aufwiesen als im Gewächshaus.

Dafür spricht auch die Beobachtung bei natürlich vorkommenden Allopolyploiden, dass diese häufig auch andere Habitate mit ungünstigeren Lebensbedingungen besiedeln als ihre Ausgangsarten. So kann beispielsweise das Schlickgras Spartina anglica höhere Salzgehalte tolerieren als seine diploiden Ursprungsarten (GRAY et al. 1991). Auch die größere Verbreitung allopolyploider Arten in arktischen Regionen und in Höhenlagen spricht für eine größere Toleranz von Allopolyploiden gegenüber ungünstigen Umweltbedingungen (LEVIN 1983), wobei einige Autoren diesen Zusammenhang auch damit erklären, dass unter ungünstigen Bedingungen häufiger unreduzierte Gameten gebildet werden und damit die Wahrscheinlichkeit der Entstehung von Polyploiden erhöht ist (OTTO und WHITTON 2000).

\subsubsection{Beziehung zwischen fixierter und klassischer Heterosis}

Eine Vorhersage der fixierten Heterosis auf Basis der klassischen Heterosis in den Elternarten war in dieser Untersuchung nicht möglich, da die Höhe der fixierte Heterosis einzelner Resynthesen nicht mit der allgemeinen Kombinationsfähigkeit für klassische Heterosis der Elterngenotypen korreliert war. Eine Voraussetzung hierfür wäre sicherlich eine geringe Bedeutung der SCA für die Leistung von Kreuzungen innerhalb der beiden Elternarten gewesen. Für das Kohl Diallel war die Varianzkomponente für die SCA jedoch etwa achtmal so groß wie die der GCA. Schon deshalb war keine Korrelation zwischen der GCA für klassische Heterosis und der GCA für fixierte Heterosis zu erwarten. Für die Herstellung von Resynthesen bedeutet dies, dass eine Vorselektion der zu verwendenden Rübsen- und Kohlgenotypen nur für spezielle Merkmale wie Resistenzen und 
Qualitätsmerkmale sinnvoll ist. Für die Vorhersage eines polygenen Merkmals wie der Biomasseproduktion kann dagegen höchstens die Eigenleistung der diploiden Ausgangsgenotypen herangezogen werden. Deren Korrelation zur Leistung der Resynthesen lag in der vorliegenden Arbeit bei 0,63 (Abb. 11).

Dagegen hatte die fixierten Heterosis einen deutlichen Einfluss auf die Höhe der klassischen Heterosis bei den Resynthesen. So lag die klassische Heterosis im Resynthese Diallel 2 im Mittel bei nur bei 19\%, während die klassische Heterosis im Kohl Diallel bei 90\% und im Rübsen Diallel bei 62\% lag, wobei sich die genetische Zusammensetzung der jeweiligen Genomen in den verschiedenen Diallelen entsprach. Die Abhängigkeit der Höhe der klassischen Heterosis von der Höhe der fixierten Heterosis war dabei auch erkennbar, wenn einzelne Kreuzungen zwischen Resynthesen betrachtet werden (Abb. 20). Die geringere klassische Heterosis bei den Resynthesen kann damit erklärt werden, dass negative Allele der diploiden Elterngenotypen in den Resynthesen durch positive Allele aus dem jeweiligen anderen elterlichen Genom ausgeglichen und deren Effekte damit verdeckt werden. Die Resynthesen weisen daher eine höhere Eigenleistung auf als ihre Elternarten (fixierte Heterosis). Da jedoch ein Teil der negativen Allele schon in diesen homozygoten Resynthesen verdeckt werden, zeigen heterozygote Resynthesen nur noch eine geringe Mehrleistung gegenüber ihren homozygoten Eltern.

Auch bei Triticale wurde beobachtet, dass die klassische Heterosis für verschiedene Ertragskomponenten in dieser allopolyploiden Art geringer ist als in den Elternarten. So ermittelten JUNG und LELLEY (1985) für das Tausendkorngewicht bei Triticale nur eine Elternmittel-Heterosis von 7,6\%, während deren Elternarten Hartweizen (Triticum durum) und Roggen (Secale cereale) im gleichen Merkmal durchschnittlich 7,6\% beziehungsweise 185,9\% Heterosis zeigten. Die Autoren sehen dabei ebenfalls Interaktionen zwischen den elterlichen Genomen als Ursache für die in bezug auf das Mittel der Elternarten geringere Heterosis von Triticale. Dabei ist jedoch zu beachten, dass der Hartweizen bereits selbst eine allopolyploide Art ist und damit schon in dieser Elternart fixierte Heterosis auftritt, die zu einer geringen klassischen Heterosis führen kann.

Homozygote Allopolyploide scheinen also schon einen Teil der möglichen heterotischen Wechselwirkungen als fixierte Heterosis $\mathrm{zu}$ nutzen. Diese bereits genutzten Wechselwirkungen stehen dann nicht mehr für die klassische Heterosis zur Verfügung, so dass diese bei Allopolyploiden geringer ausfällt. In der vorliegenden Arbeit zeigten so die Resynthesen auf homozygotem Niveau eine höhere Leistung als ihre Elternarten, während 
diese Mehrleistung auf heterozygotem Niveau nicht mehr feststellbar war (Abb. 19). Der Vorteil allopolyploider Arten in der Evolution könnte somit nicht in erster Linie auf einer generell höheren Leistung beruhen, sondern mit einer höheren Toleranz gegenüber Homozygotie beziehungsweise Inzucht erklärt werden, die wiederum auf intergenomischer Heterozygotie beziehungsweise fixierter Heterosis basiert.

\subsection{Schlussbetrachtung}

Durch die Herstellung von Resynthesen und Autotetraploiden aus den selben homozygoten Kohl- und Rübsenlinien steht ein Material zur Verfügung, dass in bezug auf die beteiligten Gene beziehungsweise Allele vollständig balanciert ist, sich aber im Ploidiegrad (diploid vs. tetraploid) und der Diversität der Genome (autotetraploid vs. allotetraploid) unterscheidet. An diesem Material ist es erstmals möglich, die Auswirkungen von Autopolyploidie und Allopolyploidie an genetisch klar definierten Genotypen zu untersuchen. In der vorliegenden Arbeit wurden dabei zunächst die globalen Effekte von Polyploidie, fixierter Heterosis und deren Wechselwirkung zur klassischen Heterosis untersucht. Hier konnte gezeigt werden, dass fixierte Heterosis entscheidend zur Leistungsfähigkeit allopolyploider Arten beiträgt und dass die fixierte Heterosis einen deutlichen Einfluss auf die Ausprägung der klassischen Heterosis bei allopolyploiden Arten hat.

In einem nächsten Schritt sollten, wie von ABEL et al. (2005) vorgeschlagen, durch ein „fixed-heterosis-QTL-mapping“ Genomabschnitte identifiziert werden, die zur Ausprägung der fixierte Heterosis beitragen. Von besonderem Interesse wird es hierbei sein, ob nur wenige oder wie bei der klassischen Heterosis viele Gene an der Ausprägung von fixierter Heterosis beteiligt sind. Ein erweitertes Verständnis der Mechanismen, die zu fixierter Heterosis führen, wird dabei voraussichtlich auch zum Verständnis der klassischen Heterosis beitragen können.

Auch für die Untersuchung der Genexpression stellt das hier entwickelte Pflanzenmaterial eine wertvolle Grundlage dar, weil hier sowohl das Zusammenwirken von verschiedenen Allelen an einem Locus als auch deren Interaktionen mit Allelen am homöologen Locus untersucht werden können. Dabei wird diesem Modellsystem insbesondere die phylogenetische Nähe zum Modellorganismus Arabidopsis thaliana zugute kommen, da hier zahlreiche Werkzeuge der Transkriptomanalyse zur Verfügung stehen (HILSON et al. 2004). 
Für die Evolutionsforschung unterstreichen die hier dargestellten Ergebnisse die Bedeutung fixierter Heterosis für die Erhaltung genetischer Variation. Durch diesen Mechanismus konnten allopolyploide Arten wahrscheinlich in Phasen extremer Inzucht und beim Durchlaufen genetischer „Flaschenhälse“ eine hohe Leistungsfähigkeit erhalten und sich im Wettbewerb mit ihren diploiden Ursprungsarten behaupten. 


\section{$5 \quad$ Zusammenfassung}

In der Evolution der Pflanzen spielte die spontane Hybridisierung verwandter Arten mit anschließender Entstehung von Allopolyploiden eine große Rolle. Auch unter den Kulturpflanzen sind allopolyploide Arten wie Brotweizen, Hafer, Baumwolle, Tabak und Raps weit verbreitet. Die hohe Leistungsfähigkeit allopolyploider Arten kann unter anderem mit günstigen Wechselwirkungen zwischen homöologen Genen der elterlichen Genome erklärt werden. Da diese Wechselwirkungen auch in homozygoten Allopolyploiden auftreten, können sie als fixierte Heterosis bezeichnet werden. Genaue experimentelle Daten zur fixierten Heterosis liegen bisher nicht vor, da die Leistungfähigkeit allopolyploider Arten neben fixierter Heterosis auch durch einen Ploidieeffekt beeinflusst werden kann und beide Effekte schwierig zu trennen sind. Hauptziele dieser Arbeit waren es daher, durch die Resynthese von Raps (Brassica napus; Genom AACC) aus seinen Ausgangsarten Rübsen (Brassica rapa; AA) und Kohl (Brassica oleracea; CC) ein geeignetes Material zur Untersuchung von fixierter Heterosis und Polyploidie herzustellen, beide Effekte zu quantifizieren und die Beziehung zwischen fixierter und klassischer Heterosis zu untersuchen.

Für die Herstellung von resynthetisiertem Raps aus seinen Elternarten wurden jeweils acht vollständig homozygote Rübsen- und Kohllinien der Subspezies oleifera, pekinensis und trilocularis beziehungsweise alboglabra und botrytis verwendet. Insgesamt konnten 61 der 64 möglichen Resynthesen hergestellt werden. Der Erfolg der interspezifischen Hybridisierung hing dabei hoch signifikant von der verwendeten Mutterlinie (B. rapa) ab und lag im Mittel bei 0,46 Embryonen je bestäubter Knospe.

Aus den selben homozygoten Rübsen- und Kohllinien wurden neben den Allopolyploiden auch Autotetraploide hergestellt, um den Effekt einer höheren Ploidiestufe der Allopolyploiden gegenüber ihren diploiden Elternarten zu bewerten. Hier konnten fünf tetraploide Rübsen- und zwei tetraploide Kohllinien hergestellt werden.

Außerdem wurden alle Kohlgenotypen, alle Rübsengenotypen, sowie acht resynthetisierte Rapsgenotypen intraspezifisch diallel untereinander gekreuzt, um das Ausmaß der klassischen Heterosis in den verschiedenen Arten zu messen. Somit stand ein Material zur Verfügung, dass in bezug auf die beteiligten Gene beziehungsweise Allele vollständig balanciert ist, sich aber in Heterozygotiegrad (homozygot vs. heterozygot), Ploidiegrad (diploid vs. tetraploid) und Diversität der Genome (autotetraploid vs. allotetraploid) unterscheidet. Alle Genotypen wurden im Gewächshaus in Gitteranlagen mit mindestens 
neun Wiederholungen und 18 Pflanzen je Wiederholung ausgesät, um die oberirdische vegetative Biomasse nach 20 und 26 Tagen zu bestimmen. Die diploiden Ausgangslinien wurden außerdem molekulargenetisch mit RAPD Markern untersucht, um genetische Distanzen zu schätzen. Hier wurden bei Kohl 87 und bei Rübsen 159 polymorphe Banden für die Schätzung der genetischen Distanzen herangezogen

Die Höhe der Heterosis für Biomasse war bei Kohl und bei Rübsen für Kreuzungen innerhalb einer Subspezies mit der genetischen Distanz der Elterngenotypen hoch korreliert. Bei Kreuzungen von Genotypen verschiedener Subspezies sowie bei Kreuzungen zwischen Resynthesen gab es dagegen keinen Zusammenhang zwischen genetischer Distanz und Heterosis.

Der allopolyploide Raps zeigte eine erhebliche Mehrleistung gegenüber seinen diploiden Elterngenotypen. Die fixierte Heterosis betrug im Durchschnitt $50 \%$ bezogen auf das Elternmittel beziehungsweise $8 \%$ bezogen auf den besseren Elter. Die Autotetraploiden zeigten dagegen eine Minderleistung zwischen 1\% und 64\% im Vergleich zu den diploiden Linien. Die klassische Elternmittel Heterosis betrug im Durchschnitt bei Rübsen 62\% (33\% gegenüber dem besseren Elter), bei Kohl 90\% (75\%) und bei resynthetisiertem Raps $20 \%(4 \%)$.

Die Ergebnisse zeigen, dass die erhebliche Mehrleistung von resynthetisiertem Raps gegenüber seinen Ausgangsarten auf fixierter Heterosis beruht und nicht mit einer höheren Ploidiestufe erklärt werden kann. Eine Vorhersage der fixierten Heterosis auf Basis der klassischen Heterosis in den Elternarten scheint nicht möglich zu sein, da die fixierte Heterosis nicht mit der allgemeinen Kombinationsfähigkeit für klassische Heterosis in den Elternarten korreliert war. Bei der Betrachtung der klassischen Heterosis beim allopolyploiden Raps und seinen Elterngenotypen zeigt sich jedoch, dass resynthetisierter Raps, der schon einen Teil der heterotischen Wechselwirkungen als fixierte Heterosis genutzt hat, weniger klassische Heterosis zeigt, als seine diploiden Ausgangsarten. Dies führte dazu, dass die Resynthesen ihren Elterngenotypen zwar auf homozygotem Niveau überlegen waren, auf heterozygotem Niveau jedoch keine Mehrleistung gegenüber dem Elternmittel entsprechender Kreuzungen auf diploider Stufe zeigten. Der Vorteil allopolyploider Arten in der Evolution könnte somit nicht in erster Linie auf einer höheren Leistung beruhen, sondern mit einer höheren Toleranz gegenüber Homozygotie beziehungsweise Inzucht erklärt werden, die wiederum auf intergenomischer Heterozygotie beziehungsweise fixierter Heterosis basiert. Fixierte Heterosis stellt somit einen entscheidenden Faktor für die Etablierung allopolyploider Arten dar. 


\section{Summary}

\section{Resynthesized rapeseed (Brassica napus) as a model to analyse fixed heterosis in allopolyploid plants}

The spontaneous hybridisation of related species by combining their genomes (allopolyploidy) has played a prominent role in plant evolution. Many wild species as well as major field crops like wheat, oats, cotton, tobacco and rapeseed are allopolyploids. One explanation for the success of allopolyploids are favourable interactions between homoeologous genes of the parental genomes. These favourable interactions may also occur in homozygous allopolyploids and can therefore be called fixed heterosis. However, experimental data on fixed heterosis is not available, since the high performance of allopolyploids can also be attributed to an effect of polyploidy which is difficult to separate from the effect of fixed heterosis. Therefore this study was carried out (1) to develop a suitable plant material for the analysis of fixed heterosis and polyploidy by the resynthesis of Brassica napus (genome AACC) from its parental species Brassica rapa (AA) and Brassica oleracea (CC), (2) to quantify both effects and (3) to study the interrelation between fixed and classical heterosis.

Eight homozygous lines of $B$. rapa (subspecies oleifera, pekinensis and trilocularis) as well as eight homozygous lines of B. oleracea (subspecies alboglabra and botrytis) were used to produce resynthesized B. napus. In total 61 of the 64 possible resynthesized lines have been produced. The success of interspecific hybridisation was significantly dependent on the maternal genotype (B. rapa) used for hybridization and averaged 0.46 vital embryos per pollinated bud.

The same B. rapa and B. oleracea genotypes were used to produce autopolyploids in order to estimate the effect of higher ploidy level. Here five autotetraploid $B$. rapa and two autotetraploid B. oleracea lines have been obtained.

Additionally intraspecific crosses between all $B$. rapa and B. oleracea genotypes as well as between eight resynthesized rapeseed genotypes were performed in a diallel manner in order to study the effect of classical heterosis within the three species. Hence a material was available which is completely balanced in the allelic contributions but differs in the amount of heterozygosity (homozygous vs. heterozygous), ploidy (diploid vs. tetraploid) and genomic diversity (autotetraploid vs. allotetraploid). All genotypes were grown in the 
greenhouse in order to measure the vegetative biomass production 20 and 26 days after sowing. At least nine replications with 18 plants per replication were sown. Morover the parental diploid lines were analysed with RAPD markers to estimate genetic distances. Here, 159 and 87 polymorphic bands were used to calculate genetic distances between the B. rapa and B. oleracea genotypes, respectively.

The magnitude of classical heterosis for vegetative biomass production was only correlated with the genetic distance when merely crosses within the same subspecies of $B$. rapa and $B$. oleracea were regarded. In contrast there was no correlation when crosses between different subspecies or crosses between resynthesised lines were regarded.

The allopolyploid B. napus genotypes showed considerable higher yields compared to their parental species. The magnitude of fixed heterosis averaged $50 \%$ relative to the parental mean and $8 \%$ relative to the better parent. In contrast the autotetraploid lines yielded from $1 \%$ to $64 \%$ less than the corresponding diploid lines. The mean midparent classical heterosis was $62 \%$ (33\% relative to the better parent) in B. rapa, $90 \%(75 \%)$ in $\mathrm{B}$. oleracea and $20 \%(4 \%)$ in B. napus.

The results show that the higher performance of resynthesised rapeseed compared to its diploid parental species is based on fixed heterosis and can not be explained by an effect of the higher ploidy level. A prediction of the magnitude of fixed heterosis in the allopolyploid based on the magnitude of classical heterosis in the diploid parents seems to be not possible since fixed heterosis of allopolyploids was not correlated to the general combining ability for classical heterosis in the parental species. On the other hand it is shown that the allopolyploid B. napus, which already benefits from heterotic interactions via fixed heterosis, shows less classical heterosis than its diploid progenitors. Therefore in the present sudy the resynthesized B. napus was only superior to its parental species when homozygous genotypes were compared but not when heterozygous genotypes were compared. Consequently the main advantage of allopolyploidy in evolution might rather be a higher tolerance to inbreeding and the resulting homozygosity than a higher performance in general. This higher tolerance against inbreeding is thereby based on intergenomic heterozygosity and the resulting fixed heterosis. Thus fixed heterosis is a decisive factor for the establishment of allopolyploid species. 


\section{$7 \quad$ Literaturverzeichnis}

Abel S, Möllers C und Becker H C 2005: Development of synthetic Brassica napus lines for the analysis of "fixed heterosis" in allopolyploid plants. Euphytica. 146: 157163.

Ahmadi M R 1988: Charakterisierung der genetischen Variabilität von amphidiploiden resynthetischen Rapsformen und deren Ausgangseltern. Dissertation GeorgAugust-Universität Göttingen, Göttingen

Akbar M A 1987: Resynthesis of Brassica napus for earliness and daylength insensitivity. Dissertation Swedish University of Agricultural Sciences, Uppsala

Akbar M A 1989: Resynthesis of Brassica napus aiming for improved earliness and carried out by different approaches. Hereditas. 111: 239-246.

Allard R W, Garcia P, Sáenz-de-Miera L E und Pérez de la Vega M 1993: Evolution of multilocus genetic structure in Avena hirtula and Avena barbata. Genetics. 135: 1125-1139.

Arabidopsis Genome Initiative 2000: Analysis of the genome sequence of the flowering plant Arabidopsis thaliana. Nature. 408: 796-815.

Attia T und Röbbelen G 1986: Cytogenetic relationship within cultivated Brassica analyzed in amphihaploids from the three diploid ancestors. Canadian Journal of Genetics and Cytology. 28: 323-329.

Becker H C, Engqvist G M und Karlsson B 1995: Comparison of rapeseed cultivars and resynthesized lines based on allozyme and RFLP markers. Theoretical and Applied Genetics. 91: 62-67.

Betrán F J, Beck D, Bänziger M und Edmeades G O 2003: Genetic analysis of inbred and hybrid grain yield under stress and nonstress environments in tropical maize. Crop Science. 43: 807-817.

Bingham E T 1980: Maximizing heterozygosity in autopolyploids. In: Lewis W H ed.: Polyploidy: Biological Relevance. Plenum Press, New York 471-489.

Brochmann C, Brysting A K, Alsos I G, Borgen L, Grundt H H, Scheen A-C und Elven R 2004: Polyploidy in arctic plants. Biological Journal of the Linnean Society. 82: 521-536.

Butterfass T 1987: Cell volume ratios of natural and of induced tetraploid and diploid flowering plants. Cytologia. 52: 309-316.

Chen B Y, Heneen W K und Jönsson R 1988: Resynthesis of Brassica napus L. through Interspecific Hybridization between B. alboglabra Bailey and B. campestris L. with Special Emphasis on Seed Colour. Plant Breeding. 101: 52-59.

de Wet J M J 1980: Origins of polyploids. In: Lewis W H ed.: Polyploidy: Biological Relevance. Plenum Press, New York 3-16. 
Diederichsen E 1992: Kombination verschiedener Resistenzen gegenüber Plasmodiophora brassicae Wor. in resynthetisierten Formen von amphidiploiden Brassica-Arten. Dissertation Freie Universität Berlin, Berlin

Diederichsen E und Sacristan M D 1994: The use of ovule culture in reciprocal hybridization between B. campestris L. and B. oleracea L.. Plant Breeding. 113: 79-82.

Diers B W, McVetty P B E und Osborn T C 1996: Relationship between heterosis and genetic distance based on restriction fragment length polymorphism markers in oilseed rape (Brassica napus L.). Crop Science. 36: 79-83.

dos Santos J B, Nienhuis J, Skroch P, Tivang J und Slocum M K 1994: Comparison of RAPD and RFLP genetic markers in determining genetic similarity among Brassica oleracea L. genotypes. Theoretical and Applied Genetics. 87: 909-915.

Ellstrand N C und Schierenbeck K A 2000: Hybridization as a stimulus for the evolution of invasiveness in plants? Proceedings of the National Acadamy of Sciences. 97: 7043-7050.

Galitski T, Saldanha A J, Styles C A, Lander E S und Fink G R 1999: Ploidy regulation of gene expression. Science. 285: 251-254.

Girke A 2002: Neue Genpools aus resynthetisiertem Raps (Brassica napus L.) für die Hybridzüchtung. Dissertation Georg-August-Universität Göttingen, http://webdoc.sub.gwdg.de/diss/2002/girke/girke.pdf

Girke A, Engqvist G und Becker H C 2000: Predicting heterosis from genetic distances for RFLP markers in resynthesized oilseed rape. In: Quantitative genetics and breeding methods: the way ahead: Proceedings of the 11th Meeting of the Section Biometrics in Plant Breeding. Paris, 30. Aug. - 1. Sept. 2000 257-262.

Gland A 1982: Gehalt und Muster der Glucosinolate in Samen von resynthetisierten Rapsformen. Zeitschrift für Pflanzenzüchtung. 88: 242-254.

Goff S A, Ricke D, Lan T H, Presting G, Wang R, Dunn M, Glazebrook J, Sessions A, Oeller P, Varma $\mathrm{H}$ et al. 2002: A draft sequence of the rice genome (Oryza sativa L. ssp. japonica). Science. 296: 92-100.

Gómez-Campo C und Prakash S 1999: Origin and domestication. In: Gómez-Campo C ed.: Biology of Brassica Coenospecies. Elsevier, Amsterdam 413-460.

Gottschalk W 1976: Die Bedeutung der Polyploidie für die Evolution der Pflanzen. Gustav Fischer Verlag, Stuttgart

Gowers S 1977: A comparison of diploid and tetraploid turnips (Brassica campestris ssp. rapifera). Euphytica. 26: 203-206.

Grant V 1971: Plant Speciation. Columbia University Press, New York

Gray A J, Marshall D F und Raybould A F 1991: A century of evolution in Spartina anglica. Advances in Ecological Research. 21: 1-61. 
Groose R W, Talbert L E, Kojis W P und Bingham E T 1989: Progressive heterosis in autotetraploid alfalfa: studies using two types of inbreds. Crop Science. 29: 11731177.

Gu Z, Steinmetz L M, Gu X, Scharfe C, Davis R W und Li W-H 2003: Role of duplicate genes in genetic robustness against null mutations. Nature. 421: 63-66.

Halldén C, Hansen M, Nilsson N-O, Hjerdin A und Säll T 1996: Competition as a source of errors in RAPD analyses. Theoretical and Applied Genetics. 93: 1185-1192.

Halldén C, Nilsson N-O, Rading I M und Säll T 1994: Evaluation of RFLP and RAPD markers in a comparison of Brassica napus breeding lines. Theoretical and Applied Genetics. 88: 123-128.

Helentjaris T, Weber D und Wright S 1988: Identification of the genomic locations of duplicate nucleotide sequences in maize by analysis of restriction fragment length polymorphisms. Genetics. 118: 353-363.

Hertzsch W und Plarre W 1970: Brassicaceen als Futterpflanzen (Brassica sp.) Blattkohl, Markstammkohl, Kohlrübe, Stoppelrübe, Raps, Rübsen. In: Hoffmann W, Mudra A und Plarre W eds.: Lehrbuch der Züchtung landwirtschaftlicher Kulturpflanzen. Band 2: Spezieller Teil. Verlag Paul Parey, Berlin 304-312.

Heun M und Helentjaris T 1993: Inheritance of RAPDs in $\mathrm{F}_{1}$ hybrids of corn. Theoretical and Applied Genetics. 85: 961-968.

Hilson P, Allemeersch J, Altmann T, Aubourg S, Avon A, Beynon J, Bhalerao R P, Bitton F, Caboche M, Cannoot B et al. 2004: Versatile gene-specific sequence tags for Arabidopsis functional genomics: transcript profiling and reverse genetics applications. Genome. 14: 2176-2189.

Hoffmann W und Peters R 1958: Versuche zur Herstellung synthetischer und semisynthetischer Rapsformen. Der Züchter. 28: 40-51.

Holland P W H, Garcia-Fernàndez J, Williams N A und Sidow A 1994: Gene duplications and the origins of vertebrate development. Development. 120 (Supplements): 125133.

Hosaka K, Kianian S F, McGrath J M, und Quiros C F 1989: Development and chromosomal localization of genome-specific DNA markers of Brassica and the evolution of amphidiploids and $n=9$ diploid species. Genome. 33: 131-142.

Inomata N 1985: A revised medium for in vitro culture of Brassica ovaries. In: Chapman G P, Mantell S H und Daniels R W eds.: The Experimental Manipulation of Ovule Tissues. Longman, London 164-176.

Jain A, Bhatia S, Banga S S, Prakash S und Lakshmikumaran M 1994: Potential use of random amplified polymorphic DNA (RAPD) technique to study the genetic diversity in Indian mustard (Brassica juncea) and its relation to heterosis. Theoretical and Applied Genetics. 88: 116-122. 
Jung C und Lelley T 1985: Genetic interactions between wheat and rye genomes in triticale: 2. Morphological and yield characters. Theoretical and Applied Genetics. 70: 427-432.

Kellog E A 2003: What happens to genes in duplicated genomes?. Proceedings of the National Acadamy of Sciences. 100: 4369-4371.

Knaak C 1996: Schätzung genetischer Distanzen mittels RFLP zur Identifikation von Genpools für die Hybridzüchtung bei Winterraps. Dissertation Georg-AugustUniversität Göttingen, Göttingen

Körber-Grohne U 1994: Nutzpflanzen in Deutschland. Kulturgeschichte und Biologie. 3. Auflage Theiss, Stuttgart

Kresovich S, Williams J G K, McFerson J R, Routman E J und Schaal B A 1992: Characterization of genetic identities and relationships of Brassica oleracea L. via a random amplified polymorphic DNA assay. Theoretical and Applied Genetics. 85: 190-196.

Lagercrantz U und Lydiate D J 1996: Comparative genome mapping in Brassica. Genetics. 144: 1903-1910.

Leitch I J und Bennett M D 2004: Polyploidy in angiosperms. Trends in Plant Science. 2: 470-476.

Levin D A 1983: Polyploidy and novelty in flowering plants. The American Naturalist. 122: $1-25$.

Levings C S, Dudley J W und Alexander D E 1967: Inbreeding and crossing in autotetraploid maize. Crop Science. 7: 72-73.

Lewis W H 1980: Polyploidy in angiosperms: dicotyledons. In: Lewis W H ed.: Polyploidy: Biological Relevance. Plenum Press, New York 241-268.

Lu C M, Zhang B, Kakihara F und Kato M 2001: Introgression of genes into cultivated Brassica napus through resynthesis of B. napus via ovule culture and the accompanying change in fatty acid composition. Plant Breeding. 120: 405-410.

Lu C M, Zhang B; Liu L und Kato M 2004: Genetic analysis of petal size through genomic manipulation in Brassica. Plant Breeding. 123: 495-496.

Lühs W 1996: Genetisch-analytische Untersuchungen zur Züchtung von Raps (Brassica napus L.) mit maximalem Erucasäure-Gehalt im Samenöl als industrieller Rohstoff. Dissertation Justus-Liebig-Universität Gießen, Gießen

Mac Key J 1976: Genetic and evolutionary principles of heterosis. In: Heterosis in plant breeding: Proceedings of the 7th Congress of EUCARPIA. Budapest, 24.-29. Juni 1974 17-33.

Masterson J 1994: Stomatal size in fossil plants: evidence for polyploidy in majority of angiosperms. Science. 264: 421-423. 
Melchinger A E 1999: Genetic diversity and heterosis. In: Coors C G and Pandey S eds.: The Genetics and Exploitation of Heterosis in Crops. American Society of Agronomy, Madison 99-118.

Meyer R C, Törjék O, Becher M und Altmann T 2004: Heterosis of biomass production in Arabidopsis: establishment during early development. Plant Physiology. 134: 18131823.

Moll R H, Lonnquist J H, Vélez Fortuno J und Johnson E C 1965: The relationship of heterosis and genetic divergence in maize. Genetics. 52: 139-144.

Morinaga T 1934: Interspecific hybridisation in Brassica. VI. The cytololgy of F1 hybrids of B. juncea and B. nigra. Cytologia. 6: 62-67.

Müntzing A 1936: The evolutionary significance of autopolyploidy. Hereditas. 21: 263378.

Murashige T und Skoog F 1962: A revised medium for rapid growth and bioassays with tobacco tissue cultures. Physiologia Plantarum. 15: 473-497.

Nebel B R 1937: Mechanism of polyploidy through colchicine. Nature. 140: 1101.

Nishi S 1980: Differentiation of Brassica crops in asia and breeding of "Hakuran", a newly synthesized leafy vegetable. In: Tsunoda S, Hinata K und Gómez-Campo C eds.: Brassica Crops and Wild Allies - Biology and Breeding. Japan Scientific Society Press, Tokio 133-150.

Nishiyama I, Sarashima M und Matsuzawa Y 1991: Critical discussion on abortive interspecific crosses in Brassica. Plant Breeding. 107: 288-302.

Olsson G 1960: Species crosses within the genus Brassica. II. Artificial Brassica napus L.. Hereditas. 46: 351-386.

Olsson G und Ellerström S 1980: Polyploidy breeding in europe. In: Tsunoda S, Hinata K und Gómez-Campo C eds.: Brassica Crops and Wild Allies - Biology and Breeding. Japan Scientific Society Press, Tokio 167-190.

Otto S P und Whitton J 2000: Polyploid incidence and evolution. Annual Reviews in Genetics. 34: 401-437.

Parkin I A P, Sharpe A G, Keith D J und Lydiate D J 1995: Identification of the A and C genomes of amphidiploid Brassica napus (oilseed rape). Genome. 38: 1122-1131.

Rafalski J A und Tingey S V 1993: Genetic diagnostics in plant breeding: RAPDs, microsatellites and machines. Trends in Genetics. 9: 275-280.

Riaz A, Li G, Quresh Z, Swati M S und Quiros C F 2001: Genetic diversity of oilseed Brassica napus inbred lines based on sequence-related amplified polymorphism and its relation to hybrid performance. Plant Breeding. 120: 411-415.

Röbbelen G 1960: Über die Kreuzungsunverträglichkeit verschiedener Brassica-Arten als Folge eines gehemmten Pollenschlauchwachstums. Der Züchter. 30: 300-312. 
Röbbelen G 1966: Beobachtungen bei interspezifischen Brassica-Kreuzungen, insbesondere über die Entstehung matromorpher $F_{1}$-Pflanzen. Angewandte Botanik. 39: 205-221.

Rohlf F J 2000: NTSYS-pc Numerical taxonomy and multivariate analysis system. Version 2.1 Exeter Publishing Co, Ltd, New York

Roose M L und Gottlieb L D 1976: Genetic and biochemical consequences of polyploidy in Tragopogon. Evolution. 30: 818-830.

Rudorf W 1951: Über die Erzeugung und die Eigenschaften synthetischer Rapsformen. Zeitschrift für Pflanzenzüchtung. 29: 35-54.

Sarawat P, Stoddard F L, Marshall D R und Ali S M 1994: Heterosis for yield and related characters in pea. Euphytica. 80: 39-48.

Schlösser L A 1936: Frosthärte und Polyploidie. Der Züchter. 8: 75-80.

Schwanitz F 1948: Untersuchungen an polyploiden Pflanzen. I. Feldversuche mit diploiden und autotetraploiden Nutzpflanzen. Der Züchter. 19: 70-86.

Schwanitz F 1952: Einige kritische Bemerkungen zur Methode der Bestimmung der Polyploidie durch Messung der Pollen- und Spaltöffnungsgröße. Der Züchter. 22: 273-275.

Smith O S, Smith J S C, Bowen S L, Tenborg R A und Wall S J 1990: Similarities among a group of elite maize inbreds as measured by pedigree, F1 grain yield, grain yield heterosis and RFLPs. Theoretical and Applied Genetics. 80: 833-840.

Soltis D E, Soltis P S and Tate J A 2004: Advances in the study of polyploidy since Plant Speciation. New Phytologist. 161: 173-191.

Soltis P S und Soltis D E 2000: The role of genetic and genomic attributes in the success of polyploids. Proceedings of the National Acadamy of Sciences. 92: 7051-7057.

Song K M und Osborn T C 1992: Polyphyletic origins of Brassica napus L.: new evidence based on organelle and nuclear RFLP analyses. Genome. 35: 992-1001.

Song K, Osborn T C und Williams P H 1990: Brassica taxonomy based on nuclear restriction fragment length polymorphisms (RFLPs). 3. Genome relationships in Brassica and related genera and the origin of $B$. oleracea and B. rapa (syn. campestris). Theoretical and Applied Genetics. 79: 497-506.

Speckmann G J, Dijkstra H und Ten Kate H A 1967: An efficient method to seperate tetraploid from diploid plants after colchicine treatment of turnips (Brassica campestris var. rapa). Euphytica. 16: 313-318.

Stebbins G L 1950: Variation and Evolution in Plants. Columbia University Press, New York

Stebbins G L 1947: Types of polyploids: their classification and significance. Advances in Genetics. 1: 403-429. 
Tate J A, Soltis D E und Soltis P S 2005: Polyploidy in plants. In: Gregory T R ed.: The Evolution of the Genome. Elsevier, London 371-426.

Thormann C E, Ferreira M E, Camargo L E A, Tivang J G und Osborn T C 1994: Comparison of RFLP and RAPD markers to estimating genetic relationships within and among cruciferous species. Theoretical and Applied Genetics. 88: 973-980.

Truco M J, Hu J, Sadowski J und Quiros C F 1996: Inter- and intra-genomic homology of the Brassica genomes: implications for their origin and evolution. Theoretical and Applied Genetics. 93: 1225-1233.

U N 1935: Genome-analyses in Brassica with special reference to the experimental formation of B. napus and peculiar mode of fertilization. Japanese Journal of Botany. 7: 389-452.

Utz H F 1989: PZ14, Diallelanalyse - Methode 4 nach Griffing. Institut für Pflanzenzüchtung, Saatgutforschung und Populationsgenetik der Universität Hohenheim, Stuttgart

Utz H F 1992: Plabstat, Computerprogramm zur statistischen Analyse von pflanzenzüchterischen Experimenten. Version 2F Institut für Pflanzenzüchtung, Saatgutforschung und Populationsgenetik der Universität Hohenheim, Stuttgart

Utz H F 1994: Plabplan, Computerprogramm zum Erstellen von Plaenen fuer Block- und Gitteranlagen. Institut für Pflanzenzüchtung, Saatgutforschung und Populationsgenetik der Universität Hohenheim, Stuttgart

von Sengbusch R 1941: Polyploide Kulturpflanzen (Roggen, Hafer, Stoppelrüben, Kohlrüben und Radieschen). Der Züchter. 13: 132-134.

Warwick S I und Black L D 1991: Molecular systematics of Brassica and allied genera (Subtribe Brassicinae, Brassiceae) - chloroplast genome and cytodeme congruence. Theoretical and Applied Genetics. 82: 81-92.

Wendel J F 2000: Genome evolution in polyploids. Plant Molecular Biology. 42: 225-249.

Yu C Y, Hu S W, Zhao H X, Guo A G und Sun G L 2005: Genetic distances revealed by morphological characters, isozymes, protein and RAPD markers and their relationships with hybrid performance in oilseed rape (Brassica napus L.). Theoretical and Applied Genetics. 110: 511-518. 


\section{$8 \quad$ Anhang}

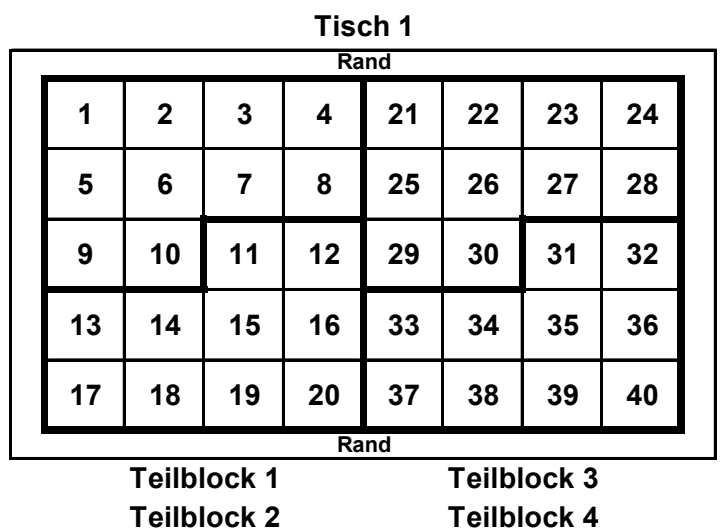

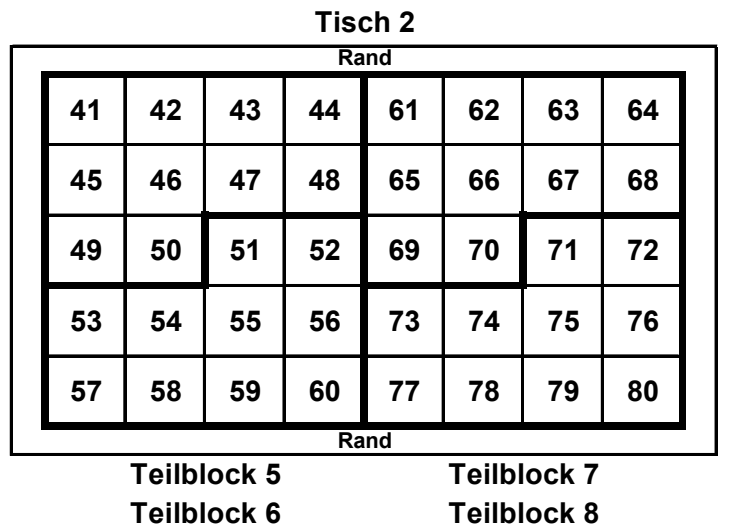

\begin{tabular}{|c|c|c|c|c|}
\hline \multicolumn{5}{|c|}{$\begin{array}{c}\text { Tisch } 3 \\
\text { Rand } \\
\end{array}$} \\
\hline 81 & 82 & 83 & 84 & Wiederholung 2 \\
\hline 85 & 86 & 87 & 88 & Teilblock 1 \\
\hline 89 & 90 & 91 & 92 & \\
\hline 93 & 94 & 95 & 96 & Wiederholung 2 \\
\hline 97 & 98 & 99 & 100 & Teilblock 2 \\
\hline
\end{tabular}
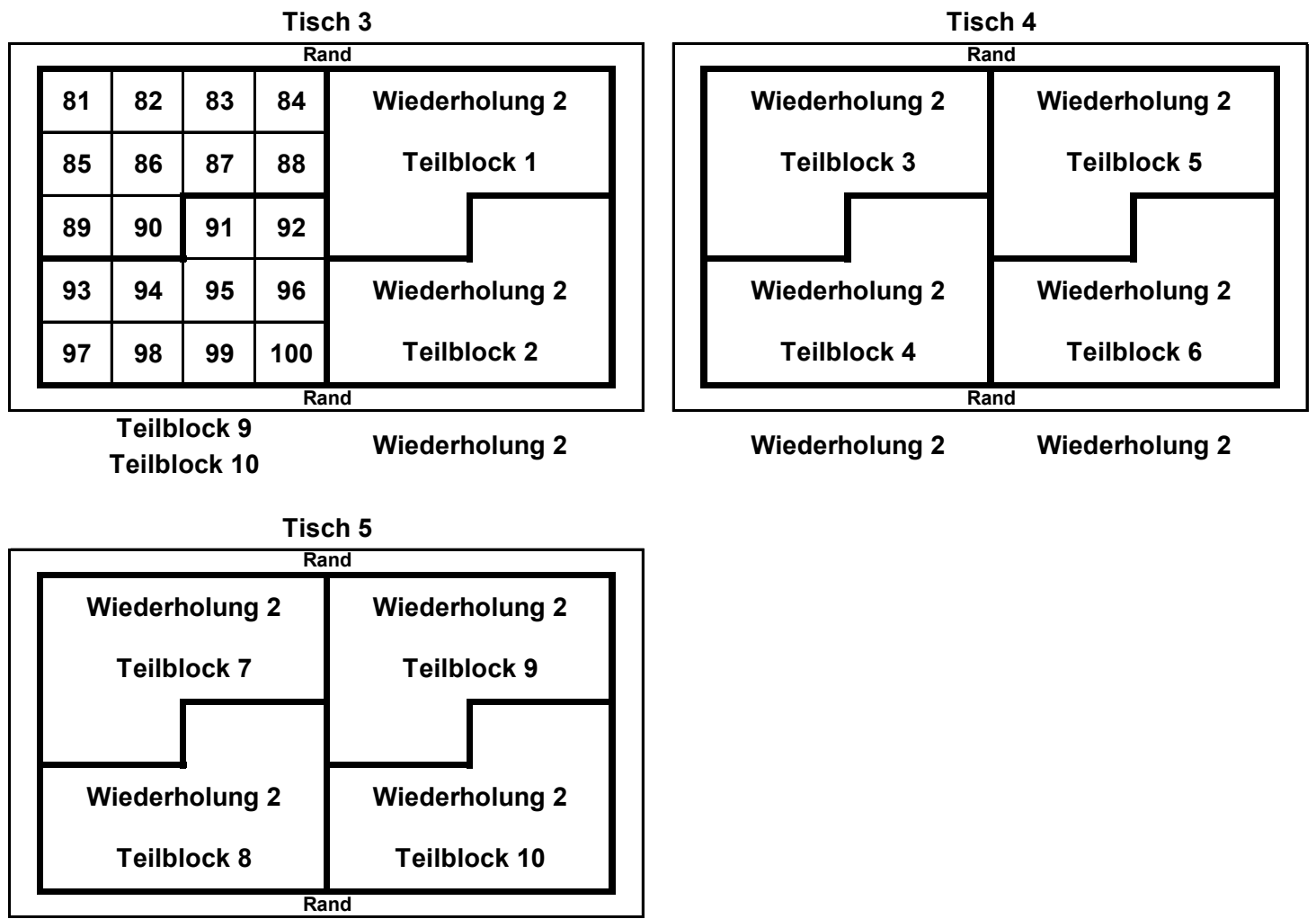

Wiederholung $2 \quad$ Wiederholung 2

Abb. 22: Skizze der Anordnung von Parzellen (1-100) und unvollständigen Blöcken (Teilblock) für die Leistungsprüfung Resynthesen und Eltern (LP 1) für zwei Wiederholungen 


\begin{tabular}{|c|c|c|c|c|c|c|c|c|}
\hline \multicolumn{10}{c|}{ Risch 1 } \\
\hline $\begin{array}{c}\text { Wdh 2 } \\
\text { TB 3 }\end{array}$ & 36 & 35 & 34 & 24 & 23 & 12 & 11 & 10 \\
\cline { 2 - 10 } & 33 & 32 & 31 & 22 & 21 & 9 & 8 & 7 \\
\hline $\begin{array}{c}\text { Wdh 2 } \\
\text { TB 2 }\end{array}$ & $\begin{array}{c}\text { Wdh 2 } \\
\text { TB 1 }\end{array}$ & 28 & 27 & 18 & 17 & 16 & 4 & 3 \\
\hline & 26 & 25 & 15 & 14 & 13 & 2 & 1 \\
\hline
\end{tabular}

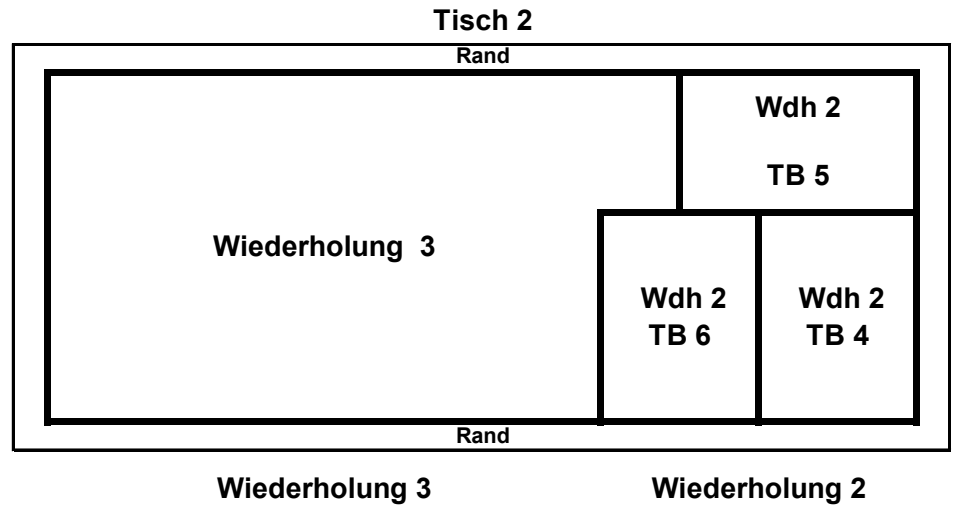

Abb. 23: Skizze der Anordnung von Parzellen (1-36) und unvollständigen Blöcken (TB: Teilblock) für die Diallel Leistungsprüfungen (LP 2-5) für drei Wiederholungen (Wdh) 
Tab. 16: Liste der für die RAPD Analyse verwendeten Primer

\begin{tabular}{|c|c|c|c|c|}
\hline \multirow[b]{2}{*}{$\begin{array}{l}\text { Operon } \\
\text { Primer }\end{array}$} & \multirow[b]{2}{*}{ Sequenz (5' - 3') } & \multicolumn{3}{|c|}{ Anzahl auswertbarer Banden } \\
\hline & & Gesamt & $\begin{array}{l}\text { polymorphe Banden } \\
\text { innerhalb B. rapa }\end{array}$ & $\begin{array}{l}\text { polymorphe Banden } \\
\text { innerhalb B. oleracea }\end{array}$ \\
\hline A 05 & AGGGGTCTTG & 6 & 2 & 2 \\
\hline A 09 & GGGTAACGCC & 6 & 2 & 1 \\
\hline A 19 & CAAACGTCGG & 11 & 8 & 4 \\
\hline A 20 & GTTGCGATCC & 6 & 3 & 2 \\
\hline AG 08 & AAGAGCCCTC & 9 & 6 & 3 \\
\hline AH 05 & TTGCAGGCAG & 16 & 10 & 6 \\
\hline AH 13 & TGAGTCCGCA & 5 & 3 & 2 \\
\hline Al 14 & TGGTGCACTC & 1 & 0 & 0 \\
\hline AJ 16 & TCTGGACCGA & 4 & 1 & 1 \\
\hline AK 05 & GATGGCAGTC & 17 & 17 & 3 \\
\hline AK 06 & TCACGTCCCT & 19 & 13 & 8 \\
\hline AK 10 & CAAGCGTCAC & 3 & 0 & 2 \\
\hline AK 11 & CAGTGTGCTC & 3 & 2 & 1 \\
\hline AK 17 & CAGCGGTCAC & 4 & 3 & 1 \\
\hline AK 18 & ACCCGGAAAC & 10 & 7 & 2 \\
\hline AL 08 & GTCGCCCTCA & 2 & 1 & 0 \\
\hline AL 09 & CAGCGAGTAG & 4 & 1 & 2 \\
\hline AM 01 & TCACGTACGG & 9 & 1 & 4 \\
\hline AM 02 & ACTTGACGGG & 9 & 8 & 4 \\
\hline AM 04 & GAGGGACCTC & 5 & 2 & 2 \\
\hline AN 01 & АCTCCACGTC & 8 & 5 & 3 \\
\hline AN 09 & GGGGGAGATG & 2 & 0 & 1 \\
\hline AN 10 & CTGTGTGCTC & 8 & 5 & 3 \\
\hline В 08 & GTCCACACGG & 18 & 14 & 7 \\
\hline В 09 & TGGGGGACTC & 2 & 1 & 0 \\
\hline B 10 & CTGCTGGGAC & 4 & 4 & 1 \\
\hline C 20 & ACTTCGCCAC & 1 & 1 & 0 \\
\hline D 02 & GGACCCAACC & 3 & 1 & 3 \\
\hline D 18 & GAGAGCCAAC & 11 & 4 & 5 \\
\hline Q 13 & GGAGTGGACA & 15 & 9 & 7 \\
\hline S 03 & CAGAGGTCCC & 8 & 6 & 2 \\
\hline T 04 & CACAGAGGGA & 10 & 5 & 3 \\
\hline T 12 & GGGTGTGTAG & 8 & 5 & 1 \\
\hline U 05 & TTGGCGGCCT & 4 & 0 & 1 \\
\hline U 06 & ACCTTTGCGG & 3 & 2 & 0 \\
\hline U 07 & ССTGCTCATC & 7 & 7 & 0 \\
\hline Mittel & & 7,3 & 4,4 & 2,4 \\
\hline Summe & & 261 & 159 & 87 \\
\hline
\end{tabular}


Tab. 17: Genetische Distanzen (Jaccard) zwischen den Rübsenlinien (a.), zwischen den Kohllinien (b.) und zwischen Rübsen- und Kohllinien (c.)

\begin{tabular}{ccccccccc} 
a.) & A4 & A6 & A7 & A8 & A9 & A13 & A16 & A19 \\
\hline A4 & 0,000 & & & & & & & \\
A6 & 0,741 & 0,000 & & & & & & \\
A7 & 0,741 & 0,327 & 0,000 & & & & & \\
A8 & 0,130 & 0,703 & 0,713 & 0,000 & & & & \\
A9 & 0,759 & 0,456 & 0,400 & 0,742 & 0,000 & & & \\
A13 & 0,669 & 0,652 & 0,575 & 0,670 & 0,577 & 0,000 & & \\
A16 & 0,170 & 0,713 & 0,713 & 0,112 & 0,732 & 0,658 & 0,000 & \\
A19 & 0,221 & 0,724 & 0,717 & 0,217 & 0,772 & 0,658 & 0,226 & 0,000 \\
\hline & & & & & & & & \\
b.) & C34 & C36 & C37 & C38 & C42 & C46 & C47 & C49 \\
\hline C34 & 0,000 & & & & & & & \\
C36 & 0,163 & 0,000 & & & & & & \\
C37 & 0,152 & 0,013 & 0,000 & & & & & \\
C38 & 0,175 & 0,062 & 0,050 & 0,000 & & & & \\
C42 & 0,480 & 0,448 & 0,457 & 0,472 & 0,000 & & & \\
C46 & 0,495 & 0,452 & 0,462 & 0,476 & 0,323 & 0,000 & & \\
C47 & 0,480 & 0,427 & 0,437 & 0,452 & 0,313 & 0,350 & 0,000 & \\
C49 & 0,434 & 0,419 & 0,429 & 0,429 & 0,324 & 0,359 & 0,317 & 0,000 \\
\hline & & & & & & & & \\
C.) & A4 & A6 & A7 & A8 & A9 & A13 & A16 & A19 \\
\hline C34 & 0,884 & 0,824 & 0,824 & 0,897 & 0,857 & 0,866 & 0,898 & 0,879 \\
C36 & 0,913 & 0,885 & 0,869 & 0,925 & 0,891 & 0,865 & 0,918 & 0,901 \\
C37 & 0,918 & 0,882 & 0,866 & 0,931 & 0,888 & 0,889 & 0,924 & 0,899 \\
C38 & 0,903 & 0,866 & 0,840 & 0,916 & 0,863 & 0,862 & 0,917 & 0,891 \\
C42 & 0,879 & 0,835 & 0,835 & 0,892 & 0,860 & 0,878 & 0,893 & 0,864 \\
C46 & 0,885 & 0,825 & 0,825 & 0,898 & 0,858 & 0,867 & 0,899 & 0,880 \\
C47 & 0,892 & 0,824 & 0,824 & 0,897 & 0,857 & 0,866 & 0,898 & 0,887 \\
C49 & 0,907 & 0,879 & 0,846 & 0,919 & 0,868 & 0,867 & 0,919 & 0,895 \\
\hline & & & & & & & &
\end{tabular}


Tab. 18: Übersicht über die Effizienz der interspezifischen Kreuzungen in den einzelnen Kreuzungskombinationen.

\begin{tabular}{|c|c|c|c|c|c|c|c|}
\hline $\begin{array}{l}\text { Kreuzungs- } \\
\text { kombination }\end{array}$ & $\begin{array}{c}\text { Anzahl } \\
\text { bestäubter } \\
\text { Knospen }\end{array}$ & $\begin{array}{c}\text { Anzahl } \\
\text { Embryonen }\end{array}$ & $\begin{array}{l}\text { Kreuzungs- } \\
\text { effizienz }\end{array}$ & $\begin{array}{l}\text { Kreuzungs- } \\
\text { kombination }\end{array}$ & $\begin{array}{c}\text { Anzahl } \\
\text { bestäubter } \\
\text { Knospen }\end{array}$ & $\begin{array}{c}\text { Anzahl } \\
\text { Embryonen }\end{array}$ & $\begin{array}{l}\text { Kreuzungs- } \\
\text { effizienz }\end{array}$ \\
\hline $\mathrm{A} 4{ }^{*} \mathrm{C} 34$ & 21 & 7 & 0,33 & $\mathrm{~A}^{*} \mathrm{C} 34$ & 24 & 1 & 0,04 \\
\hline $\mathrm{A} 4^{*} \mathrm{C} 36$ & 41 & 14 & 0,34 & $A 9 * C 36$ & 33 & 8 & 0,24 \\
\hline $\mathrm{A} 4^{*} \mathrm{C} 37$ & 26 & 2 & 0,08 & $A 9^{*} \mathrm{C} 37$ & 29 & 3 & 0,10 \\
\hline$A 4^{*} \mathrm{C} 38$ & 22 & 4 & 0,18 & $A 9 * C 38$ & 34 & 3 & 0,09 \\
\hline$A 4^{*} \mathrm{C} 42$ & 27 & 19 & 0,70 & $A 9^{*} \mathrm{C} 42$ & 36 & 3 & 0,08 \\
\hline $\mathrm{A} 4^{*} \mathrm{C} 46$ & 28 & 7 & 0,25 & $\mathrm{~A} 9^{*} \mathrm{C} 46$ & 28 & 10 & 0,36 \\
\hline $\mathrm{A} 4^{*} \mathrm{C} 47$ & 53 & 11 & 0,21 & $\mathrm{~A} 9^{*} \mathrm{C} 47$ & 34 & 16 & 0,47 \\
\hline$A 4^{*} \mathrm{C} 49$ & 27 & 7 & 0,26 & $A 9 * C 49$ & 25 & 3 & 0,12 \\
\hline$A 6^{*} \mathrm{C} 34$ & 27 & 23 & 0,85 & $A 13^{*} \mathrm{C} 34$ & 32 & 15 & 0,47 \\
\hline$A 6^{*} \mathrm{C} 36$ & 33 & 10 & 0,30 & $A 13^{*} \mathrm{C} 36$ & 22 & 5 & 0,23 \\
\hline$A 6^{*} \mathrm{C} 37$ & 35 & 12 & 0,34 & $A 13^{*} \mathrm{C} 37$ & 30 & 17 & 0,57 \\
\hline$A 6^{*} \mathrm{C} 38$ & 20 & 4 & 0,20 & $\mathrm{~A} 13^{*} \mathrm{C} 38$ & 38 & 22 & 0,58 \\
\hline$A 6^{*} \mathrm{C} 42$ & 24 & 36 & 1,50 & $\mathrm{~A} 13^{\star} \mathrm{C} 42$ & 20 & 16 & 0,80 \\
\hline $\mathrm{A} 6^{\star} \mathrm{C} 46$ & 33 & 13 & 0,39 & $\mathrm{~A} 13^{*} \mathrm{C} 46$ & 23 & 12 & 0,52 \\
\hline $\mathrm{A} 6{ }^{*} \mathrm{C} 47$ & 24 & 7 & 0,29 & $\mathrm{~A} 13^{*} \mathrm{C} 47$ & 32 & & 0,00 \\
\hline$A 6^{*} \mathrm{C} 49$ & 25 & 5 & 0,20 & $\mathrm{~A} 13^{*} \mathrm{C} 49$ & 27 & 5 & 0,19 \\
\hline$A 7^{*} \mathrm{C} 34$ & 27 & 7 & 0,26 & $\mathrm{~A} 16^{*} \mathrm{C} 34$ & 22 & 6 & 0,27 \\
\hline$A 7^{*} \mathrm{C} 36$ & 25 & 52 & 2,08 & $A 16^{*} \mathrm{C} 36$ & 31 & 6 & 0,19 \\
\hline$A 7^{*} \mathrm{C} 37$ & 27 & 36 & 1,33 & $\mathrm{~A} 16^{*} \mathrm{C} 37$ & 23 & 25 & 1,09 \\
\hline$A 7^{*} \mathrm{C} 38$ & 26 & 77 & 2,96 & $A 16^{*} \mathrm{C} 38$ & 26 & 5 & 0,19 \\
\hline $\mathrm{A} 7^{\star} \mathrm{C} 42$ & 25 & 9 & 0,36 & $\mathrm{~A} 16^{*} \mathrm{C} 42$ & 21 & 18 & 0,86 \\
\hline $\mathrm{A} 7^{*} \mathrm{C} 46$ & 31 & 39 & 1,26 & $\mathrm{~A} 16^{*} \mathrm{C} 46$ & 41 & 23 & 0,56 \\
\hline $\mathrm{A} 7^{*} \mathrm{C} 47$ & 36 & 42 & 1,17 & $\mathrm{~A} 16^{*} \mathrm{C} 47$ & 35 & 29 & 0,83 \\
\hline$A 7^{*} \mathrm{C} 49$ & 30 & 15 & 0,50 & $\mathrm{~A} 16^{*} \mathrm{C} 49$ & 18 & 27 & 1,50 \\
\hline$A 8 * C 34$ & 24 & 14 & 0,58 & $\mathrm{~A} 19 * \mathrm{C} 34$ & 29 & 8 & 0,28 \\
\hline$A 8{ }^{*} \mathrm{C} 36$ & 22 & 22 & 1,00 & $A 19 * C 36$ & 41 & 2 & 0,05 \\
\hline $\mathrm{A} 8{ }^{*} \mathrm{C} 37$ & 31 & 3 & 0,10 & $A 19 * C 37$ & 22 & 2 & 0,09 \\
\hline$A 8 * C 38$ & 20 & 2 & 0,10 & $A 19 * C 38$ & 30 & 7 & 0,23 \\
\hline$A 8^{*} \mathrm{C} 42$ & 27 & 13 & 0,48 & $\mathrm{~A} 19 * \mathrm{C} 42$ & 46 & 1 & 0,02 \\
\hline$A 8^{*} \mathrm{C} 46$ & 30 & 10 & 0,33 & $\mathrm{~A} 19^{*} \mathrm{C} 46$ & 52 & 14 & 0,27 \\
\hline $\mathrm{A} 8{ }^{*} \mathrm{C} 47$ & 22 & 15 & 0,68 & $\mathrm{~A} 19 * \mathrm{C} 47$ & 34 & 3 & 0,09 \\
\hline$A 8^{*} \mathrm{C} 49$ & 23 & 12 & 0,52 & $\mathrm{~A} 19^{*} \mathrm{C} 49$ & 43 & 2 & 0,05 \\
\hline
\end{tabular}

Kreuzungseffizienz = Anzahl Embryonen / Anzahl bestäubter Knospen 
Tab. 19: Übersicht über die erfassten Frisch- und Trockenmasse-Erträge für die LP 1 Resynthesen und Eltern

\begin{tabular}{|c|c|c|c|c|c|c|c|c|c|}
\hline Genotyp & FM1 & TM1 & FM2 & TM2 & Genotyp & FM1 & TM1 & FM2 & TM2 \\
\hline$\overline{\mathrm{A} 4}$ & 2,89 & 0,20 & 8,21 & 0,58 & A8C42 & 4,80 & 0,34 & 11,11 & 0,84 \\
\hline A6 & 5,45 & 0,36 & 13,11 & 1,01 & A8C46 & 4,54 & 0,33 & 11,13 & 0,88 \\
\hline A7 & 4,75 & 0,31 & 12,99 & 0,97 & A8C47 & 4,18 & 0,31 & 10,86 & 0,89 \\
\hline A8 & 2,68 & 0,19 & 8,21 & 0,63 & A8C49 & 3,95 & 0,26 & 10,52 & 0,75 \\
\hline A9 & 3,08 & 0,21 & 8,48 & 0,62 & A9C34 & 4,34 & 0,32 & 11,06 & 0,86 \\
\hline A13 & 6,92 & 0,36 & 16,91 & 0,93 & A9C36 & 3,58 & 0,24 & 9,05 & 0,64 \\
\hline A16 & 3,31 & 0,23 & 9,72 & 0,67 & A9C37 & 3,77 & 0,26 & 9,49 & 0,67 \\
\hline A19 & 3,61 & 0,24 & 9,48 & 0,67 & A9C38 & 3,51 & 0,25 & 8,78 & 0,65 \\
\hline C34 & 0,91 & 0,07 & 2,68 & 0,19 & A9C42 & 3,27 & 0,24 & 7,80 & 0,58 \\
\hline C36 & 1,23 & 0,09 & 4,41 & 0,33 & A9C46 & 3,28 & 0,23 & 6,83 & 0,51 \\
\hline C37 & 1,20 & 0,09 & 4,10 & 0,29 & A9C47 & 3,47 & 0,28 & 8,05 & 0,65 \\
\hline C38 & 1,48 & 0,10 & 4,89 & 0,37 & A9C49 & 4,48 & 0,32 & 10,91 & 0,78 \\
\hline C42 & 1,72 & 0,12 & 4,43 & 0,29 & A13C34 & --- & --- & --- & --- \\
\hline C46 & 1,81 & 0,12 & 5,88 & 0,39 & A13C36 & 5,74 & 0,37 & 14,69 & 0,99 \\
\hline $\mathrm{C} 47$ & 1,61 & 0,12 & 5,45 & 0,42 & A13C37 & 6,00 & 0,39 & 14,59 & 1,01 \\
\hline C49 & 1,86 & 0,14 & 6,18 & 0,45 & A13C38 & 5,16 & 0,31 & 13,48 & 0,91 \\
\hline A4C34 & 4,52 & 0,35 & 11,56 & 0,91 & A13C42 & 6,74 & 0,40 & 17,07 & 1,04 \\
\hline A4C36 & 4,06 & 0,31 & 10,54 & 0,83 & A13C46 & 7,05 & 0,43 & 16,57 & 1,11 \\
\hline A4C37 & 3,60 & 0,26 & 9,30 & 0,68 & A13C47 & --- & --- & --- & --- \\
\hline A4C38 & --- & --- & --- & --- & A13C49 & 7,24 & 0,43 & 19,37 & 1,17 \\
\hline A4C42 & 4,14 & 0,28 & 10,55 & 0,76 & A16C34 & 3,87 & 0,28 & 9,93 & 0,73 \\
\hline A4C46 & 3,17 & 0,22 & 8,17 & 0,58 & A16C36 & 3,62 & 0,28 & 9,69 & 0,77 \\
\hline A4C47 & 3,91 & 0,28 & 9,72 & 0,73 & A16C37 & 3,51 & 0,25 & 10,00 & 0,75 \\
\hline A4C49 & 3,47 & 0,23 & 10,51 & 0,74 & A16C38 & 4,24 & 0,33 & 9,42 & 0,74 \\
\hline A6C34 & 5,14 & 0,36 & 12,74 & 0,96 & A16C42 & 3,24 & 0,22 & 8,66 & 0,61 \\
\hline A6C36 & 6,00 & 0,42 & 14,02 & 1,05 & A16C46 & 3,89 & 0,29 & 10,25 & 0,82 \\
\hline A6C37 & 6,35 & 0,44 & 13,49 & 1,05 & A16C47 & 4,97 & 0,38 & 11,11 & 0,91 \\
\hline A6C38 & 5,43 & 0,37 & 13,12 & 1,01 & A16C49 & 3,67 & 0,26 & 10,81 & 0,82 \\
\hline $\mathrm{A} 6 \mathrm{C} 42$ & 4,54 & 0,33 & 10,44 & 0,75 & A19C34 & 4,96 & 0,36 & 12,57 & 1,02 \\
\hline A6C46 & 3,14 & 0,21 & 7,71 & 0,55 & A19C36 & 3,88 & 0,26 & 10,19 & 0,76 \\
\hline $\mathrm{A} 6 \mathrm{C} 47$ & 3,63 & 0,26 & 8,83 & 0,67 & A19C37 & 4,05 & 0,29 & 10,83 & 0,84 \\
\hline $\mathrm{A} 6 \mathrm{C} 49$ & 5,79 & 0,39 & 14,06 & 1,00 & A19C38 & 4,29 & 0,31 & 10,59 & 0,82 \\
\hline A7C34 & 5,04 & 0,37 & 13,13 & 1,00 & A19C42 & 4,76 & 0,32 & 11,60 & 0,80 \\
\hline A7C36 & 4,43 & 0,30 & 11,11 & 0,82 & A19C46 & 3,86 & 0,24 & 9,18 & 0,65 \\
\hline A7C37 & 4,76 & 0,31 & 13,15 & 0,91 & A19C47 & 3,80 & 0,26 & 8,72 & 0,65 \\
\hline A7C38 & 5,07 & 0,33 & 12,35 & 0,91 & A19C49 & 2,56 & 0,17 & 7,82 & 0,58 \\
\hline A7C42 & 6,36 & 0,42 & 12,86 & 0,92 & & & & & \\
\hline A7C46 & 3,65 & 0,25 & 8,31 & 0,61 & A7A7 & 4,26 & 0,25 & 10,51 & 0,68 \\
\hline A7C47 & 5,67 & 0,39 & 13,32 & 0,99 & A8A8 & 2,27 & 0,14 & 7,23 & 0,48 \\
\hline A7C49 & 5,97 & 0,39 & 13,06 & 0,94 & A13A13 & 6,67 & 0,33 & 17,06 & 0,86 \\
\hline $\mathrm{A} 8 \mathrm{C} 34$ & 4,57 & 0,31 & 11,65 & 0,82 & A16A16 & 2,42 & 0,16 & 6,48 & 0,41 \\
\hline A8C36 & 3,56 & 0,26 & 9,87 & 0,73 & A19A19 & 2,47 & 0,16 & 6,41 & 0,44 \\
\hline A8C 37 & 4,24 & 0,33 & 10,76 & 0,87 & C46C46 & 0,72 & 0,05 & 2,00 & 0,13 \\
\hline A8C38 & 3,52 & 0,29 & 8,32 & 0,70 & C47C47 & 1,03 & 0,07 & 3,20 & 0,22 \\
\hline \multicolumn{10}{|c|}{ Statistische Maßzahlen } \\
\hline GD & 0,82 & 0,05 & 2,07 & 0,14 & Mittel & 4,01 & 0,28 & 10,21 & 0,75 \\
\hline
\end{tabular}


Tab. 20: Übersicht über die Frischmasse-Gesamterträge (g/Topf) und die allgemeine Kombinationsfähigkeit (GCA) in der LP 1 Resynthesen und Eltern

\begin{tabular}{|c|c|c|c|c|c|c|c|c|c|c|c|}
\hline & Eltern & $\begin{array}{c}\text { A4 } \\
11,10\end{array}$ & $\begin{array}{c}\mathbf{A 6} \\
18,56\end{array}$ & $\begin{array}{c}\text { A7 } \\
17,74\end{array}$ & $\begin{array}{c}\text { A8 } \\
10,89\end{array}$ & $\begin{array}{c}\text { A9 } \\
11,56\end{array}$ & $\begin{array}{c}\text { A13 } \\
23,83\end{array}$ & $\begin{array}{c}\text { A16 } \\
13,03\end{array}$ & $\begin{array}{c}\text { A19 } \\
13,09\end{array}$ & $\begin{array}{c}\text { Mittel } \\
14,98\end{array}$ & GCA \\
\hline C34 & 3,59 & 16,08 & 17,88 & $\overline{18,17}$ & 16,22 & 15,40 & $\overline{(24,16)}$ & 13,80 & 17,53 & 17,41 & 1,68 \\
\hline C36 & 5,64 & 14,61 & 20,02 & 15,54 & 13,43 & 12,63 & 20,43 & 13,32 & 14,07 & 15,51 & $-0,22$ \\
\hline C37 & 5,31 & | 12,90 & 19,84 & 17,91 & 15,00 & 13,26 & 20,59 & 13,51 & 14,88 & 15,99 & 0,26 \\
\hline C38 & 6,37 & I $(13,14)$ & 18,55 & 17,42 & 11,84 & 12,29 & 18,64 & 13,66 & 14,88 & 15,05 & $-0,68$ \\
\hline C42 & 6,14 & | 14,70 & 14,97 & 19,22 & 15,91 & 11,07 & 23,81 & 11,90 & 16,35 & 15,99 & 0,26 \\
\hline C46 & 7,69 & | 11,35 & 10,85 & 11,96 & 15,67 & 10,11 & 23,62 & 14,14 & 13,04 & 13,84 & $-1,89$ \\
\hline C47 & 7,07 & | 13,62 & 12,47 & 18,99 & 15,04 & 11,51 & $(22,04)$ & 16,07 & 12,52 & 15,28 & $-0,45$ \\
\hline C49 & 8,04 & $\begin{array}{l}13,98 \\
\end{array}$ & 19,85 & 19,03 & 14,46 & 15,38 & 26,61 & 14,48 & 10,38 & 16,77 & 1,04 \\
\hline Mittel & 6,23 & 13,80 & 16,80 & 17,28 & 14,70 & 12,71 & 22,49 & 13,86 & 14,21 & 15,73 & \\
\hline GCA & & $-1,93$ & 1,07 & 1,55 & $-1,03$ & $-3,02$ & 6,76 & $-1,87$ & $-1,52$ & & \\
\hline
\end{tabular}

Grenzdifferenz bei $5 \%$ Irrtumswahrscheinlichkeit: $2,61 \mathrm{~g} / \mathrm{Topf}$

( ) fehlende Werte wurden geschätzt 
Tab. 21: Übersicht über die erfassten Frisch- und Trockenmasse-Erträge für die LP 2 Rübsen Diallel

\begin{tabular}{cccccccccc} 
Genotyp & FM1 & TM1 & FM2 & TM2 & Genotyp & FM1 & TM1 & FM2 & TM2 \\
\hline A4 & 1,66 & 0,10 & 4,27 & 0,28 & A6A13 & 7,94 & 0,47 & 17,28 & 1,08 \\
A6 & 5,16 & 0,29 & 10,20 & 0,64 & A6A16 & 5,54 & 0,36 & 13,60 & 0,96 \\
A7 & 3,75 & 0,22 & 8,76 & 0,59 & A6A19 & 5,56 & 0,37 & 13,35 & 1,00 \\
A8 & 2,94 & 0,20 & 6,72 & 0,50 & A7A8 & 5,78 & 0,37 & 12,66 & 1,00 \\
A9 & 2,64 & 0,15 & 6,50 & 0,40 & A7A9 & 6,90 & 0,43 & 14,07 & 1,02 \\
A13 & 6,81 & 0,34 & 15,64 & 0,82 & A7A13 & 8,44 & 0,47 & 18,19 & 1,09 \\
A16 & 3,30 & 0,20 & 7,93 & 0,52 & A7A16 & 5,38 & 0,32 & 11,67 & 0,88 \\
A19 & 2,15 & 0,12 & 5,54 & 0,36 & A7A19 & 6,11 & 0,39 & 12,38 & 1,02 \\
A4A6 & 6,14 & 0,40 & 13,06 & 1,01 & A8A9 & 4,74 & 0,30 & 11,51 & 0,93 \\
A4A7 & 5,71 & 0,35 & 12,16 & 1,02 & A8A13 & 7,85 & 0,46 & 14,97 & 1,01 \\
A4A8 & 3,48 & 0,23 & 8,47 & 0,58 & A8A16 & 3,45 & 0,22 & 7,67 & 0,56 \\
A4A9 & 5,60 & 0,36 & 13,53 & 1,02 & A8A19 & 4,61 & 0,30 & 10,61 & 0,80 \\
A4A13 & 5,42 & 0,32 & 12,73 & 0,84 & A9A13 & 8,09 & 0,51 & 16,93 & 1,15 \\
A4A16 & 2,81 & 0,17 & 7,30 & 0,46 & A9A16 & 5,02 & 0,31 & 12,56 & 0,95 \\
A4A19 & 2,90 & 0,19 & 8,01 & 0,54 & A9A19 & 6,88 & 0,42 & 14,51 & 1,14 \\
A6A7 & 7,44 & 0,47 & 13,35 & 0,99 & A13A16 & 5,84 & 0,34 & 12,62 & 0,78 \\
A6A8 & 5,82 & 0,35 & 13,88 & 1,05 & A13A19 & 7,66 & 0,46 & 14,74 & 1,03 \\
A6A9 & 7,44 & 0,48 & 14,07 & 1,03 & A16A19 & 4,10 & 0,26 & 9,56 & 0,66 \\
\hline Statistische Maßzahlen & & & & & & & \\
GD & 1,22 & 0,07 & 2,32 & 0,17 & Mittel & 5,13 & 0,32 & 11,69 & 0,82 \\
\hline
\end{tabular}

GD: Grenzdifferenz bei 5\% Irrtumswahrscheinlichkeit

Tab. 22: Übersicht über die Frischmasse-Gesamterträge (g/Topf) und die allgemeine Kombinationsfähigkeit (GCA) in der LP 2 Rübsen Diallel

\begin{tabular}{cccccccccc} 
& $\mathbf{A 4}$ & $\mathbf{A 6}$ & $\mathbf{A 7}$ & $\mathbf{A 8}$ & $\mathbf{A 9}$ & $\mathbf{A 1 3}$ & $\mathbf{A 1 6}$ & $\mathbf{A 1 9}$ & Mittel \\
Eltern & 5,88 & 15,35 & 12,55 & $\mathbf{9 , 5 6}$ & $\mathbf{9 , 1 5}$ & 22,46 & 11,3 & 7,63 & $\mathbf{1 1 , 7 4}$ \\
\hline $\mathbf{A 4}$ & & & & & & & & & \\
A6 & 19,13 & & & & & & & & \\
A7 & 17,79 & 20,89 & & & & & & & \\
A8 & 11,87 & 19,78 & 18,53 & & & & & & \\
A9 & 19,07 & 21,53 & 21,10 & 16,24 & & & & & \\
A13 & 18,22 & 25,29 & 26,58 & 22,77 & 25,09 & & & & \\
A16 & 10,08 & 19,08 & 17,03 & 11,13 & 17,45 & 18,41 & & & \\
A19 & 10,88 & 19,07 & 18,52 & 15,21 & 21,47 & 22,31 & 13,61 & & \\
\hline Mittel & $\mathbf{1 5 , 2 9}$ & $\mathbf{2 0 , 6 8}$ & $\mathbf{2 0 , 0 6}$ & $\mathbf{1 6 , 5 0}$ & $\mathbf{2 0 , 2 7}$ & $\mathbf{2 2 , 6 6}$ & $\mathbf{1 5 , 2 5}$ & $\mathbf{1 7 , 2 9}$ & $\mathbf{1 8 , 5 0}$ \\
GCA & $-3,21$ & 2,17 & 1,55 & $-2,00$ & 1,77 & 4,16 & $-3,24$ & $-1,20$ & \\
\hline Grenzdifferenz bei 5\% Irrtumswahrscheinlichkeit: 3,15g/Topf & & & & & &
\end{tabular}

Grenzdifferenz bei 5\% Irrtumswahrscheinlichkeit: 3,15g/Topf 
Tab. 23: Übersicht über die erfassten Frisch- und Trockenmasse-Erträge für die LP 3 Kohl Diallel

\begin{tabular}{cccccccccc} 
Genotyp & FM1 & TM1 & FM2 & TM2 & Genotyp & FM1 & TM1 & FM2 & TM2 \\
\hline C47 & 2,25 & 0,18 & 6,08 & 0,5 & C46C36 & 4,08 & 0,31 & 10,55 & 0,86 \\
C46 & 2,41 & 0,16 & 6,11 & 0,43 & C46C38 & 4,24 & 0,33 & 12,38 & 1,03 \\
C49 & 2,17 & 0,16 & 6,09 & 0,45 & C46C34 & 4,24 & 0,30 & 11,91 & 0,94 \\
C42 & 1,97 & 0,14 & 5,82 & 0,42 & C49C42 & 4,12 & 0,31 & 12,26 & 0,93 \\
C37 & 2,01 & 0,15 & 5,69 & 0,44 & C49C37 & 4,13 & 0,33 & 10,94 & 0,89 \\
C36 & 1,71 & 0,13 & 5,33 & 0,41 & C49C36 & 4,21 & 0,32 & 12,09 & 0,97 \\
C38 & 1,78 & 0,14 & 4,63 & 0,39 & C49C38 & 4,07 & 0,32 & 11,95 & 0,99 \\
C34 & 1,51 & 0,11 & 4,09 & 0,29 & C49C34 & 3,91 & 0,29 & 11,74 & 0,96 \\
C47C46 & 2,43 & 0,18 & 7,77 & 0,58 & C42C37 & 4,27 & 0,34 & 11,28 & 0,98 \\
C47C49 & 4,03 & 0,31 & 11,71 & 0,98 & C42C36 & 4,57 & 0,36 & 11,38 & 0,95 \\
C47C42 & 4,37 & 0,33 & 11,62 & 0,93 & C42C38 & 4,4 & 0,36 & 11,97 & 1,04 \\
C47C37 & 4,19 & 0,35 & 12,16 & 1,04 & C42C34 & 4,28 & 0,32 & 11,61 & 0,94 \\
C47C36 & 4,31 & 0,35 & 12,83 & 1,10 & C37C36 & 2,31 & 0,17 & 6,24 & 0,49 \\
C47C38 & 3,79 & 0,31 & 11,59 & 1,00 & C37C38 & 2,86 & 0,22 & 7,48 & 0,61 \\
C47C34 & 4,25 & 0,34 & 12,25 & 1,04 & C37C34 & 2,99 & 0,23 & 8,10 & 0,62 \\
C46C49 & 3,08 & 0,22 & 10,80 & 0,8 & C36C38 & 2,47 & 0,19 & 7,54 & 0,62 \\
C46C42 & 3,66 & 0,26 & 9,86 & 0,74 & C36C34 & 2,04 & 0,15 & 6,38 & 0,47 \\
C46C37 & 3,2 & 0,24 & 10,52 & 0,82 & C38C34 & 2,52 & 0,19 & 6,64 & 0,52 \\
\hline Statistische Maßzahlen & & & & & & & \\
GD & 0,52 & 0,04 & 1,91 & 0,14 & Mittel & 3,30 & 0,25 & 9,37 & 0,75 \\
\hline GD Granz
\end{tabular}

GD: Grenzdifferenz bei 5\% Irrtumswahrscheinlichkeit

Tab. 24: Übersicht über die Frischmasse-Gesamterträge (g/Topf) und die allgemeine Kombinationsfähigkeit (GCA) in der LP 3 Kohl Diallel

\begin{tabular}{cccccccccc} 
& $\mathbf{C 4 7}$ & $\mathbf{C 4 6}$ & $\mathbf{C 4 9}$ & $\mathbf{C 4 2}$ & $\mathbf{C 3 7}$ & $\mathbf{C 3 6}$ & $\mathbf{C 3 8}$ & $\mathbf{C 3 4}$ & Mittel \\
Eltern & 8,33 & 8,52 & 8,26 & $\mathbf{7 , 7 9}$ & $\mathbf{7 , 7 0}$ & $\mathbf{7 , 0 3}$ & 6,41 & 5,60 & $\mathbf{7 , 4 6}$ \\
\hline $\mathbf{C 4 7}$ & & & & & & & & & \\
C46 & 10,20 & & & & & & & & \\
C49 & 15,74 & 13,88 & & & & & & & \\
C42 & 15,99 & 13,51 & 16,37 & & & & & & \\
C37 & 16,35 & 13,72 & 15,08 & 15,55 & & & & & \\
C36 & 17,14 & 14,63 & 16,30 & 15,95 & 8,54 & & & & \\
C38 & 15,38 & 16,63 & 16,02 & 16,38 & 10,34 & 10,01 & & & \\
C34 & 16,50 & 16,15 & 15,65 & 15,89 & 11,09 & 8,42 & 9,16 & & \\
\hline Mittel & $\mathbf{1 5 , 3 3}$ & $\mathbf{1 4 , 1 0}$ & $\mathbf{1 5 , 5 8}$ & $\mathbf{1 5 , 6 6}$ & $\mathbf{1 2 , 9 5}$ & $\mathbf{1 3 , 0 0}$ & $\mathbf{1 3 , 4 2}$ & $\mathbf{1 3 , 2 7}$ & $\mathbf{1 4 , 1 6}$ \\
GCA & 1,17 & $-0,06$ & 1,41 & 1,50 & $-1,21$ & $-1,16$ & $-0,75$ & $-0,90$ & \\
\hline
\end{tabular}

Grenzdifferenz bei 5\% Irrtumswahrscheinlichkeit: 2,25g/Topf 
Tab. 25: Übersicht über die erfassten Frisch- und Trockenmasse-Erträge für die LP 4 Resynthese Diallel 1

\begin{tabular}{cccccccccc} 
Genotyp & FM1 & TM1 & FM2 & TM2 & Genotyp & FM1 & TM1 & FM2 & TM2 \\
\hline A4C47 & 3,91 & 0,27 & 9,56 & 0,72 & A7C38A7C47 & 5,28 & 0,38 & 12,21 & 0,98 \\
A6C47 & 4,64 & 0,32 & 9,75 & 0,76 & A7C38A6C47 & 5,36 & 0,38 & 10,31 & 0,79 \\
A7C37 & 4,07 & 0,27 & 11,16 & 0,79 & A7C38A16C47 & 4,94 & 0,37 & 10,74 & 0,87 \\
A7C38 & 4,90 & 0,35 & 10,26 & 0,81 & A7C46A9C47 & 4,93 & 0,34 & 11,44 & 0,86 \\
A7C46 & 3,69 & 0,24 & 8,33 & 0,57 & A7C46A7C37 & 5,22 & 0,38 & 10,88 & 0,85 \\
A7C47 & 4,20 & 0,27 & 10,33 & 0,72 & A7C46A7C47 & 5,11 & 0,33 & 11,21 & 0,81 \\
A9C47 & 3,03 & 0,23 & 7,81 & 0,61 & A7C46A6C47 & 4,89 & 0,34 & 10,83 & 0,83 \\
A16C47 & 3,91 & 0,26 & 9,28 & 0,74 & A7C46A16C47 & 4,29 & 0,30 & 9,98 & 0,81 \\
A4C47A7C38 & 5,59 & 0,42 & 12,19 & 1,02 & A9C47A7C37 & 4,72 & 0,33 & 10,44 & 0,8 \\
A4C47A7C46 & 4,13 & 0,28 & 9,27 & 0,70 & A9C47A7C47 & 5,20 & 0,36 & 10,14 & 0,78 \\
A4C47A9C47 & 3,72 & 0,29 & 9,27 & 0,72 & A9C47A6C47 & 3,72 & 0,26 & 8,25 & 0,64 \\
A4C47A7C37 & 4,73 & 0,34 & 10,50 & 0,85 & A9C47A16C47 & 4,20 & 0,32 & 10,21 & 0,82 \\
A4C47A7C47 & 4,36 & 0,31 & 10,70 & 0,83 & A7C37A7C47 & 5,44 & 0,39 & 12,67 & 0,99 \\
A4C47A6C47 & 4,83 & 0,33 & 10,95 & 0,80 & A7C37A6C47 & 5,36 & 0,39 & 11,58 & 0,96 \\
A4C47A16C47 & 4,23 & 0,28 & 11,18 & 0,84 & A7C37A16C47 & 4,50 & 0,33 & 12,39 & 0,96 \\
A7C38A7C46 & 5,43 & 0,39 & 10,56 & 0,84 & A7C47A6C47 & 4,25 & 0,30 & 9,01 & 0,70 \\
A7C38A9C47 & 5,41 & 0,37 & 11,43 & 0,87 & A7C47A16C47 & 4,65 & 0,34 & 10,98 & 0,88 \\
A7C38A7C37 & 5,36 & 0,36 & 12,97 & 0,96 & A6C47A16C47 & 4,23 & 0,30 & 10,36 & 0,83 \\
\hline Statistische Maßzahlen & & & & & & & & \\
GD & 0,85 & 0,07 & 1,87 & 0,15 & Mittel & 4,62 & 0,33 & 10,53 & 0,81 \\
\hline
\end{tabular}

GD: Grenzdifferenz bei 5\% Irrtumswahrscheinlichkeit

Tab. 26: Übersicht über die Frischmasse-Gesamterträge (g/Topf) und die allgemeine Kombinationsfähigkeit (GCA) in der LP 4 Resynthese Diallel 1

\begin{tabular}{cccccccccc} 
& A4C47 & $\mathbf{A 6 C 4 7}$ & $\mathbf{A 7 C 3 7}$ & $\mathbf{A 7 C 3 8}$ & $\mathbf{A 7 C 4 6}$ & $\mathbf{A 7 C 4 7}$ & $\mathbf{A 9 C 4 7}$ & $\mathbf{A} 16 \mathbf{C} 47$ & Mittel \\
Eltern & 13,47 & 14,39 & 15,23 & 15,16 & 12,03 & 14,52 & 10,85 & 13,19 & $\mathbf{1 3 , 6 1}$ \\
\hline A4C47 & & & & & & & & & \\
A6C47 & 17,78 & & & & & & & & \\
A7C37 & 13,40 & 15,99 & & & & & & & \\
A7C38 & 12,99 & 16,84 & 16,37 & & & & & & \\
A7C46 & 15,23 & 18,33 & 16,10 & 15,16 & & & & & \\
A7C47 & 15,06 & 17,50 & 16,32 & 15,34 & 18,11 & & & & \\
A9C47 & 15,78 & 15,67 & 15,72 & 11,96 & 16,94 & 13,26 & & & \\
A16C47 & 15,42 & 15,68 & 14,27 & 14,41 & 16,89 & 15,63 & 14,59 & & \\
\hline Mittel & $\mathbf{1 5 , 0 9}$ & $\mathbf{1 6 , 8 3}$ & $\mathbf{1 5 , 4 5}$ & $\mathbf{1 4 , 7 2}$ & $\mathbf{1 6 , 6 8}$ & $\mathbf{1 5 , 8 9}$ & $\mathbf{1 4 , 8 5}$ & $\mathbf{1 5 , 2 7}$ & $\mathbf{1 5 , 6 0}$ \\
GCA & $-0,50$ & 1,23 & $-0,15$ & $-0,87$ & 1,08 & 0,29 & $-0,75$ & $-0,33$ & \\
\hline
\end{tabular}

Grenzdifferenz bei 5\% Irrtumswahrscheinlichkeit: 2,41g/Topf 
Tab. 27: Übersicht über die erfassten Frisch- und Trockenmasse-Erträge für die LP 5 Resynthese Diallel 2

\begin{tabular}{|c|c|c|c|c|c|c|c|c|c|}
\hline Genotyp & FM1 & TM1 & FM2 & TM2 & Genotyp & FM1 & TM1 & FM2 & TM2 \\
\hline A4C34 & 3,47 & 0,27 & 3,10 & 0,72 & A8C46A16C37 & 3,76 & 0,28 & 7,62 & 0,66 \\
\hline $\mathrm{A} 6 \mathrm{C} 42$ & 21 & 23 & 95 & 51 & 8C46A19C47 & 85 & 29 &, 53 &, 64 \\
\hline A7C49 & 05 & 0,33 & ,93 & 0,79 & A8C46A13C36 & 3,70 &, 27 &, 05 & 0,76 \\
\hline $\mathrm{A} 8 \mathrm{C} 46$ & 2,77 & 0,20 &, 19 & 0,54 & A6C42A7C49 & 4,85 & 0,33 & 8,90 & 0,71 \\
\hline A9C38 & 2,33 & 0,18 & 4,21 & 0,36 & $\mathrm{~A} 6 \mathrm{C} 42 \mathrm{~A}$ & 2,67 & 0,21 &, 06 & 0,56 \\
\hline A13C36 & 3,62 & 0,23 & 8,61 & 0,68 & A6C42A & 4,04 &, 30 & 02 & 0,70 \\
\hline A16C37 & 3,43 & 0,25 & 7,69 & 0,66 & A6C42A & 3,92 & 0,29 & 8,00 & 0,65 \\
\hline A19C & 53 & 0,16 & 5,42 & 0,42 & A6C & 4,86 & 0,36 &, 85 & 0,81 \\
\hline A4C34A8C46 & 3,66 & 0,27 & ,33 & 0,69 & & 4,73 &, 34 &, 47 & 0,79 \\
\hline A4C34A6C42 & 3,65 & 0,28 & 8,10 & 0,70 & A7 & 4,34 & 0,32 & 8,49 & 0,70 \\
\hline $\mathrm{A} 4 \mathrm{C} 3$ & 4,37 & 0,32 &, 59 & 0,74 & 47 & 4,00 & 0,29 & 8,22 & 0,69 \\
\hline A4C3 & 3,90 & 0,31 & 7,54 & 0,68 & 36 & 5,27 &, 39 & 10,70 & 0,85 \\
\hline A4C34 & 3,11 & 0,24 & 7,46 & 0,6 & & 2,71 & 0,22 & 6,83 & 0,60 \\
\hline A4C34A & 3,95 & 0,30 & 7,63 & 0,68 & A9c & 2,58 & 0,18 & 6,80 & 0,57 \\
\hline A4C34 & 4,67 & 0,36 & 8,90 & 0,75 & 36 & 12 &, 30 & 3,50 & 0,71 \\
\hline A8C46A6C42 & 3,45 & 0,26 & 7,11 & 0,63 & A16C37 & 2,94 & 0,22 & 7,03 & 0,61 \\
\hline A8C46A7C49 & 3,98 & 0,26 & 7,20 & 0,59 & A16C3 & 4,09 & 0,31 & 8,17 & 0,71 \\
\hline A8C46A9C38 & 3,09 & 0,25 & 6,59 & 0,62 & A19C47A13C36 & 4,25 & 0,30 & 8,88 & 0,69 \\
\hline \multicolumn{10}{|c|}{ Statistische Maßzahlen } \\
\hline GD & 0,66 & 0,05 & 1,38 & 0,11 & Mittel & 3,75 & 0,28 & 7,82 & 0,66 \\
\hline
\end{tabular}

GD: Grenzdifferenz bei 5\% Irrtumswahrscheinlichkeit

Tab. 28: Übersicht über die Frischmasse-Gesamterträge (g/Topf) und die allgemeine Kombinationsfähigkeit (GCA) in der LP 5 Resynthese Diallel 2

\begin{tabular}{cccccccccc} 
& A4C34 & A6C42 & A7C49 & A8C46 & A9C38 & A13C36 A16C37 A19C47 & Mittel \\
Eltern & 11,57 & 9,17 & 14,98 & 8,96 & 6,54 & 12,24 & 11,11 & $\mathbf{7}, 94$ & $\mathbf{1 0 , 3 1}$ \\
\hline A4C34 & & & & & & & & & \\
A6C42 & 11,99 & & & & & & & & \\
A7C49 & 11,75 & 10,56 & & & & & & & \\
A8C46 & 12,97 & 11,18 & 13,76 & & & & & & \\
A9C38 & 11,44 & 9,68 & 8,73 & 14,20 & & & & & \\
A13C36 & 10,57 & 11,37 & 12,06 & 12,83 & 9,54 & & & & \\
A16C37 & 11,58 & 11,37 & 11,91 & 12,22 & 9,38 & 9,96 & & & \\
A19C47 & 13,57 & 12,75 & 14,71 & 15,97 & 12,62 & 12,27 & 13,13 & & \\
\hline Mittel & $\mathbf{1 1 , 9 8}$ & $\mathbf{1 1 , 2 7}$ & $\mathbf{1 1 , 9 3}$ & $\mathbf{1 3 , 3 0}$ & $\mathbf{1 0 , 8 0}$ & $\mathbf{1 1 , 2 3}$ & $\mathbf{1 1 , 3 6}$ & $\mathbf{1 3 , 5 7}$ & $\mathbf{1 1 , 9 3}$ \\
GCA & 0,05 & $-0,66$ & $-0,01$ & 1,37 & $-1,13$ & $-0,70$ & $-0,57$ & 1,64 & \\
\hline
\end{tabular}

Grenzdifferenz bei 5\% Irrtumswahrscheinlichkeit: 1,80g/Topf 
Tab. 29: Übersicht über die erfassten Frisch- und Trockenmasse-Erträge für die LP 6 Kältestress

\begin{tabular}{ccccccc} 
Genotyp & FM1 & TM1 & FM2 & TM2 & FMZuwachs & FMGesamt \\
\hline A7 & 1,72 & 0,13 & 5,36 & 0,40 & 3,64 & 7,08 \\
A19 & 1,50 & 0,13 & 5,28 & 0,40 & 3,79 & 6,78 \\
C34 & 0,68 & 0,05 & 2,19 & 0,21 & 1,51 & 2,87 \\
C46 & 1,23 & 0,10 & 4,51 & 0,35 & 3,28 & 5,74 \\
A7C34 & 3,24 & 0,26 & 8,29 & 0,67 & 5,05 & 11,53 \\
A7C46 & 1,50 & 0,14 & 2,88 & 0,26 & 1,38 & 4,38 \\
A19C34 & 2,53 & 0,21 & 8,23 & 0,67 & 5,70 & 10,76 \\
A19C46 & 3,11 & 0,25 & 10,76 & 0,81 & 7,66 & 13,87 \\
\hline GD \\
Mittel \\
GD: Grenzdifferenz bei 5\% Irrtumswahrscheinlichkeit
\end{tabular}




\section{Lebenslauf}

\section{Persönliche Daten}

Name:

Geburtsdatum:

Geburtsort:

Familienstand:

Nationalität:

\section{Schulausbildung}

1982-1986

1986-1988

1988-1992

1992-1995

\section{Zivildienst}

Juli 1995-Aug. 1996

\section{Studium}

Okt. 1996-Juli 1998

Aug. 1998-Aug. 1999

Okt. 1999-März 2002

\section{Berufstätigkeit}

Seit April 2002

April 2002-Mai 2003

Seit Juni 2003
Stefan Abel

13.08.75

Verden (Aller)

verheiratet, ein Kind

deutsch

Grund- und Hauptschule Wechold

Orientierungsstufe Hoya

Gymnasium Hoya

Domgymnasium Verden

Alten- und Pflegeheim St. Johannis in Verden

Grundstudium der Agrarwissenschaften an der GeorgAugust-Universität Göttingen

Landwirtschaftliches Praktikum mit Praktikantenprüfung bei Familie Friedrichs in Eystrup und an der University of Science and Technology in Kumasi/Ghana

Hauptstudium der Agrarwissenschaften an der GeorgAugust-Universität Göttingen mit Studienaufenthalten an der Christian-Albrechts-Universität Kiel (WS 1999/2000) und an der landwirtschaftlichen Universität Norwegens in Ås (SS 2001)

Abschluss: Master of Science (Universität Göttingen)

Wissenschaftlicher Mitarbeiter am Institut für Pflanzenbau und Pflanzenzüchtung der Universität Göttingen

GFP-Projekt: ÖE 113/00 Identifizierung und Analyse von Formenkreisen bei Ackerbohnen-Elitematerial sowie Entwicklung von Basismaterial für die Hybridzüchtung

DFG-Projekt: Raps als Modell zur Untersuchung der fixierten Heterosis bei allopolyploiden Pflanzen 


\section{Danksagung}

Herrn Prof. Dr. Heiko Becker danke ich für die Überlassung des sehr interessanten Themas sowie die stete Diskussionsbereitschaft insbesondere während der Fertigstellung dieser Arbeit.

Herrn Prof. Dr. Wolfgang Friedt danke ich für die Übernahme des Korreferates.

Den Mitarbeiterinnen und Mitarbeitern des Instituts für Pflanzenbau und Pflanzenzüchtung danke ich für die große Unterstützung bei der Durchführung meiner Versuche und das sehr angenehme Arbeitsklima. Mein besonderer Dank gilt dabei Andreas Henn, für die vielen technischen Hilfestellungen und die Gesunderhaltung der Pflanzen, sowie Sonja Yaman, ohne deren unermüdlichen Einsatz, die umfangreichen Arbeiten nicht möglich gewesen wären.

Iris und Leah danke ich ganz herzlich für die Geduld während der zeitaufwändigen Arbeiten und für die liebevolle Unterstützung.

Diese Arbeit wurde im Rahmen des Forschungsschwerpunktes „Heterosis in plants“ von der Deutschen Forschungsgemeinschaft (DFG) finanziert.

Es war eine schöne Zeit! 